$20 v^{\prime}$

ROTATIONAL PERTURBATIONS AND LOW - LYING

ELECTRONIC STATES OF CaO

\title{
Helen Johansen
}

(Ph.D. Thesis)

August 1970

AEC Contract No. W $-7405-$ eng -48
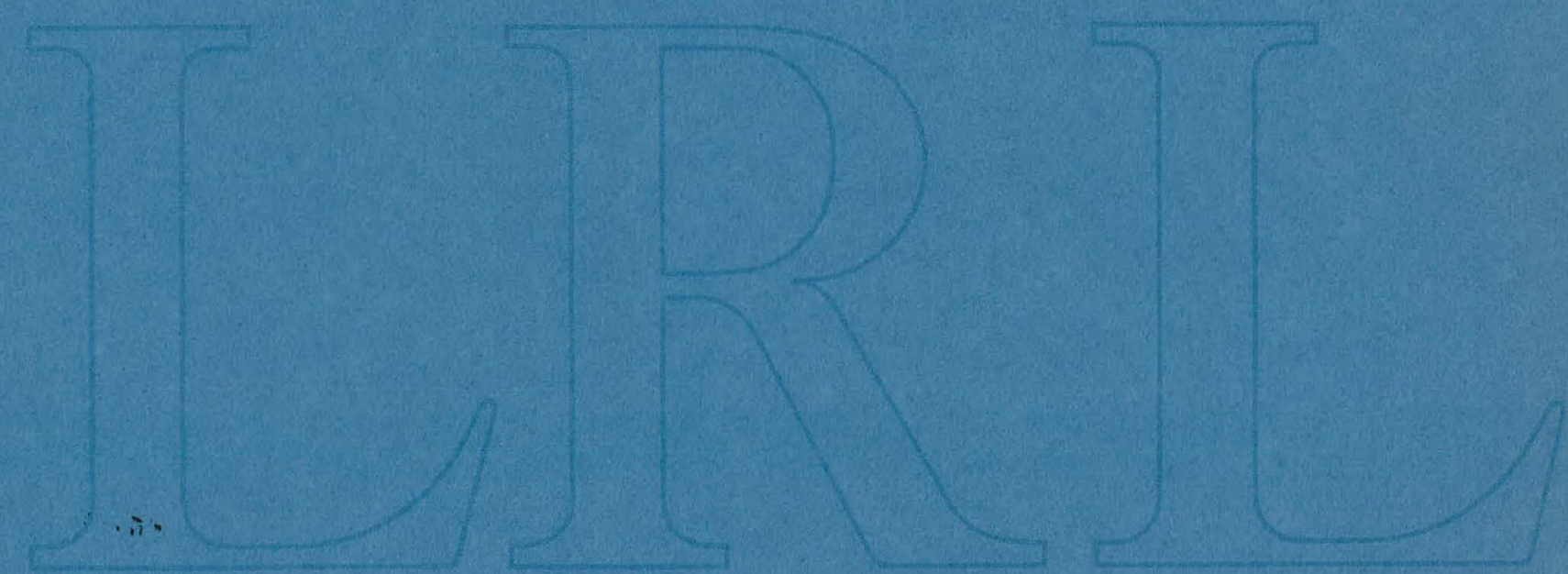

LAWRENCF, RADIATION I,ABORATORY 


\section{DISCLAIMER}

This report was prepared as an account of work sponsored by an agency of the United States Government. Neither the United States Government nor any agency Thereof, nor any of their employees, makes any warranty, express or implied, or assumes any legal liability or responsibility for the accuracy, completeness, or usefulness of any information, apparatus, product, or process disclosed, or represents that its use would not infringe privately owned rights. Reference herein to any specific commercial product, process, or service by trade name, trademark, manufacturer, or otherwise does not necessarily constitute or imply its endorsement, recommendation, or favoring by the United States Government or any agency thereof. The views and opinions of authors expressed herein do not necessarily state or reflect those of the United States Government or any agency thereof. 


\section{DISCLAIMER}

Portions of this document may be illegible in electronic image products. Images are produced from the best available original document. 


\section{PAGES $\mathrm{i}$ to $\mathrm{ii}$ WERE INTENTIONALLY LEFT BLANK}




\section{Conterits}

Abstract

I Introduction

II Experimental _- 5

III Results: $\mathrm{CaO}^{18}$

A. Analysis

B. Rotational Constants

C. Vibrational Constants

D. Perturbations

IV Compartson of $\mathrm{CaO}^{16}$ and $\mathrm{CaO}^{18}$

$\mathrm{V}$ Conclusion

Appendix A Comparison of $\mathrm{CaO}^{16}$ and $\mathrm{CaO}^{18}$

Appendix B Computer Programs - 66

Acknowledgments- 107

References - 108 


\section{THIS PAGE}

\section{WAS INTENTIONALLY \\ LEFT BLANK}


ROTATIONAL PERTURIBATIONS AND LON-LYING JELCTRONIC STATES OF CAO

Helen Joharisen

Department of Chemistry, University of California, and

Inorganic Materials Research Division,

Lawrence Radjation Laboratory,

Berkeley, California 94,720

ABSTRACT

Sixteen bands of the $\mathrm{A}^{I} \Sigma-X^{1} \sum$ transition of $\mathrm{CaO}^{18}$ were

analyzed. They are the $(6,3),(5,2),(5,3),(4,1),(4,2),(3,0)$, $(3,1),(3,2),(2,0),(2,1),(2,3),(1,0),(1,1),(1,2),(0,0)$, and. $(0,1)$ bands. The spectroscopic constants found are:

$$
\begin{array}{ll}
x^{1} \Sigma & A^{I} \Sigma \\
\omega_{e}=702.18 & \omega_{e}=\sim 686.5 \\
\omega_{e} x_{e}=4.29 & \omega_{e} x_{e}=1.5 \\
B_{e}=.4093 & B_{e}=.3733 \\
\alpha_{e}=.003 & \alpha_{e}=.0009 \\
D_{e}=\sim 5.24 \times 10^{-7} & D_{e} \cong 4.58 \times 10^{-7} \\
\beta_{e}=\sim 5.9 \times 10^{-8} & v_{0,0}=11548.6
\end{array}
$$

Thirty-seven perturbations were found in the upper state.

They are due to six electronic states or substates. A comparison of these perturbations with those found in $\mathrm{CaO}^{16}$ (Hultiri and Lagerqvist, 1950) indicates that four of these perturbing states lie below the $x^{1} \Sigma$, one is at $\sim 8080 \mathrm{~cm}^{-1}$ and one j.s the $x^{1} \Sigma$ strite. 


\section{INTRODUCTION}

Previously analyzed spectra have shown four electronic states of $\mathrm{CaO}: \mathrm{X}^{I} \Sigma(0.0), \mathrm{A}^{I} \Sigma\left(\sim 11500 \mathrm{~cm}^{-1}\right), \mathrm{B}^{1} \Pi\left(\sim 25900 \mathrm{~cm}^{-1}\right)$ and $\mathrm{C}^{I} \Sigma\left(\sim 28800 \mathrm{~cm}^{-1}\right)$. (Lagerqvist, 1954; Hultin and Lagerqvist, 1950). However, a comparison of the electronic states of the eight-electron isoelectronic molecules and their trends in energy (Brewer, 1962), indicates low-lying ${ }^{3} \pi,{ }^{3} \Sigma$ ${ }^{I} I$ and ${ }^{I} \triangle$ states. There are also experimental indications that unanalyzed low-lying electronic states exist. First, the spectra of CaO contains several regions ( $5555 \AA, 6100 \AA$ ) of very dense, complex structure which have so far resisted a complete analysis. (Gaydon, 1955; Kobajiehok and Sokolov, 1968) It is possible that they are due to triplet states of $\mathrm{CaO}$. Other possibilities include $\mathrm{Ca}_{2} \mathrm{O}_{2}, \mathrm{CaOH}$ and $\mathrm{Ca}_{2}$. Second, the Birge-Sponer extrapolation of the $x^{l} \dot{\Sigma}$ state gives 37 kcal for the dissociation energy. This value is at least $45 \mathrm{kcal}$ lower than those obtained by other methods (Gaydon, 1968) which suggests that either $x^{1} \Sigma$ is not the ground state or that the extrapolation is anomalous: Third, some 30 rotational perturbations have been found in the $A^{l} \Sigma$ state of CaO. (Hultin and Lagerqvist, 1950). They have been explained as interactions between $A^{I} \Sigma$ and six other states or substates. The absolute vibrational numbering of these perturbing states, and hence their origins, were not obtained since the $\mathrm{v}^{\prime}=0$ level of $\mathrm{A}^{1} \Sigma$ was perturbed. All that can be deduced from the $\mathrm{CaO}^{16}$ data is that at least 6 electronic states or substates lie below $11500 \mathrm{~cm}^{-1}$.

It wuld be helptil to know the relative energies of these perturbing states especially since some of them are predicted to be triplets. 
No triplet state has been directly analyzed in $\mathrm{CaO}$ and there is some controversy on whether the ground state is a singlet or a triplet. The statistical weight of the ground and low-lying electronic states is important in thermochemical calculations. For example in calculating the dissociation energy by a third law method $\left(\mathrm{T}=2000^{\circ} \mathrm{K}\right)$, a difference of $7 \mathrm{kcal} / \mathrm{mole}$ is obtained depending on whether the ground state of $\mathrm{CaO}$ is ${ }^{I_{\Sigma}}$ or ${ }^{3} \Pi$ (Gaydon, 1968).

Before we consider a way of determining these relative energies, a word is in order concerning rotational perturbations. A rotational perturbation is an interaction between rotational energy levels. Theoretically, it is a mixing of wavefunctions, the Hamiltonian being cross-terms not considered in the Born-Oppenheimer approximation. Experimentally it is seen as a shift of rotational energy levels away from their otherwise regular spacing. The following selection rules should hold in order for a rotational perturbation to occur:

(1) Both states must have the same total angular momentum, I, at approximately the same energy; $\Delta \mathrm{J}=0, \Delta \mathrm{E} \sim 0$.

(2) Both states must have the multiplicity; $\Delta S=0$.

This rule holds only approximately (Ballik and Ramsey, 1962)

(3) $\Delta \Lambda=0, \pm 1$ for Hund's coupling cases (a.) and (b) $\Delta \Omega=0, \pm 1$ for Hund's case (c)

(4) Both states must be positive, or both must be negative; $+\leftrightarrow \rightarrow-$

(5) For identical nuclei, both states must have the same symmetry in the nuclei; s $\leftrightarrow$ a

(6) There must be sufficient overlap of the vibrational eigenfunctions . 
More thorough discussions of rotational perturbations can be found in Herzberg, Spectra of Diatomic Molecules, 1965, and Kovacs, Rotational Structure in the Spectra of Diatomic Molecules, 1969.

A standard method of assigning vibrational numbers, $v$, is to observe the isotopic shift of the vibrational levels according to formula (I):

$$
\text { SHIFT }=\omega_{e}\left(v+\frac{1}{2}\right)-\omega_{e} x_{e}\left(v+\frac{1}{2}\right)^{2}-\rho \omega_{e}\left(v+\frac{1}{2}\right)+\rho^{2} \omega_{2} x_{e}\left(v+\frac{1}{2}\right)^{2}
$$

where $\rho=\sqrt{\mu} / \mu_{i}$, and $\mu$ is the reduced mass. The higher the $v$-number, the greater the shift, until the $\omega_{e} x_{e}$ terms become dominant. A similar method can be used with the six states perturbing the $A^{I} \Sigma$ state. A perturbation can occur when two (or more) vibrational levels (from different electronic states) have approximately the same energy at the same rotational quantum number, $J(\Delta E \sim 0, \Delta J=0)$. Therefore on a plot of energy vs $J(J+I)$, a perturbation is possible where the lines representing the two vibrational levels cross (see Fig. 1). When a heavier isotope is used these levels shift downward in energy as indicated by formula (1) and intersect one another at a new energy and $J$ value. (The isotopiceffect on the rotational constants is ignored in this example for simplicity. It would change the slope of the lines slightly.) The amount of the shift, and hence the position of the perturbation, is dependent upon which vibrational levels are involved. Thus a comparison of the perturbations in the $\mathrm{A}^{1} \Sigma$ state of $\mathrm{CaO}^{16}$ and $\mathrm{CaO}^{18}$ should help clarify the relative energies of the six perturbing states. With this end in mind the spectrum of $\mathrm{CaO}^{18}$ in the region of $7200 \AA$ to $9400 \AA$ ( ${ }^{\perp} \Sigma-\mathrm{X}^{1} \Sigma$ system) was taken and analyzed. 


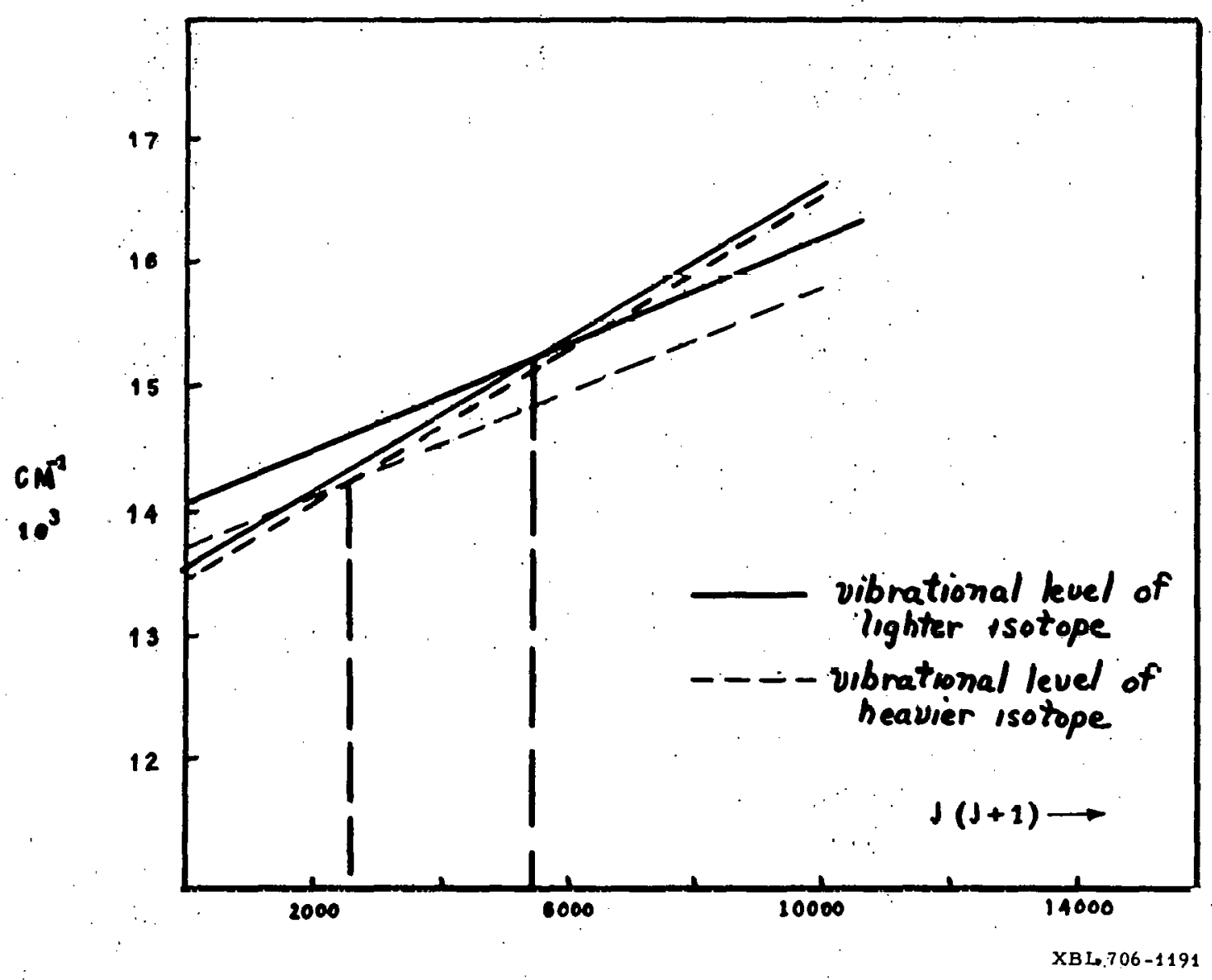

Fig. 1. Plot of energy vs $J(J+1)$ showing how a rotational perturbation shitts with a change of isotope. 


\section{EXPERTMENTAL}

The light source used was a reduced pressure arc operated by a 300 volt d.c. power supply at a current of 1 amp (Hauge, 1965) (Figs. 2 and 3). The electrode-holders were water-cooled and held calcium rods one-fourth inch in diameter. The arc was initiated with a Tesla coil and run at a pressure of 1 torr of He gas and $\sim 0.3$ torr of $0_{2}^{18}$. Oxygen was added to the system as it was used up at regular intervals. $\mathrm{A}_{2} \mathrm{O}_{5}$ trap was used to absorb water vapor. Before new electrodes were used, their tips were first scraped clear of $\mathrm{CaO}$.

The spectrograms were taken in the first order of a 1.5 meter. Jarell Ash grating spectrograph(1180 grooves $/ \mathrm{mm}$ ). Exposure times ran from $15 \mathrm{~min}$ to $1 \mathrm{hr}$. Eastman Kodak IN and IM plates were used; the IM plates were hypersensitized first with ammonia. * A Kodak Wratten gelatin filter No. 89B was also used. The dispersion was $4.4 \AA / \mathrm{mm}$; resolution approximately $0.1 \mathrm{~cm}^{-1}$. A thorium electrodeless discharge tube generated the standard lines. (A neon Osram lamp was used in the $9000 \AA-9400 \AA$ region to identify the Th lines.)

\footnotetext{
* The hypersensitizing procedure was obtained from Dr. Sumner Davis and is as follows:

(1) Four minutes in a solution of $6 \%$ ammonium hydroxide at $40^{\circ} \mathrm{F}$

(2) One minute in a solution of one part isopropyl alcohol, two parts distilled water, and one cc of glacial acetic acid per one hundred ce of solution.

(3) Four minutes in a solution of two parts isopropyl alcohol and one part distilled water by volume.

(4) Dry the plate before storage or use. The plate should be stored in the freezer and used within two weeks.
} 


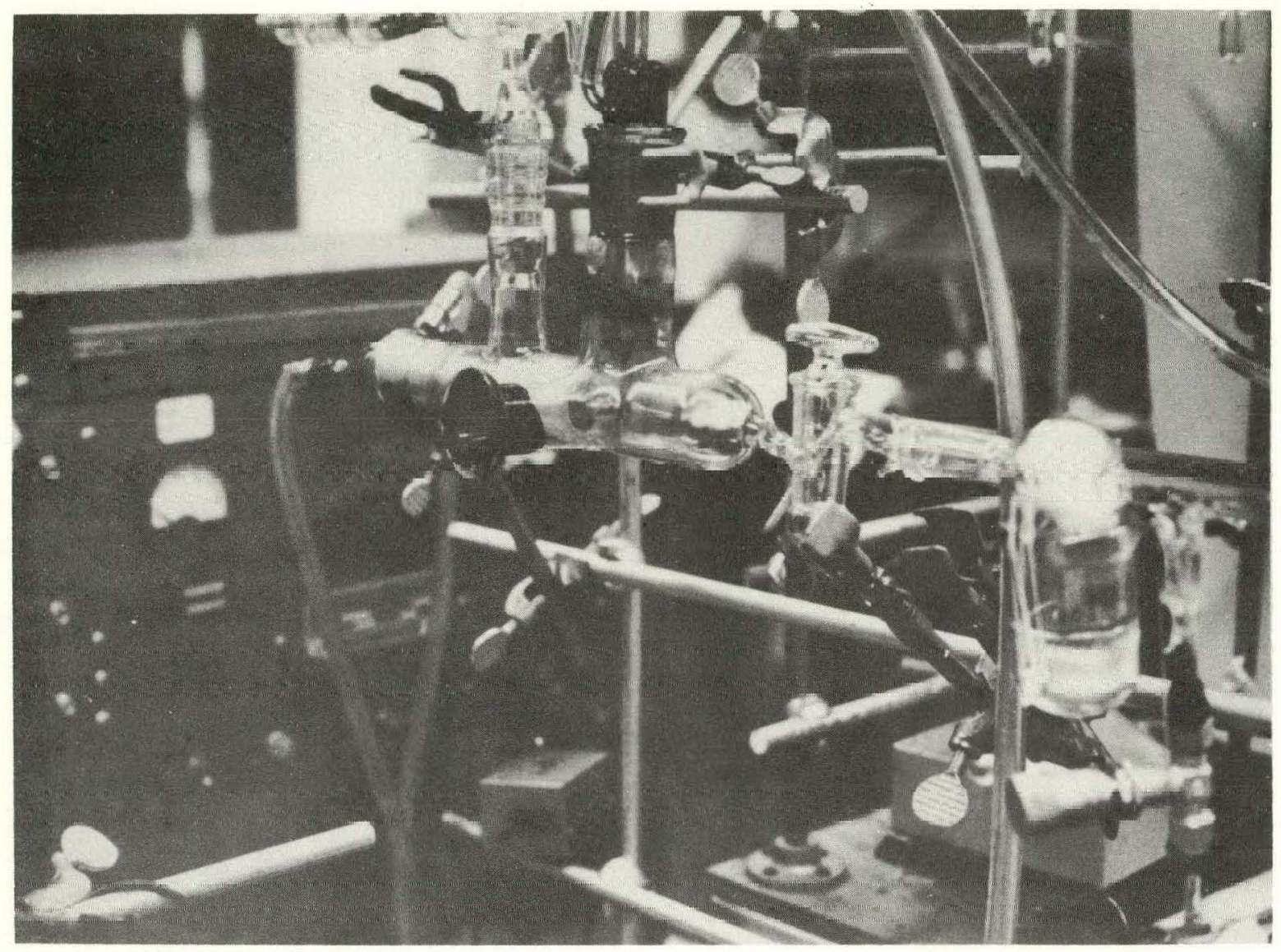

XBB 706-2709

Fig. 2. Photograph of arc. 


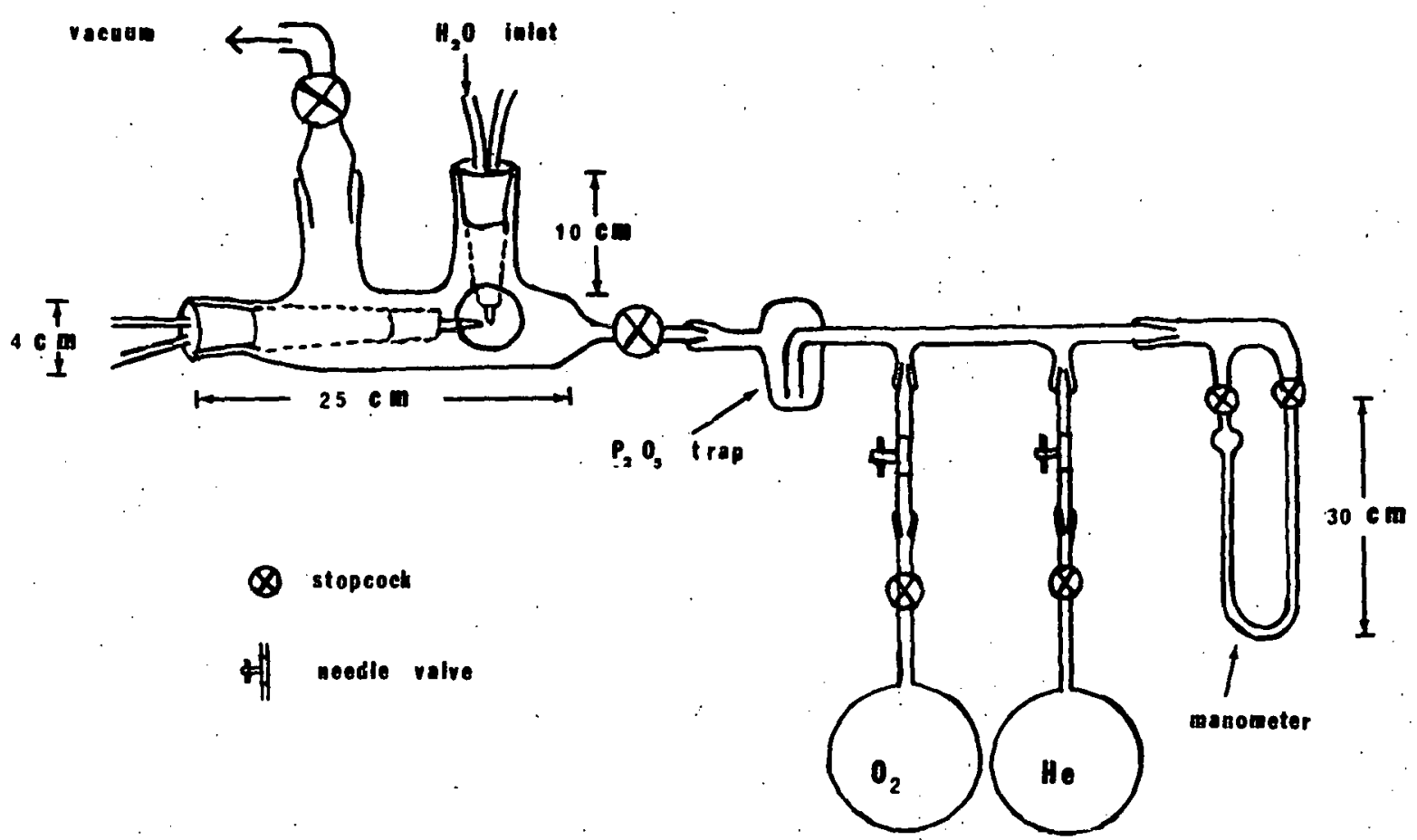

XBL 706-1163

Fig. 3. Schematic of vacuum systein. 


\section{RESULTS}

\section{A. Analysis}

Five red-degraded sequences appeared in the CaO spectrum at approximately $7300,7700,8150,8650$, and $9200 \AA$. Analysis has shown them to be respectively the $(3,0),(2,0),(1,0),(0,0)$, and $(0,1)$ sequences of the ${ }_{A}{ }^{1} \sum-X^{1} \sum$ transition of $\mathrm{CaO}^{18}$. There was no problem with contamination by $0_{2}^{16}$. However strong atomic lines blotted out part of the $(2,0)$ and $(0,0)$ sequences. Weak exposures were taken in these regions to pick up as many $\mathrm{CaO}^{18}$ lines as possible (see Figs. $4,5,6,7$ ).

Sixteen bands were analyzed: $(0,0),(0,1),(1,0),(1,1),(1,2),(2,0)$, $(2,1),(2,3),(3,0),(3,1),(3,2),(4,1),(4,2),(5,2),(5,3)$, and $(6,3)$. Perturbations have been found in the upper level of each of these bands. See Table 2 for a listing of the assigned lines. Two columns are given for both the R- and $\mathrm{P}$ - branches. A shift from one column to the other indicates a perturbation. M's stand for missing lines, A's for lines that have been obscured by an atomic line, and H's for lines obscured by band heads.

The analysis itself was accomplished by calculating the combination differences, $\Delta_{2} F^{\prime \prime}(J)$, of the $X^{l} \Sigma$ vibrational levels using $\rho$ and the spectroscopic constants of $\mathrm{CaO}^{16}$ (Hultin and Lagerqvist, 1950). The spectrum was then scanned by computer for sets of lines. which satisfied these combination differences and the results were plotted out (Kopp, et al. 1965).

$$
\Delta_{2} F^{\prime \prime}(J)=R(J-I)-P(J+I)=F_{v}^{\prime \prime}(J+I)-F_{v}^{\prime \prime}(J-I)
$$

$R(J)$ and $P(J)$ refer to the indicated $J$ lines in the $R$ and $P$ branches and $F_{v} "(J)$ is the cnergy of the J-rotational level of the lower 
vibrational state. A more detailed explanation and a listing of the computer program is found in Appendix B.

B. Determination of Rotational Constants

The rotational constants of the unperturbed $\mathrm{X}^{\mathrm{l}} \Sigma$ vibrational levels were determined by plotting $\Delta_{2} F^{\prime \prime}(J) / 4\left(J+\frac{1}{2}\right)$ vs $\left(J+\frac{1}{2}\right)^{2}$ where

$$
\Delta_{2} F^{\prime \prime}(J)=R(J-I)-P(J+I)=4 B_{v}^{\prime \prime}\left(J+\frac{1}{2}\right)-8 D_{\forall} "\left(J+\frac{1}{2}\right)^{3}
$$

A sample plot is found in Appendix B and the rotational constants, $B_{i}$ " and $D_{\forall}^{\prime \prime}$ in l'able 3 .

The corresponding plot for the upper-state levels (i.e. $\left.\triangle_{2} F^{\prime}(J)=R(J)-P(J)\right)$ fluctuated greatly due to the perturbations and could only give very approximate : B-values. However, for such strongly perturbed levels it is meaningless to speak of a fixed $B$-value since every rotational level: has a $\mathrm{B}_{y}$-value which is a mixture of the $E_{\mathrm{v}}$-values of the perturbed and perturbing states. One can however obtain a good approximation to the "unperturbed" $B_{v}$ values by plotting $T / 4 \mathrm{~J}$ vs $\mathrm{J}^{2}$ where:

$$
\frac{T}{4 J}=\frac{R(J-2)-R(J-I)+P(J)-P(J+I)}{4 J}=B^{\prime \prime}-B^{\prime}+6 D^{\prime \prime}-2 J^{2}\left(D^{\prime \prime}-D^{\prime}\right)
$$

This gives $\left(B_{v}{ }^{\prime \prime}-B_{\gamma}^{\prime}\right)$ as the intercept at $J=0$. Using the $B_{v}$ " values found with Eq. (3), the $B_{v}{ }^{\prime}$ values are easily calculated. The $D_{v}{ }^{\prime}$ constants were obtained from the unperturbed sections of a plot of $\triangle_{2} F^{\prime \prime}(J) / 4\left(J+\frac{1}{2}\right)^{2}$. Their average is found in Table 4. The calculated $\mathrm{B}$-values in Table 3 are from the equations:

$$
\begin{aligned}
& B_{v^{\prime}}^{\prime \prime}=0.1 .093-0.003\left(V+\frac{1}{2}\right) \\
& B_{v}^{\prime}=0.3733-0.0009\left(V+\frac{1}{2}\right)
\end{aligned}
$$




\section{Determination of Vibrational Constants}

The: band origins, $v_{0}$, were determined in two ways. The first was the usual plot of $[(R(J-1)+P(J)) / 2]$ vs $J^{2}$

$$
R(J-1)+P(J)=2 v_{0}+2\left(B^{\prime}-B^{\prime \prime}\right) J^{2}
$$

The second method was to plot the left-hand side of Eq. (7) vs J.

$$
B_{\dot{v}}{ }^{\prime \prime}-\frac{1}{4}\{J(J+1)[P(J)+R(J-2)]-(J-1)[P(J+1)+R(J-1)]\}=v_{0}
$$

Both of these methods however could only give approximate values of $v_{0}$ since the upper state is highly perturbed. For example, the $V^{\prime}=I$ level is shifted $\sim 8 \mathrm{~cm}^{-1}$.

In order to calculate the vibrational constants of the unperturbed lower state, the influence of the upper. state was subtracted out as follows (Hultin and Lagerqvist, 1950). Equation (6) was written for the two bands with the same upper level but with different lower levels $a$ and $b$.

$$
\begin{aligned}
& {[R(J-1)+P(J)]_{v^{\prime}, v_{a}^{\prime \prime}}=2 v_{0}\left(v^{\prime}, v_{a}^{\prime \prime}\right)+2\left(B^{\prime}-B_{a}^{\prime \prime}\right) J^{2}} \\
& {[R(J-I)+P(J)]_{v^{\prime}, v_{b}^{\prime \prime}}=2 v_{0}\left(v^{\prime}, v_{b}^{\prime \prime}\right)+2\left(B^{\prime}-B_{b}^{\prime \prime}\right) J^{2}}
\end{aligned}
$$

The difference between Eqs. (8) and (9), A, is

$$
\begin{aligned}
A & =2\left[v_{0}\left(v^{\prime}, v_{a}^{\prime \prime}\right)-v_{0}\left(v^{\prime} v_{l}^{\prime \prime}\right)+2\left(B_{b}^{\prime \prime}-B_{a}^{\prime \prime}\right) J^{2}\right. \\
& =2\left[G^{\prime \prime}\left(v_{b}^{\prime \prime}\right)-G^{\prime \prime}\left(v_{a}^{\prime \prime}\right)\right]+2\left(B_{b}^{\prime \prime}-B_{a}^{\prime \prime}\right) J^{2}
\end{aligned}
$$

where $G^{\prime \prime}\left(v_{a}^{\prime \prime}\right)$ is the energy of the $v_{a}^{\prime \prime}$ vibrational level of the lower state at $J=0$. The quantity 'A/2 is plotted vs. $J^{2}$. to obtain [ $\left.G^{\prime \prime}\left(\dot{\mathrm{v}}_{\mathrm{b}}^{\prime \prime}\right)-G^{\prime \prime}\left(\mathrm{v}_{\mathrm{a}}^{\prime \prime}\right)\right]$ as intercept and $\left[\mathrm{B}_{b}^{\prime \prime}-\mathrm{B}_{\mathrm{a}}^{\prime \prime}\right]$ as slope. The values obtained were very 
close to those calculated for $\mathrm{CaO}^{18}$ from the $\mathrm{CaO}^{16}$ spectroscopic constants given by Hultin and Lagerqvist (1950). The $\omega_{\epsilon}$ and $\omega_{\mathrm{e}} \mathrm{x}_{\mathrm{e}}$ constants calculated from the $\left[G^{\prime \prime}\left(v_{b}^{\prime \prime}\right)-G^{\prime \prime}\left(v_{\ddot{a}}^{\prime \prime}\right)\right]$ values are found in Table 4. Using these $\left[G^{\prime \prime}\left(v_{\cdot b}^{\prime \prime}\right)-G^{\prime \prime}\left(v_{a}^{\prime \prime}\right)\right]$ differences, a consistent set of band origins were picked out of the results of Eqs. (6) and (7). They are given in the Deslandre's Table of Table 1. :These origins and the calculated intercepts at $\mathrm{J}=0$ of the lower state vibrational level were used to calculate the energies of the upper state vibrational levels and the average values of these energies were in turn used to obtain the upper state vibrational constants (Table 3).

\section{Perturbations in $\mathrm{CaO}^{18}$.}

The 37 perturbations found in the $\mathrm{A}^{1} \Sigma$ state of $\mathrm{CaO}^{18}$ are listed in Table 5. They can be assigned to six perturbing states: $\mathrm{z}^{18}, \mathrm{Q}^{18}$, $\mathrm{Y}^{18}, \mathrm{~W}^{18}, \mathrm{X}^{18}$, and $\mathrm{B}^{18}$. On the plot of energy vs $\mathrm{J}(\mathrm{J}+1)$ in Fig. 14 , the solid lines represent the first seven vibrational levels of the $A^{I} \Sigma$ state and the squares shuw the perturbations. The circles indicate the end of the analysis for that particular level and in all probability another perturbation. The dashed lines connect perturbations arising from the same perturbing state. In Table 5 the relative vibrational numbering for the perturbing states is given in column $\mathrm{v}_{\mathrm{P}}$, with the lowest levels of each state called $X, Y, Z, Q, W$, and $B$ respectively.

In order to determine the $B_{v}$ values of the perturbing levels, plots (Figs: 8-IS) were made of T/4J v.S.J.(see Eq. (4)) for all the analyzed bands. : (Gerö, 19.35; Kovaes, 1937; Hultin and Lagerquist, 1950) For the unperturbed regions an almost horizontal line is obtained, while at a perturbation, two $T / 4 \mathrm{~T}$ curves, $F_{1}$ and $F_{2}$, rioc to a peak. Equations 
(11) and (12) are applicable: for these :plots:

$$
\begin{aligned}
& B_{\mathbb{V}} P^{\prime}=2 B_{v}^{\prime \prime}-B_{v}^{\prime}-2 S \\
& J_{O^{\sim}} J^{*}-\frac{i}{2}
\end{aligned}
$$

where $S$ is the value of $T / 4 \mathrm{~J}$ at which the curves $F_{1}$ and $F_{2}$ cross and $J^{*}$ is the $J$ value at this point, $J_{0}$ is the $J$ value at which the perturbation culminates, $B_{v}^{P}$ is the $B$ value of the perturbing state, $B_{v}^{\prime}$ the $B$ values of the $A^{I} \Sigma$ state, and $B_{V}^{\prime \prime}$ the $B$ value of the $X^{I} \Sigma$ state. $A$ proof of the se equations is found in Kovacs (1937). The $B_{v} P$ values are listed in Table 5. They compare quite weil with the expected valucs calculated from Eq. (13)

$$
B_{v}^{i}=\rho^{2} B_{v}
$$

where

$$
\begin{aligned}
\rho^{2} & =0.9204 \\
\mathrm{~B}_{v}{ }^{i} & =\mathrm{B}_{v} \text { for } \mathrm{CaO}^{18} \\
\mathrm{~B}_{\mathrm{v}} & =\mathrm{B}_{v} \text { for } \mathrm{CaO}^{16}
\end{aligned}
$$

Lagerqvist and Hultin obtained $B_{v} \sim 0.33$ for the $X^{16}, Y^{16}, z^{16}$ and $Q^{16}$ states of $\mathrm{CaO}^{16}$ and $\sim 0.38$ for the $\mathrm{B}^{16}$ state. For. $\mathrm{CaO}^{18}, \mathrm{~B}_{\mathrm{v}} \sim 0.308$ for the $\mathrm{X}^{18}, \mathrm{Y}^{18}, \mathrm{Q}^{18}$ and $\mathrm{Z}^{18}$ states and $\sim 0.35$ for $\mathrm{B}^{18}$.

The error in the $\mathrm{B}_{\vec{v}}{ }^{\mathrm{P}}$ values found by the above method depends on the number of comparison lines found at each perturbation, the quality of these lines (i.e. overlapped, well-defined), the number of bands in which the perturbation is found, whether or not there are nearby perturbations to distort the $B_{v}$ values of the perturbed level, etc. Because of the difficulty in estimating this error, the $G(v)$ values 
(where $G(v)$ is the energy of the $v$-vibrational level at $J=0$ ) were obtained by a simple graphical procedure. Consider the $(Y+1)$ level of $Y^{18}$ as an example. As shown in Table 5, the $(Y+1)$ level of $Y^{18}$ interacts with $\mathrm{A}^{\mathrm{I} \Sigma}$ at two points, $\mathrm{v}_{\mathrm{A}^{\prime} \Sigma}=0, J_{0}=93.50$ and $\mathrm{v}_{\mathrm{A}^{\prime} \Sigma}=1, \mathrm{~J}_{0}=27.0$. If $D_{V}$ is assumed to be small (or, since both isotopic states are treated in the same way, the effect of $D_{V}$ should cancel), the $(Y+I)$ vibrational level can be represented as a straight line on a graph of energy vs $J(J+1)$ (Fig. 14). That straight line is determined by the two points of perturbation mentioned above. The slope of the line is equal to the $\mathrm{B}_{\mathrm{V}}$ value for that level and is listed in Table 5 under $\mathrm{B}_{\mathrm{v}}{ }^{\mathrm{P}}$ (slope). In both $\mathrm{CaO}^{16}$ and $\mathrm{CaO}^{18}$ the $\mathrm{B}_{\mathrm{V}}{ }^{\mathrm{P}}$ (slope) values are $\sim 0.02$ lower than the $\mathrm{B}_{\mathrm{V}}{ }^{\mathrm{P}}$. values.

Since the $B_{v}$ values of the other vibrational levels of $\mathrm{Y}^{18}$ would be expected to be similar to that of the $(Y+1)$ level, the $Y^{18}$ state can be shown as a series of lines parallel to $(Y+I)$ and cutting through the other $Y^{18}$ perturbations. The dashed lines in Fig. 14 represent the $Y^{18}$ state; the solid lines the $A^{\prime} \Sigma$ state. This was done for all the perturbing states of $\mathrm{CaO}^{18}$ and $\mathrm{CaO}^{16}$. The perturbations of $\mathrm{CaO}^{16}$ were first replotted using the bottom of the potential curve of the $\mathrm{X} \cdot \Sigma$ state as the zero of energy。 This was done so that the $\mathrm{CaO}^{16}$ and $\mathrm{CaO}^{18}$ levels would have the same reference point and could be compared. The $G(v)$ results are given in Table 6 and the vibrational levels are graphed in Figs. 17 to 20. For the $\mathrm{Z}^{18}$ and $\mathrm{Q}^{18}$ states, the dashed Lines in Fig. 14 connecting the perturbations coming from the same state were extended and the points of probable perturbation found used in graphing. 

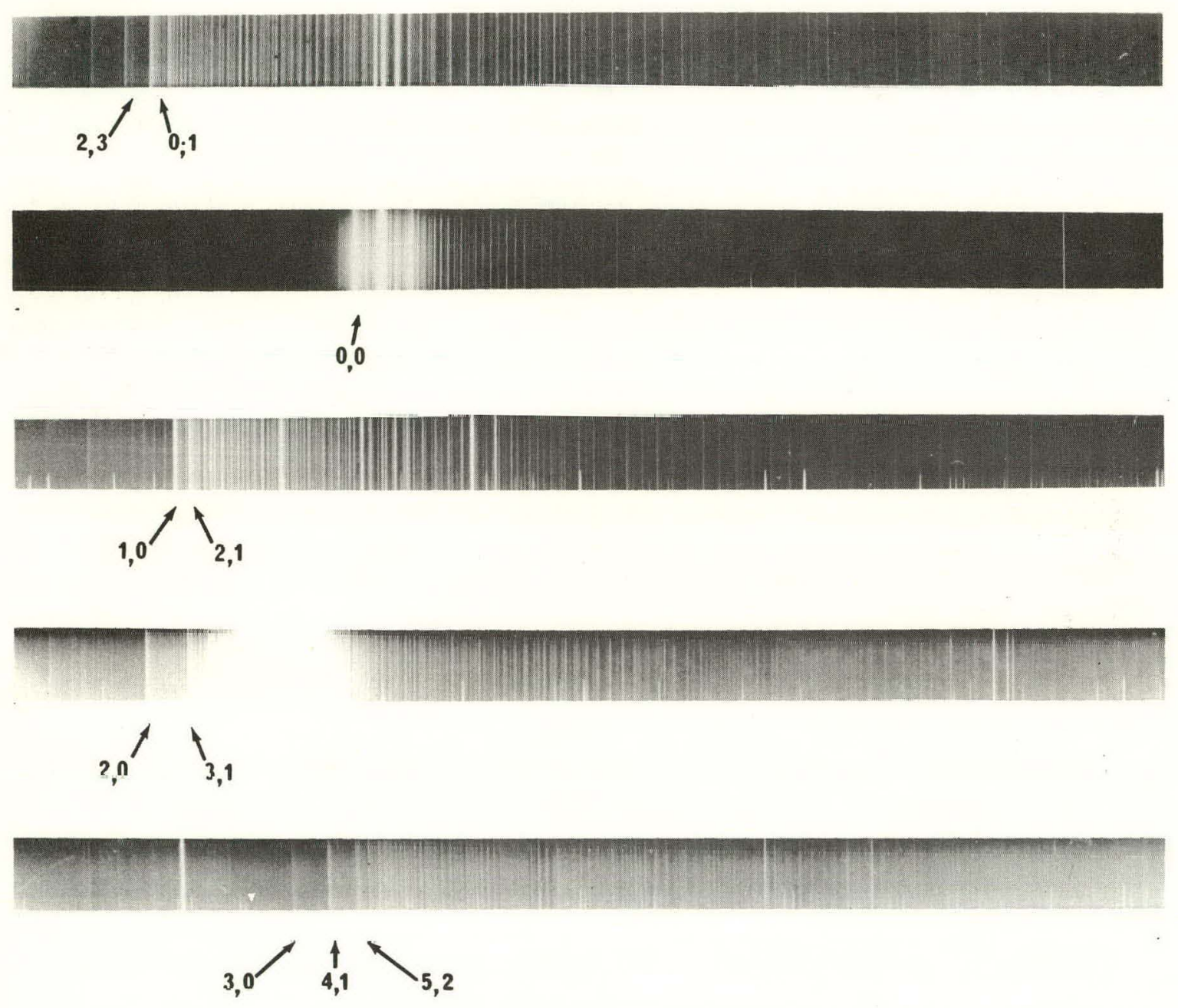

XBB 706-2706

Fig. 4. Spectrograms of the $(0,0),(0,1),(1,0),(2,0)$, and $(3,0)$ sequences of the $\mathrm{A}^{\prime} \Sigma_{1}-\mathrm{X}^{\prime} \Sigma$ transition of $\mathrm{CaO}^{16}$. 


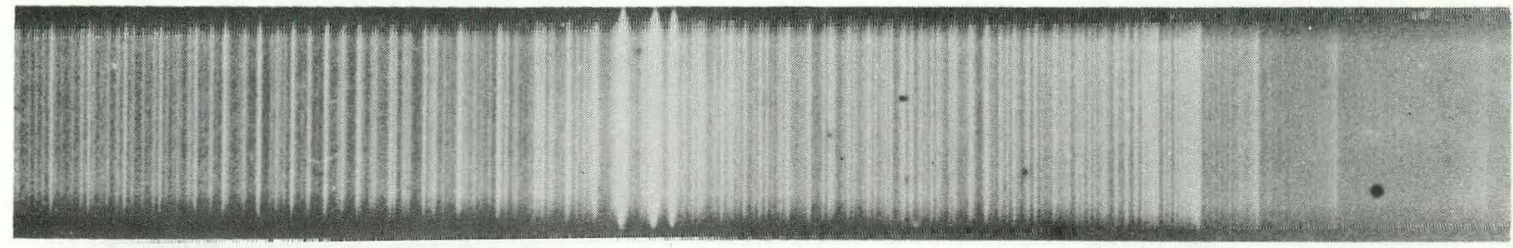

$$
\int_{(0,1)} \overbrace{(2,3)}
$$

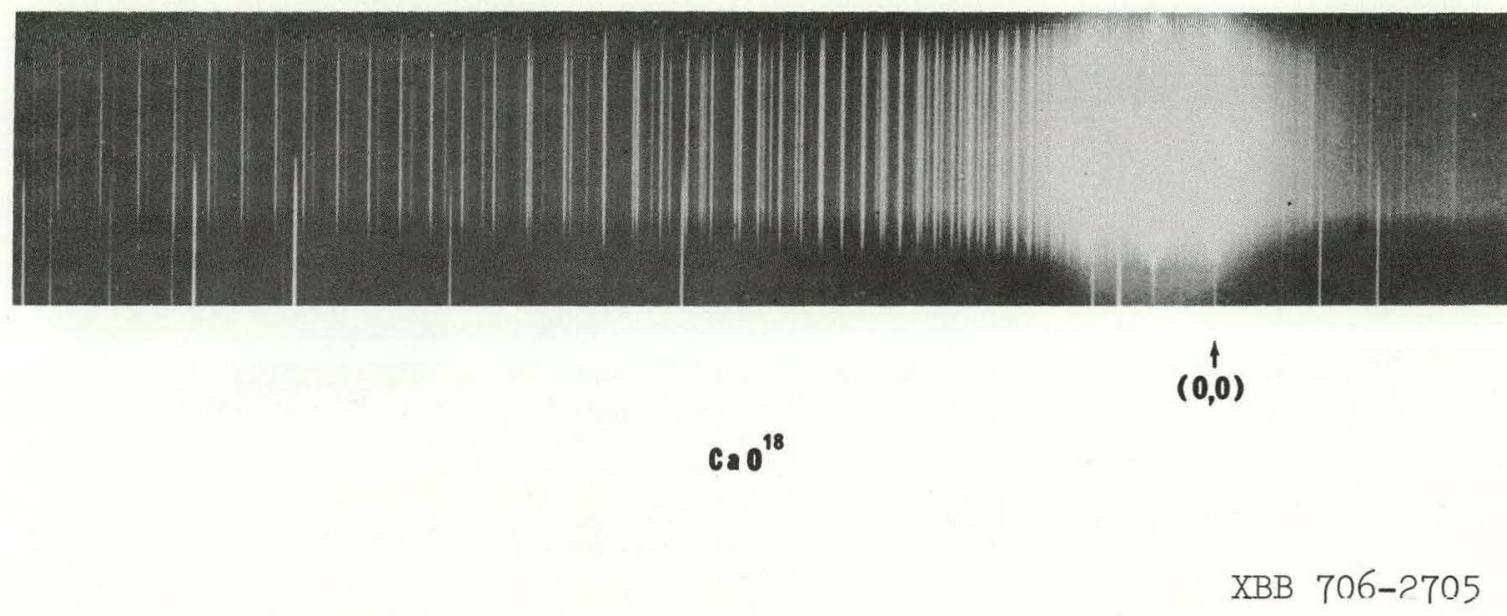

Fig. 5. Reproduction of the $(0,0)$ and $(0,1)$ sequences. 


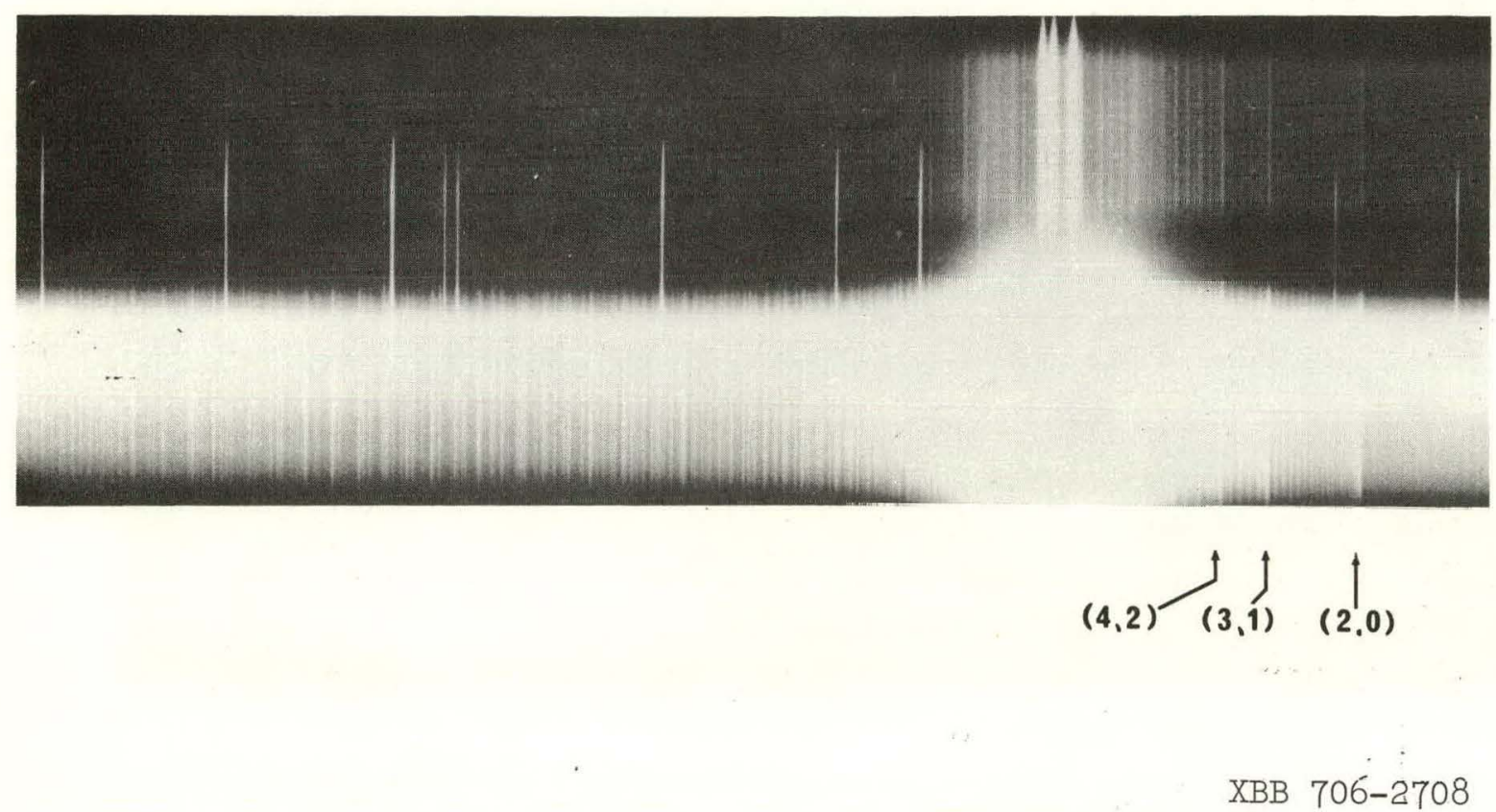

Fig. 6. Reproduction of the $(2,0)$ sequence. 


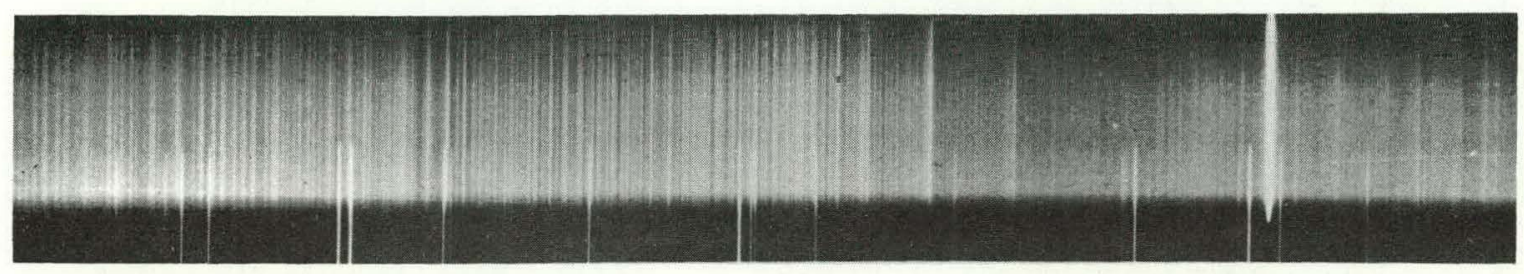

$$
\rfloor_{(5,2)}^{\dagger} \uparrow_{(4,1)}\right\rfloor_{(3,0)}
$$

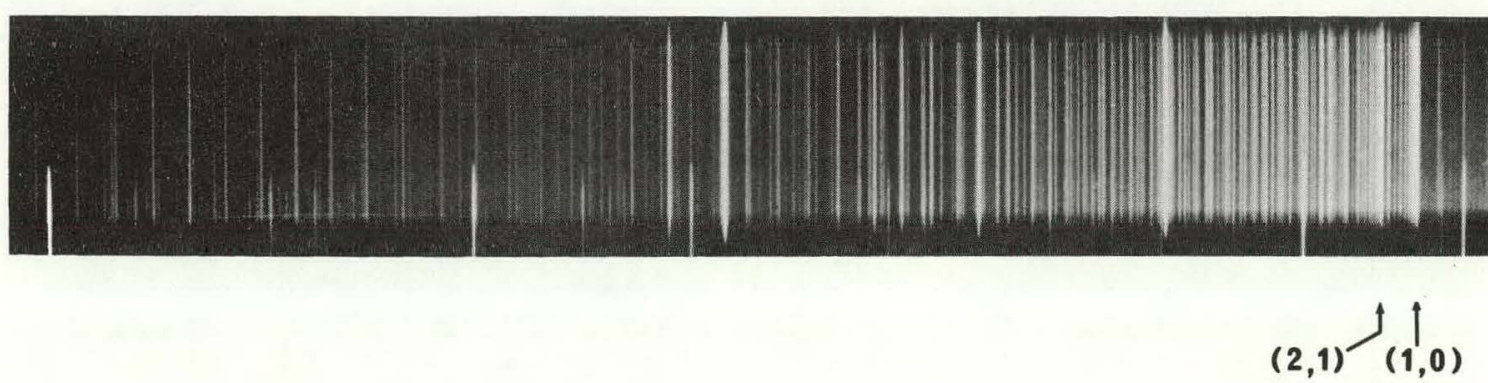

$$
\mathrm{Ca} 0^{18}
$$

XBB 706-2707

Fig. 7. Reproductions of the $(1,0)$ and $(3,0)$ sequences. 
Table 1. Deslandres Tables - Band Origins: $\mathrm{CaO}^{18}$

\begin{tabular}{|c|c|c|c|c|c|c|c|c|}
\hline & 6 & & & & & & & 13548.6 \\
\hline & 5 & & & & & 13558.8 & 677.1 & $\begin{array}{r}666.9 \\
12881.7\end{array}$ \\
\hline & 4 & & & 13571.7 & 685.5 & $\begin{array}{r}672.6 \\
12886.2\end{array}$ & & \\
\hline & 3 & $=3589.7$ & 691.7 & $\begin{array}{r}673.7 \\
12898 .\end{array}$ & 685.7 & $\begin{array}{r}674.9 \\
12212.3\end{array}$ & & \\
\hline & 2 & $\begin{array}{r}676.9 \\
-2912.8\end{array}$ & 693.2 & $\begin{array}{r}678.4 \\
12219.6\end{array}$ & & & & 10858.6 \\
\hline & 1 & $\begin{array}{r}674.8 \\
-2238.5\end{array}$ & 689.1 & $\begin{array}{r}679.2 \\
11540.4\end{array}$ & 682.8 & 10857.6 & & \\
\hline $\begin{array}{l}\uparrow \\
\mathrm{V}^{\prime}\end{array}$ & 0 & $\begin{array}{r}689.9 \\
-1548.6\end{array}$ & 695.8 & $\begin{array}{r}687.6 \\
10852.8\end{array}$ & & & & \\
\hline & & 0 & & 1 & & 2 & & 3 \\
\hline
\end{tabular}


Table 2. Listing of assigned lines in $\mathrm{CaO}^{18}$

\begin{tabular}{llllll}
\hline$V^{\prime} V^{\prime \prime}$ & 0. & 0. & & & \\
\hline$J$ & $P(J)$ & $R(J)$ & $P(J)$ & 1.0 & \\
\hline
\end{tabular}

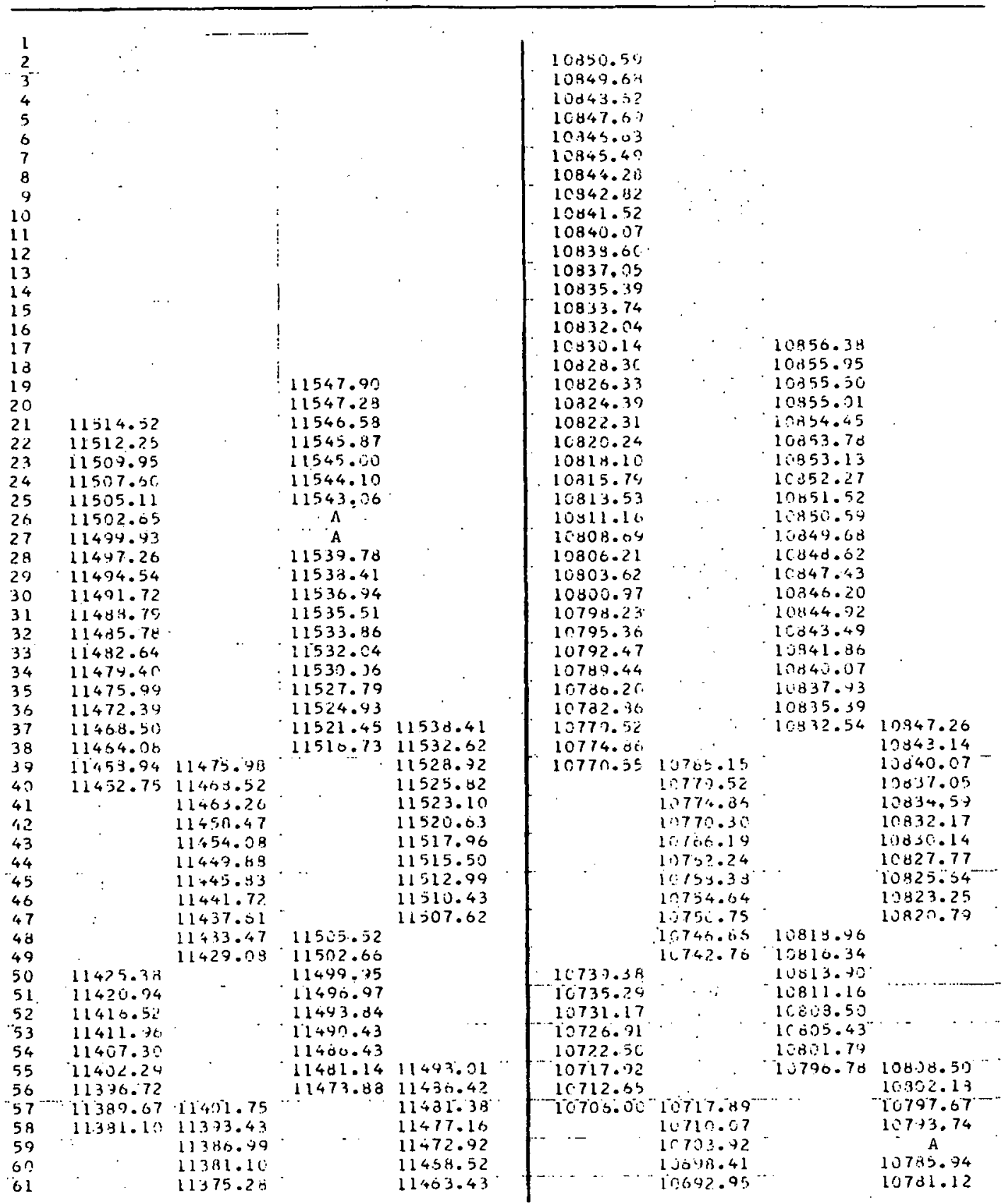


Table 2, continued.

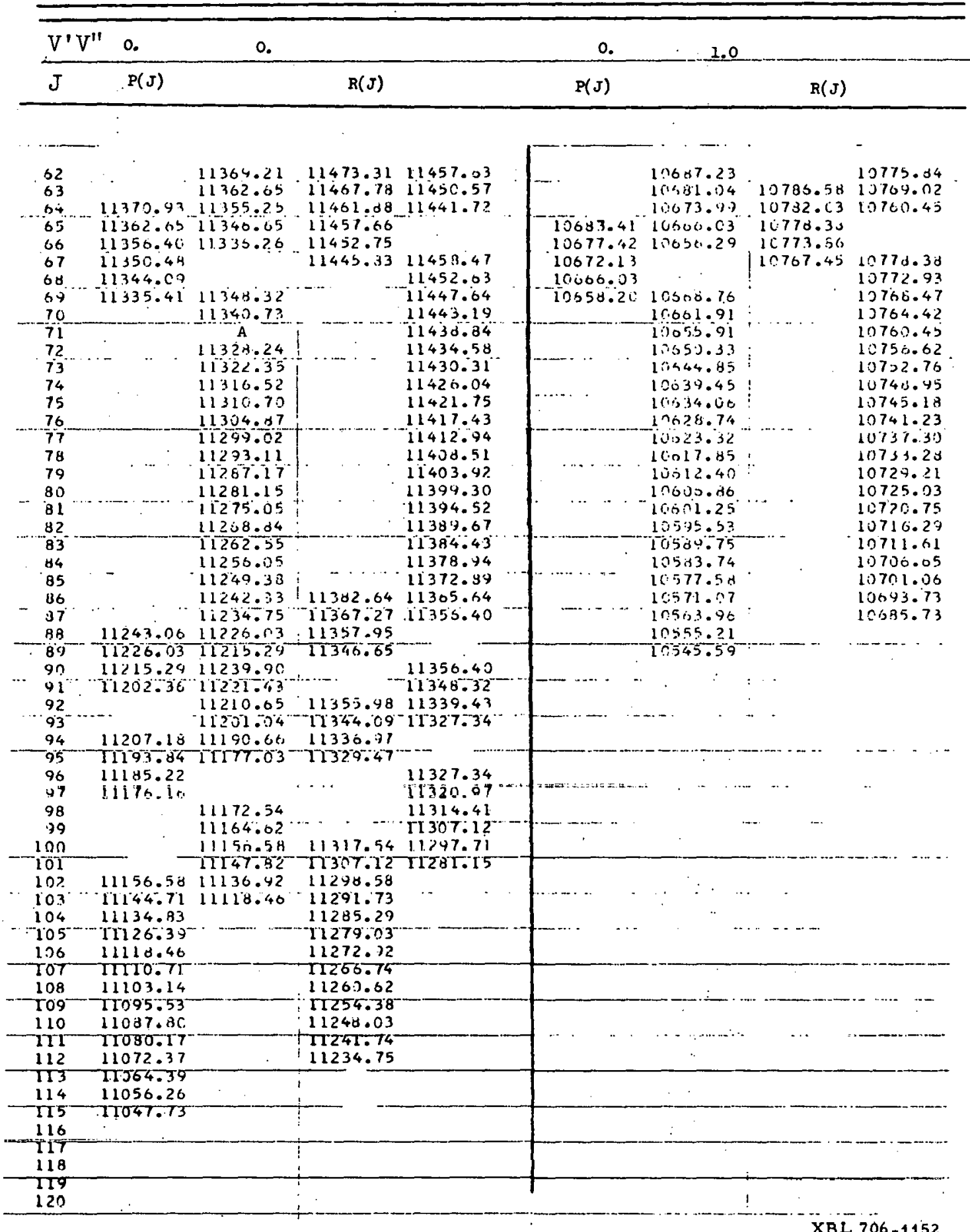




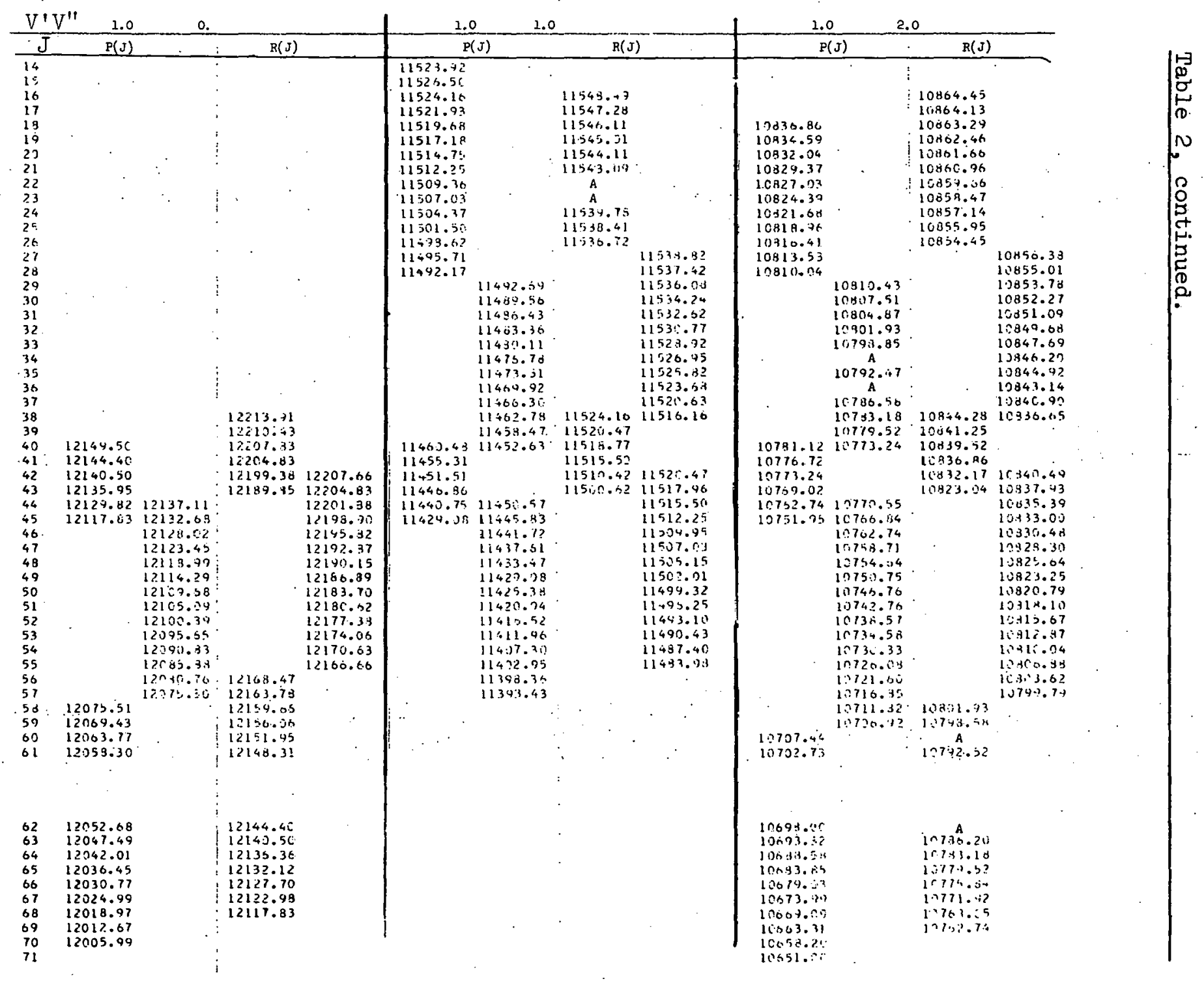




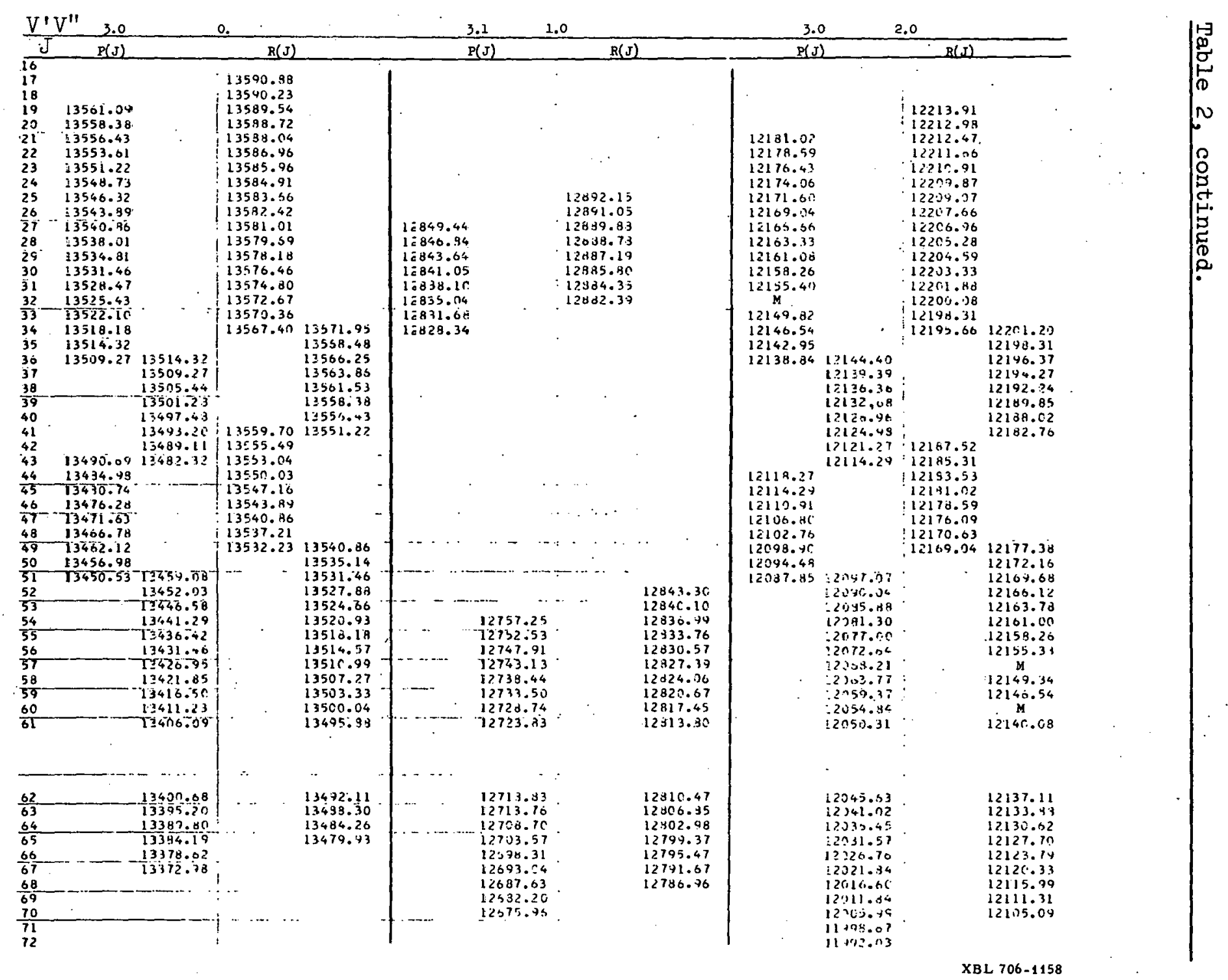


Table 2, continued.

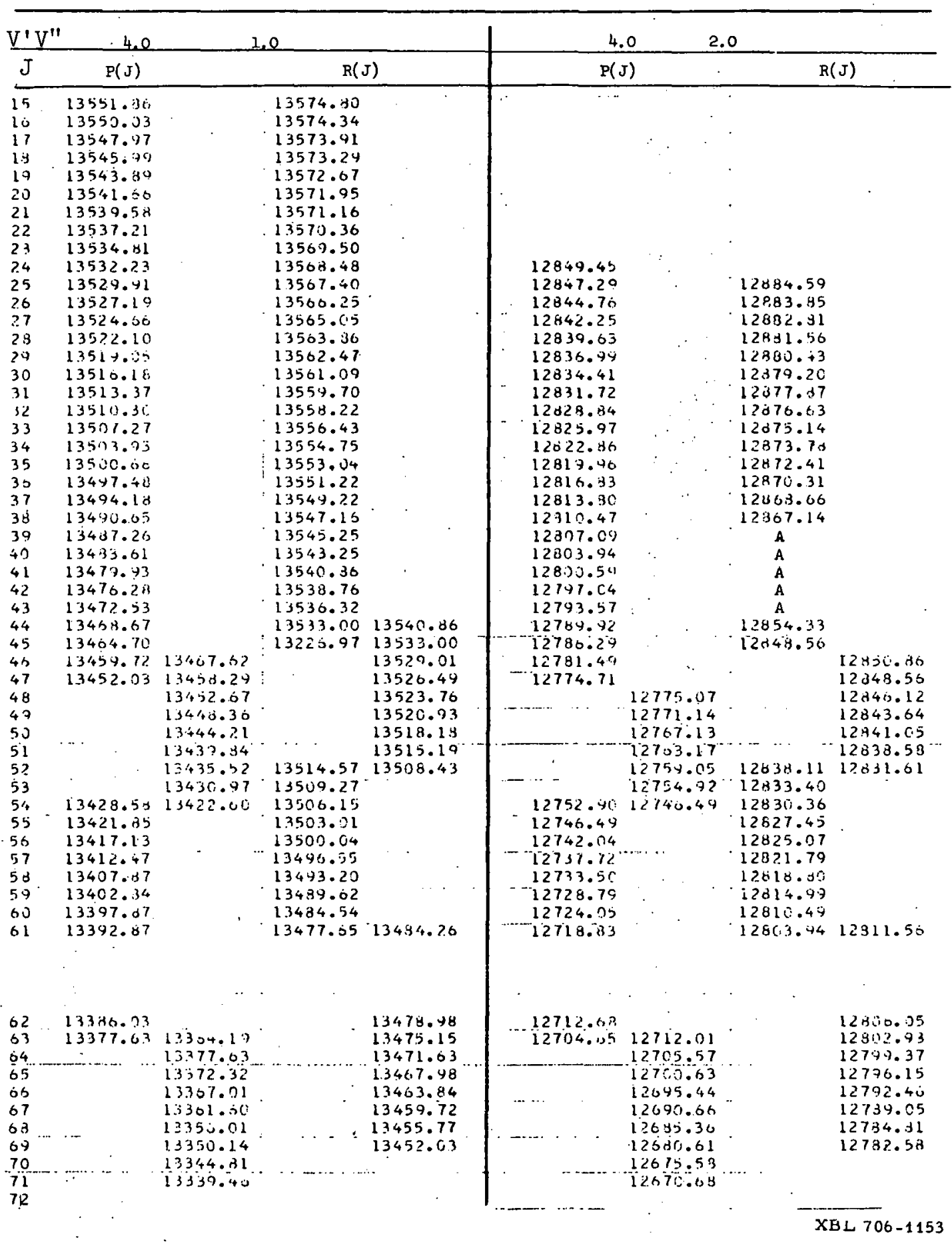




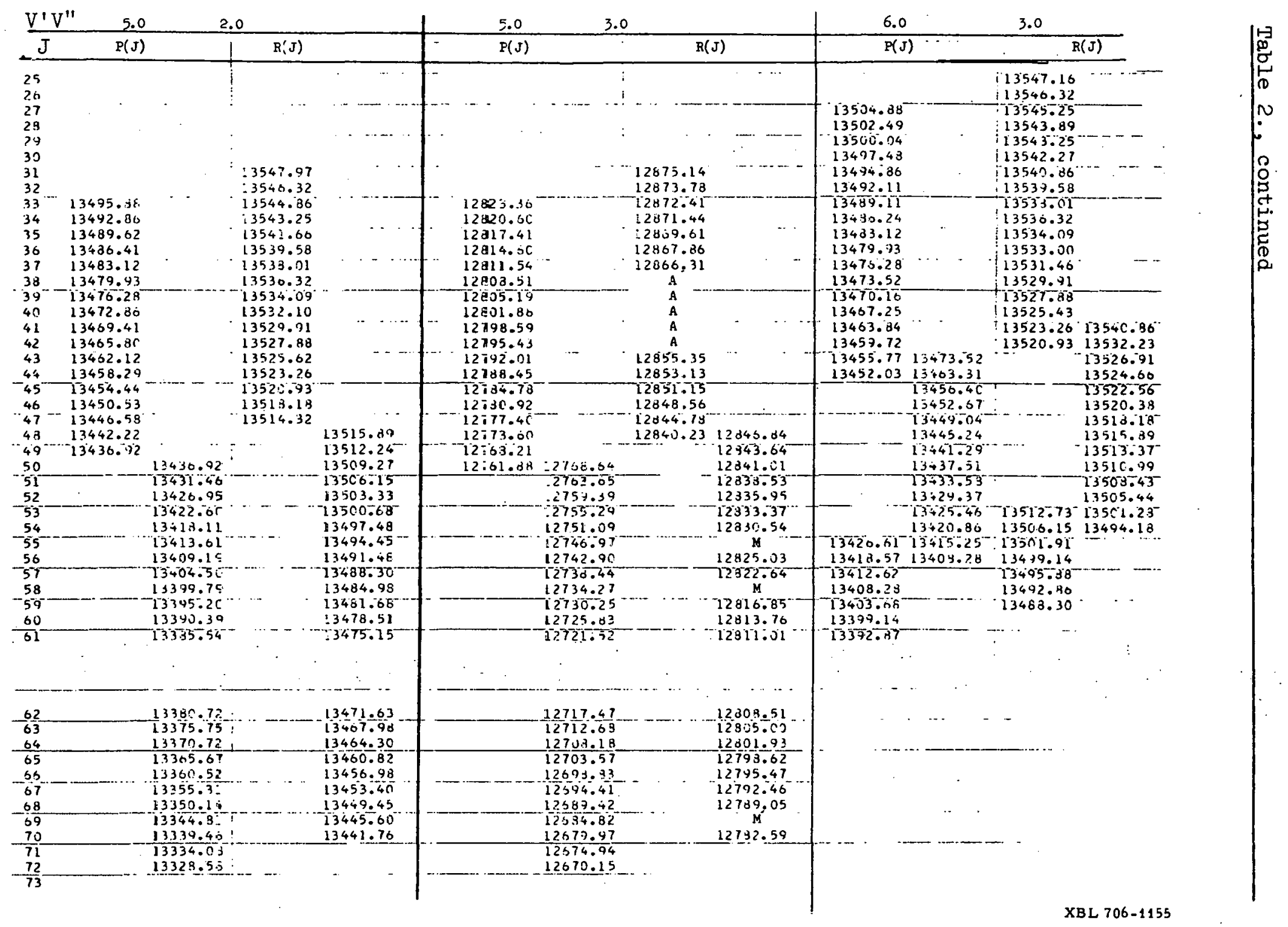


Table 2, continued.

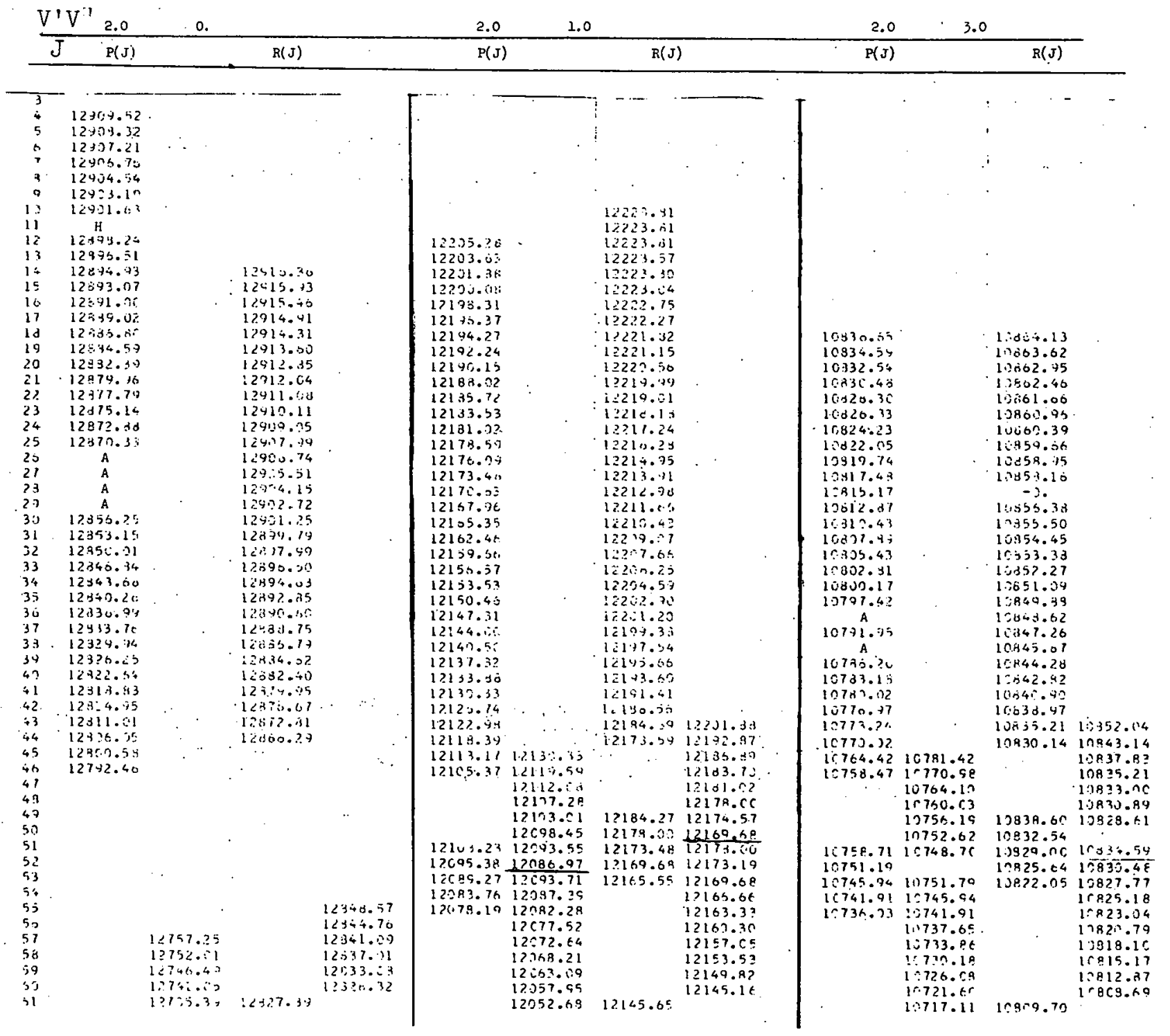


Table 2, continued.

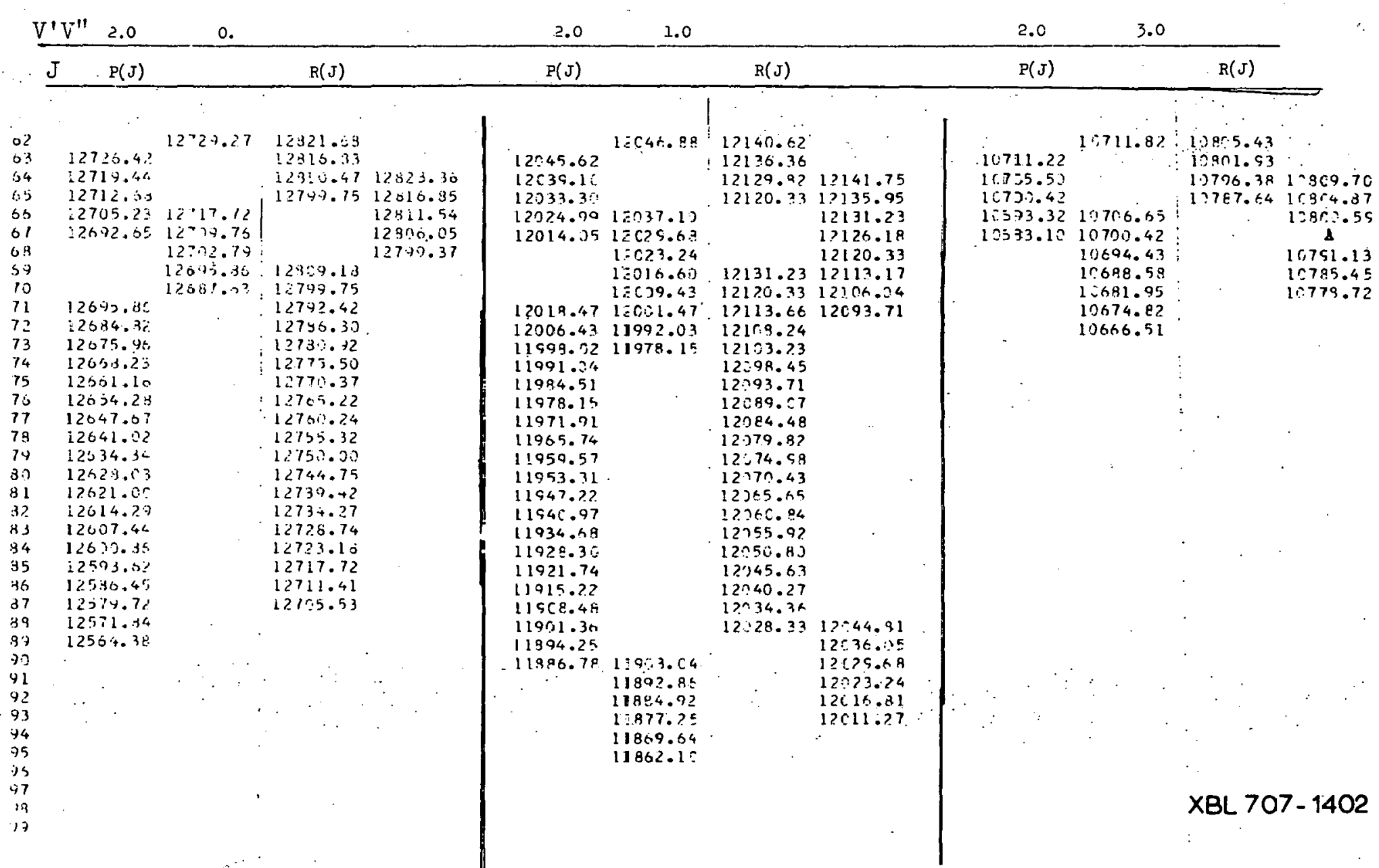


Table 3. Rotational Cortants for the $X^{\prime} \Sigma$ and $A ! \Sigma$ States: CaO ${ }^{18}$

\begin{tabular}{|c|c|c|c|c|}
\hline$v$ & B"obs. & B"calc. & B'obs. & B'calc'. \\
\hline 0 & .3732 & .3728 & .4078 & .4078 \\
1 & .3725 & .3720 & .4049 & .4048 \\
2 & .3706 & .3710 & .4017 & .4018 \\
3 & .3698 & .3702 & .3988 & .3988 \\
4 & .3693 & .3692 &. & \\
5 & .3681 & .3684 & & \\
\hline 6 & .3678 & .3674 & & \\
\hline
\end{tabular}


Table 4. Spectroscopic Constants: $\mathrm{CaO}^{18}$

\begin{tabular}{|c|c|c|c|c|}
\hline & $\begin{array}{l}\text { Constan } \\
\text { found }\end{array}$ & $\begin{array}{l}\text { ts for } x^{1} \Sigma \\
\text { Cal from } \mathrm{CaO}^{16}\end{array}$ & $\begin{array}{l}\text { Constant } \\
\text { found }\end{array}$ & $\begin{array}{l}s \text { for } A^{1} \Sigma \\
\text { Cal from } \mathrm{CaO}^{16}\end{array}$ \\
\hline $\mathrm{v}(0,0)$ & 0.0 & 0.0 & 11548.6 & 11548.80 \\
\hline we & 702.18 & 702.40 & $\sim 686.5$ & 686.9 \\
\hline wexe & 4.29 & 4.43 & $\sim 1.5$ & 1.47 \\
\hline $\mathrm{Be}$ & .4093 & .4091 & .3733 & .3740 \\
\hline$\alpha e$ & .003 & .00296 & .0009 & .0012 \\
\hline De & $\sim 5.24 \times 10^{-1}$ & $5.56 \times 10^{-1}$ & $<4.58 \times 10^{-7}>$ & $4.57 \times 10^{-7}$ \\
\hline $\mathrm{Be}$ & $\sim 5.9 \times 10^{-8}$ & $2.4 \times 10^{-8}$ & & \\
\hline
\end{tabular}


Table 5. Summary of the Perturbations: $\mathrm{CaO}^{18}$

\begin{tabular}{|c|c|c|c|c|}
\hline $\mathrm{V}_{\mathrm{P}}$ & ${ }^{\mathrm{V}}{ }^{\mathrm{I}} \Sigma$ & $\mathrm{J}_{\mathrm{O}}$ & $\mathrm{B}_{\mathrm{v}}^{\mathrm{P}}$ & $\mathrm{B}_{\mathrm{v}}^{\mathrm{P}}$ (Slope) \\
\hline Z & 0 & 38.70 & .304 & \\
\hline $\begin{array}{l}Q \\
Y\end{array}$ & $\begin{array}{l}0 \\
0\end{array}$ & $\begin{array}{l}48.50 \\
56.20\end{array}$ & .3088 & \\
\hline $\begin{array}{l}W \\
X\end{array}$ & $\begin{array}{l}0 \\
0\end{array}$ & $\begin{array}{l}63.20 \\
67.80\end{array}$ & .328 & \\
\hline $\begin{array}{l}Z+1 \\
Q+1\end{array}$ & $\begin{array}{l}0 \\
0\end{array}$ & $\begin{array}{l}87.80 \\
89.90\end{array}$ & $\begin{array}{l}.3018 \\
.2938\end{array}$ & \\
\hline $\begin{array}{l}Y+1 \\
W+1\end{array}$ & $\begin{array}{l}0 \\
0\end{array}$ & $\begin{array}{l}93.50 \\
96.50\end{array}$ & .306 & $\begin{array}{l}.284 \\
.281\end{array}$ \\
\hline $\begin{array}{l}X+1 \\
Z+2\end{array}$ & $\begin{array}{l}0 \\
0\end{array}$ & $\begin{array}{r}101.10 \\
\sim 114.00\end{array}$ & .311 & .280 \\
\hline $\begin{array}{l}Y+I \\
W+I\end{array}$ & $\begin{array}{l}1 \\
I\end{array}$ & $\begin{array}{l}27.00 \\
38.80\end{array}$ & $\therefore$ & $\begin{array}{l}.284 \\
.281\end{array}$ \\
\hline$\frac{X+1}{B}$ & $\frac{1}{1}$ & $\begin{array}{l}42.40 \\
57.90\end{array}$ & $\begin{array}{l}(.295) \\
(.35)\end{array}$ & \\
\hline $\begin{array}{l}z+2 \\
z+3\end{array}$ & $\begin{array}{l}1 \\
2\end{array}$ & $\begin{array}{r}70.70 \\
44.80\end{array}$ & .269 & .280 \\
\hline $\begin{array}{l}B+1 \\
Q+3 \\
Y+3\end{array}$ & $\begin{array}{l}2 \\
2 \\
2\end{array}$ & $\begin{array}{l}53 . \\
51.40 \\
61.40\end{array}$ & .35 & \\
\hline $\begin{array}{l}w+3 \\
x+3\end{array}$ & $\begin{array}{l}2 \\
2\end{array}$ & $\begin{array}{l}64.90 \\
71.00\end{array}$ & $\begin{array}{l}.314 \\
.3025\end{array}$ & \\
\hline $\begin{array}{l}Z+4 \\
Y+4\end{array}$ & $\begin{array}{l}2 \\
3\end{array}$ & $\begin{array}{r}89.75 \\
35.00\end{array}$ & & \\
\hline $\begin{array}{l}w+4 \\
x+4\end{array}$ & $\begin{array}{l}3 \\
3\end{array}$ & $\begin{array}{l}42.00 \\
50.00\end{array}$ & & \\
\hline
\end{tabular}


Table 5. Summary of the Perturbations: $\mathrm{CaO}^{18}$ (continued)

\begin{tabular}{|c|c|c|c|c|}
\hline$V_{P}$ & ${ }_{A^{I} \Sigma}$ & $J_{0}$ & $\mathrm{~B}_{\mathrm{v}}^{\mathrm{P}}$ & $\mathrm{B}_{\mathrm{v}}^{\mathrm{P}}$ (Slope) \\
\hline $\begin{array}{l}z+5 \\
z+6\end{array}$ & $\begin{array}{l}3 \\
4\end{array}$ & $\begin{array}{r}270.60 \\
45.70\end{array}$ & & \\
\hline $\begin{array}{l}Q+6 \\
Y+6(?)\end{array}$ & $\begin{array}{l}4 \\
4\end{array}$ & $\begin{array}{l}52.70 \\
61.70\end{array}$ & & . \\
\hline $\begin{array}{l}X+6 \\
Y+7(?)\end{array}$ & $\begin{array}{l}4 \\
5\end{array}$ & $\begin{array}{l}-70.50 \\
\sim 31.50\end{array}$ & . & \\
\hline $\begin{array}{l}x+7 \\
z+8\end{array}$ & $\begin{array}{l}5 \\
5\end{array}$ & $\begin{array}{r}48.50 \\
\sim 71.75\end{array}$ & $\therefore$ & \\
\hline \multirow[t]{2}{*}{$\begin{array}{c}Z+9 \\
Y\end{array}$} & $\begin{array}{l}6 \\
6\end{array}$ & $\begin{array}{l}43.10 \\
54.60\end{array}$ & . 3012 & \\
\hline & 6 & .60 .60 & & \\
\hline
\end{tabular}


Takle 6. Term Values of the Perturbirg States at $\mathrm{J}=0$ for $\mathrm{CaO}^{18}$

\begin{tabular}{|c|c|c|c|c|c|c|c|c|c|}
\hline z & 12010 & Q & 12100 & $\mathrm{Y}$ & 12170 & W & 12270 & $\mathrm{x}$ & 12300 \\
\hline$z+1$ & 12480 & $Q+1$ & 12565 & $Y+i$ & 12650 & $w+1$ & 12720 & $x+1$ & 12730 \\
\hline$z+2$ & 12945 & $Q+2$ & 13035 & $Y+2$ & 13120 & $\mathrm{w}+2$ & $(13190)$ & $x+2$ & (13210) \\
\hline$z+3$ & 13405 & $Q+3$ & 13485 & $Y+3$ & 13595 & $w+3$ & 13645 & $x+3$ & 13705 \\
\hline$z+4$ & $(13880)$ & $Q+4$ & 13940 & $Y+4$ & 14060 & $w+4$ & 14105 & $x+4$ & 14160 \\
\hline $2+5$ & 14300 & & & & & & & $x+5$ & (14605) \\
\hline$z+6$ & 14755 & & & $Y+6 \cdot(?)$ & 14940 & & & $x+6$ & 15010 \\
\hline$z+7$ & $(15200)$ & B & 12650 & $Y+7(?)$ & 15370 & & & $x+6$ & 15480 \\
\hline$z+8$ & 15640 & $B+1$ & 13322 & $Y+8(?)$ & 16235 & & & & \\
\hline$z+9$ & 15070 & & & & & & & & \\
\hline
\end{tabular}


Table 6, continued. Term Values of the Perturbing States at $\mathrm{J}=0$ for $\mathrm{CaO}^{16}$

\begin{tabular}{|c|c|c|c|c|c|c|c|}
\hline z & 12165 & 2 & 12735 & $\mathrm{Y}$ & 12325 & $\mathrm{x}$ & 12430 \\
\hline$z+1$ & 12660 & $Q+I$ & 13235 & $Y+1$ & 12820 & $x+1$ & 12885 \\
\hline$z+2$ & 13155 & $Q+2$ & 13710 & $Y+2$ & (13295) & $x+2$ & 13345 \\
\hline$z+3$ & 13680 & $Q+3$ & 14210 & $Y+3$ & 13780 & $x+3$ & 13850 \\
\hline$z+4$ & 14155 & & & $Y+4$ & 14250 & $x+4$ & 14340 \\
\hline$z+5$ & $(14590)$ & & & & & $x+5$ & 14800 \\
\hline$z+6$ & 15125 & B. & 12113 & & & $x+6$ & $(15280)$ \\
\hline \multirow[t]{2}{*}{$z+7$} & 15635 & $B+1$ & 12690 & & & $x+7$ & 15765 \\
\hline & & & & & & $x+8$ & 16220 \\
\hline
\end{tabular}




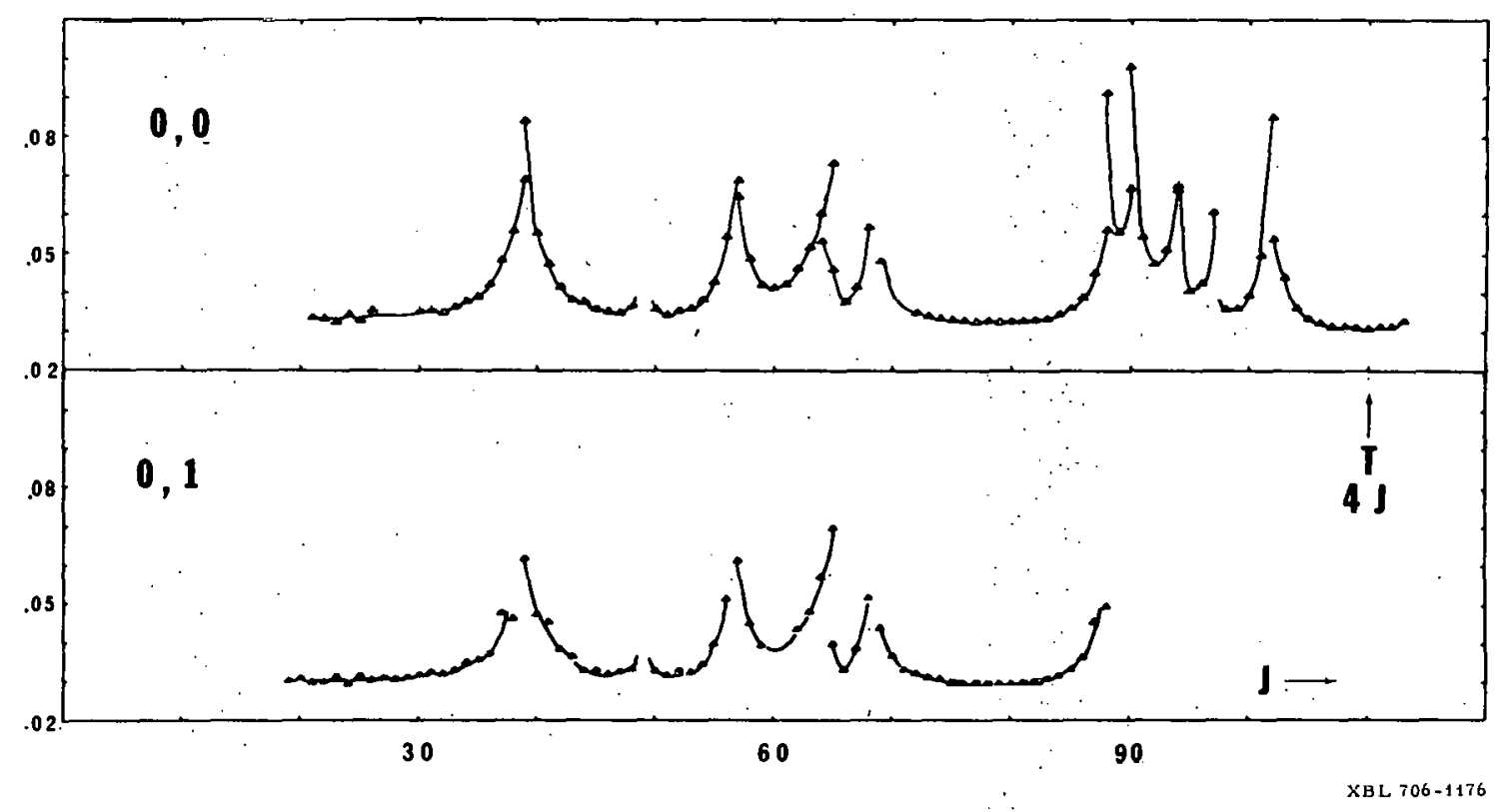

Fig. 8. $T / 4 J=[R(J-2)-R(J-1)+P(J)-P(J+1)] / 4 J$ plotted vs $J$ for the $(0,0)$ and $) 0,1)$ bands. 


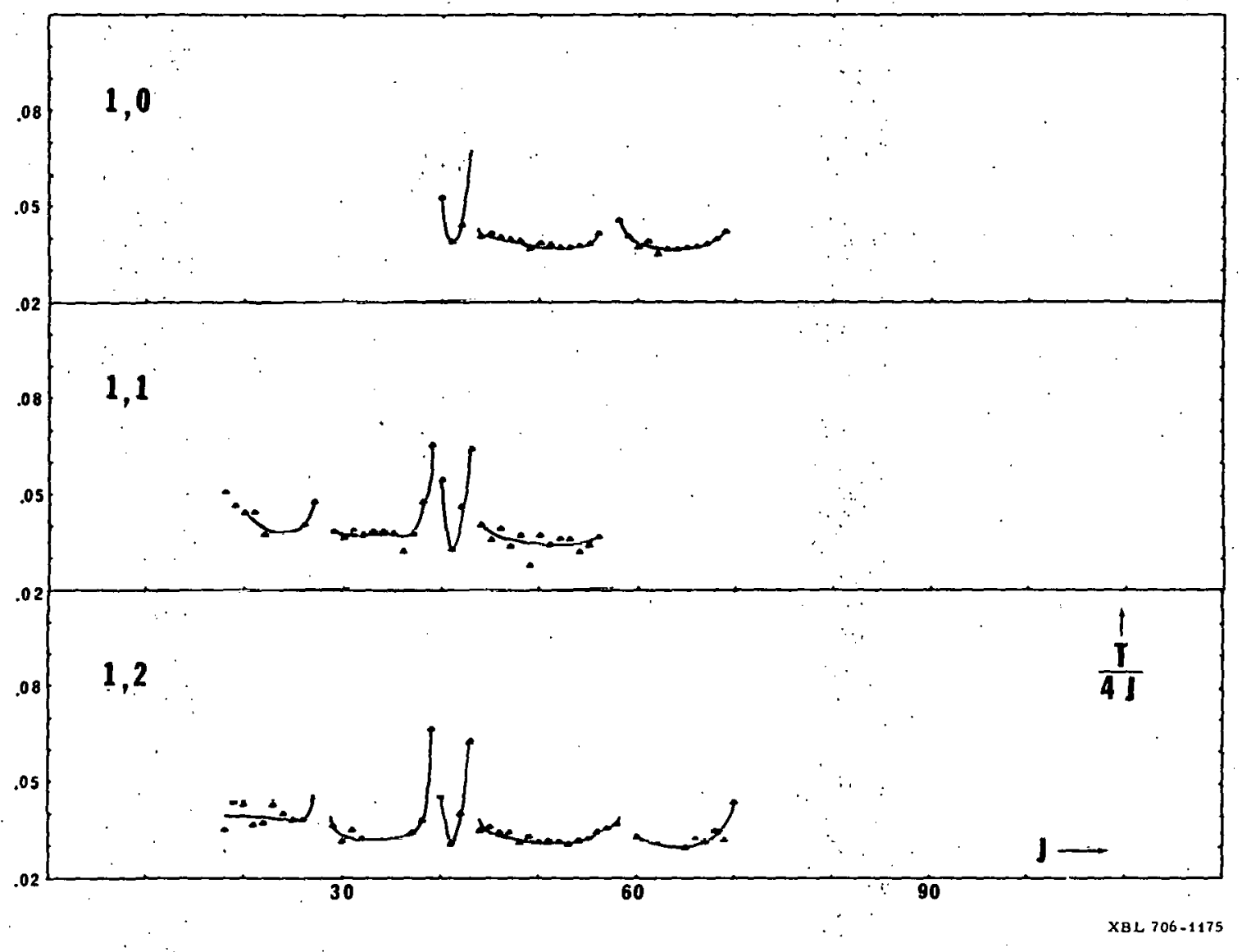

Fig. 9. T/4J plotted against $J$ for the $(1,0),(1,1)$, and $(1,2)$ bands. 


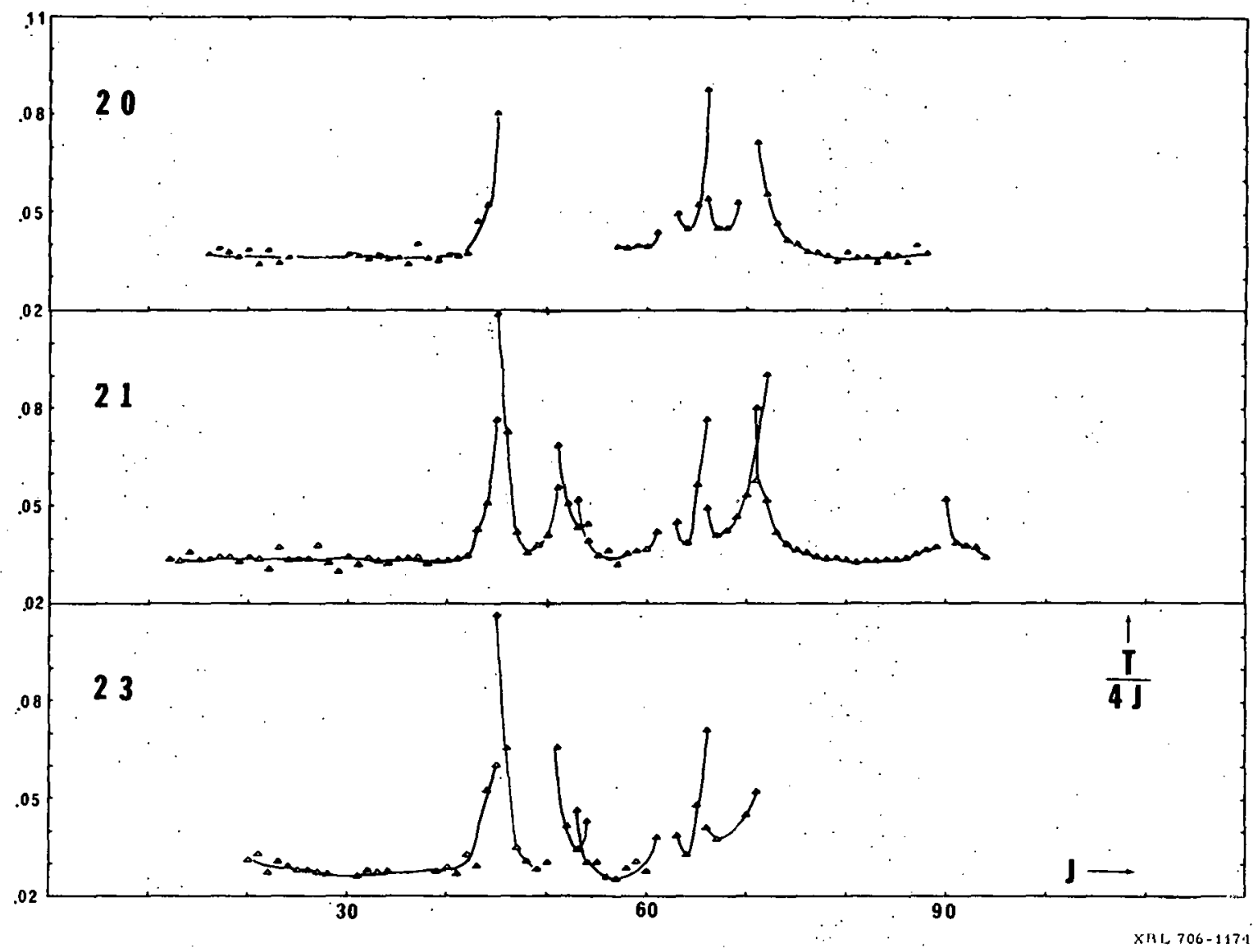

Fig. 10. T/4J plotted against $J$ for the $(2,0) ;(2,1)$, and $(2,3)$ bands. The blank spot in the $(2,0)$ plot is due to atomic lines which blotted out the CaO spectra. 


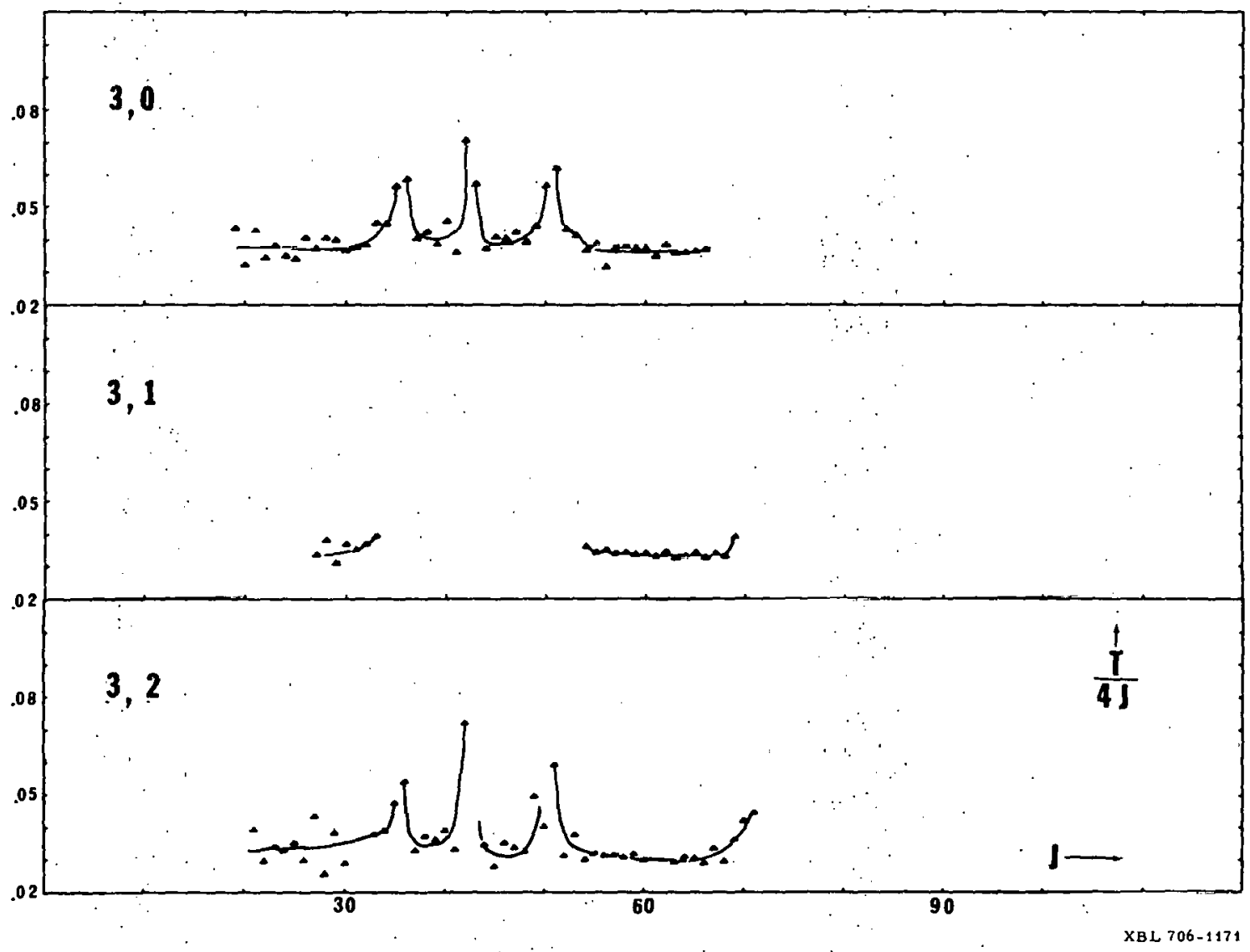

Fig. 11. T/4J plotted vs $J$ for the $(3,0),(3,1)$, and $(3,2)$ bande . 


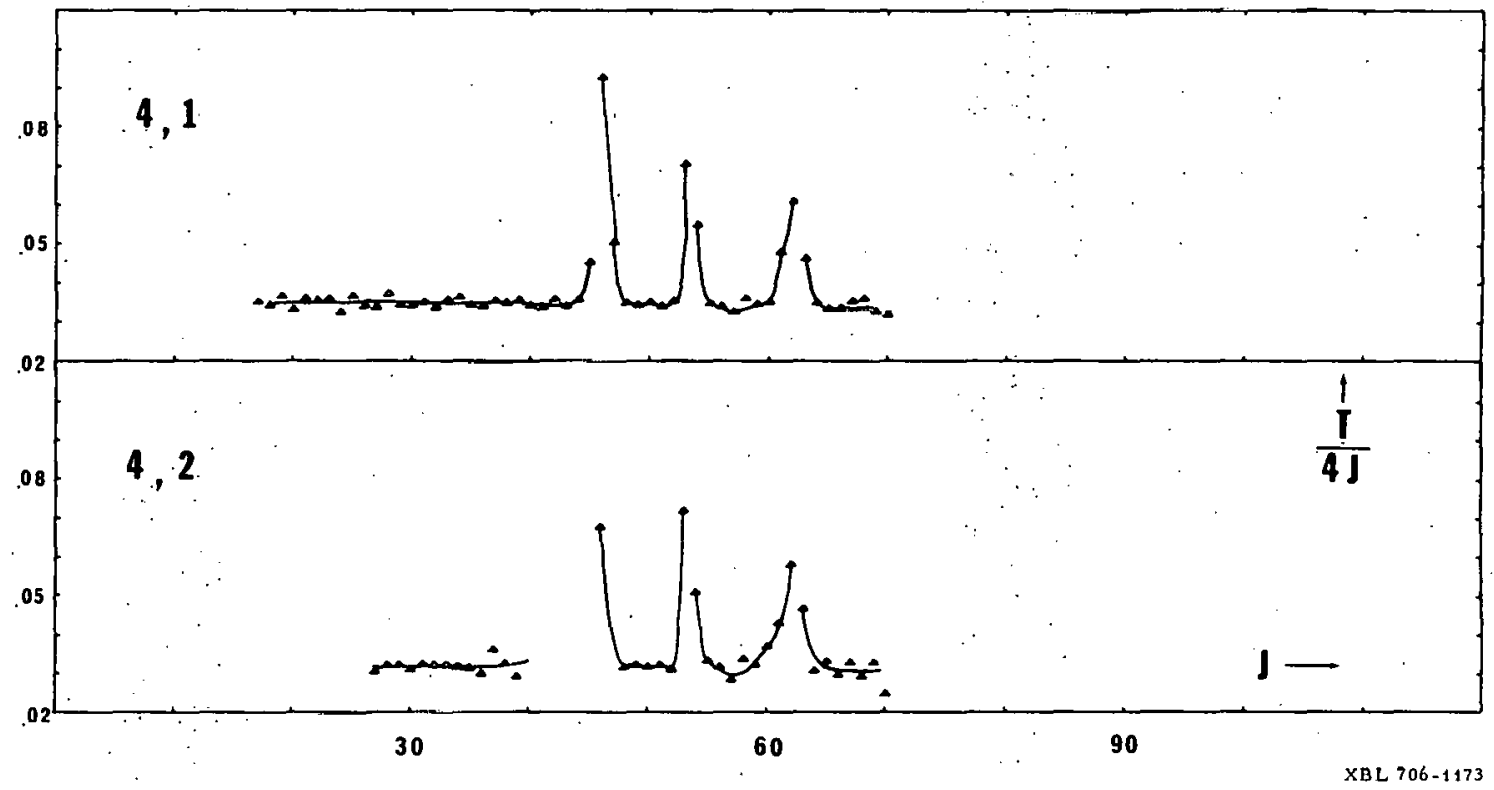

Fig. 12. T/4J plotted against $J$ for the $(4,1)$ and $(4,2)$ bands. 


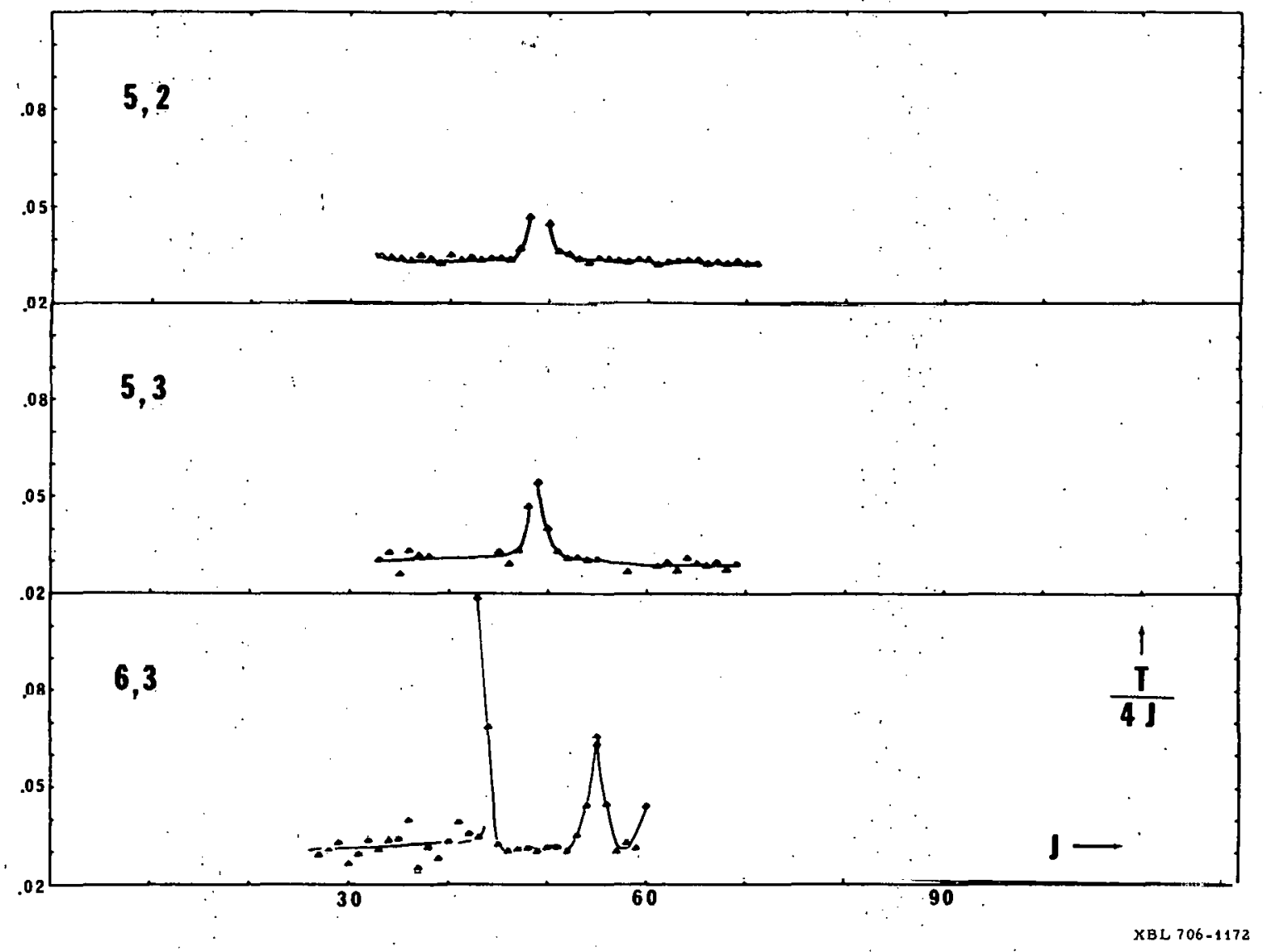

Fig. 13. T/4J plotted against $J$ for the $(5 ; 2),(5,3)$, and $(6,3)$ bands. 


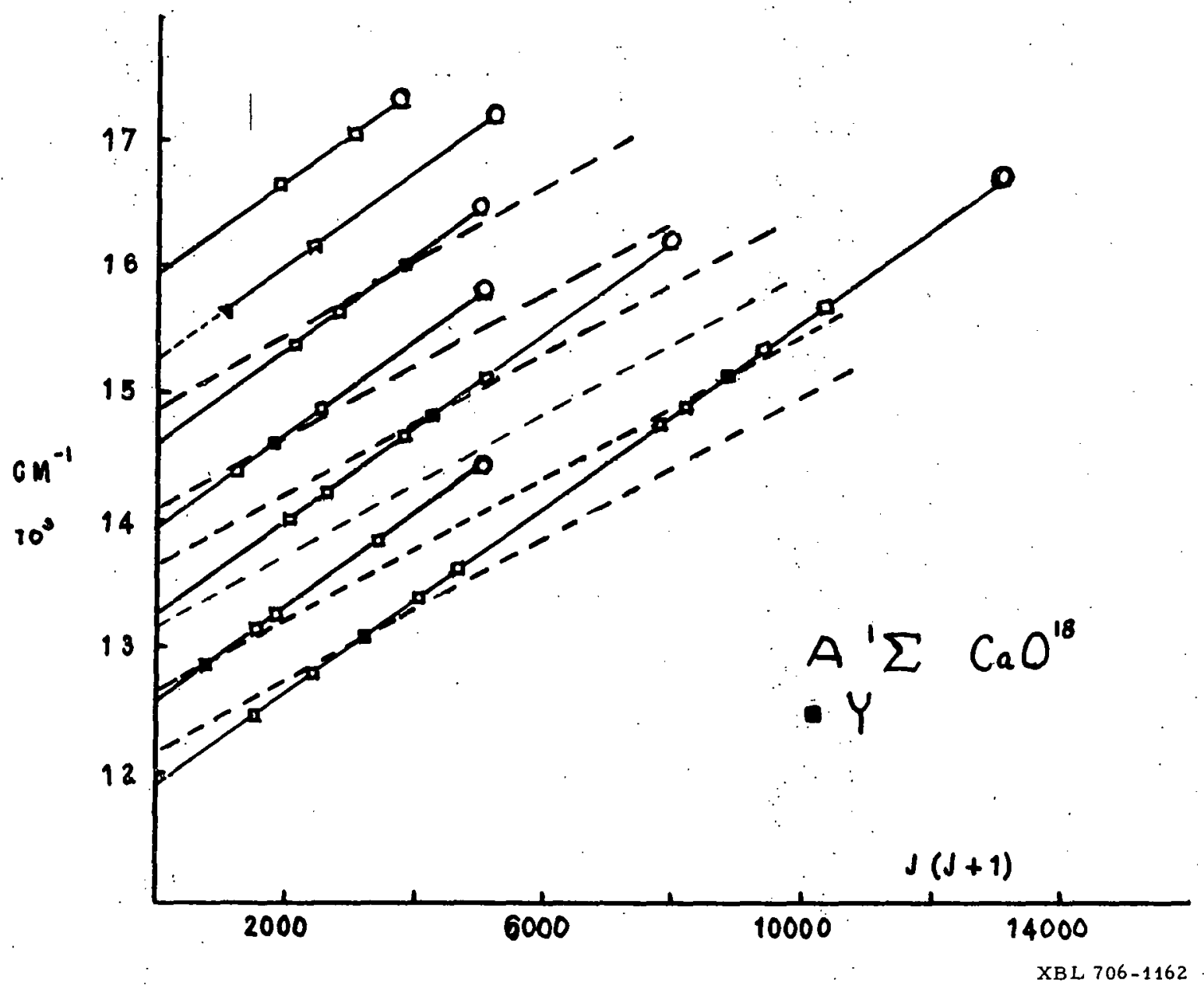

Fig. 14. Plot of energy vs $\mathrm{J}(\mathrm{J}+\mathrm{I})$. The solid lines represent the first seven vibrational levels of the $A^{\prime} \Sigma$ state of $\mathrm{CaO}^{18}$ and the squares show the positions of the perturbations. The dashed lines indicate some vibrational levels of the $\mathrm{Y}^{18}$ perturbing state. 


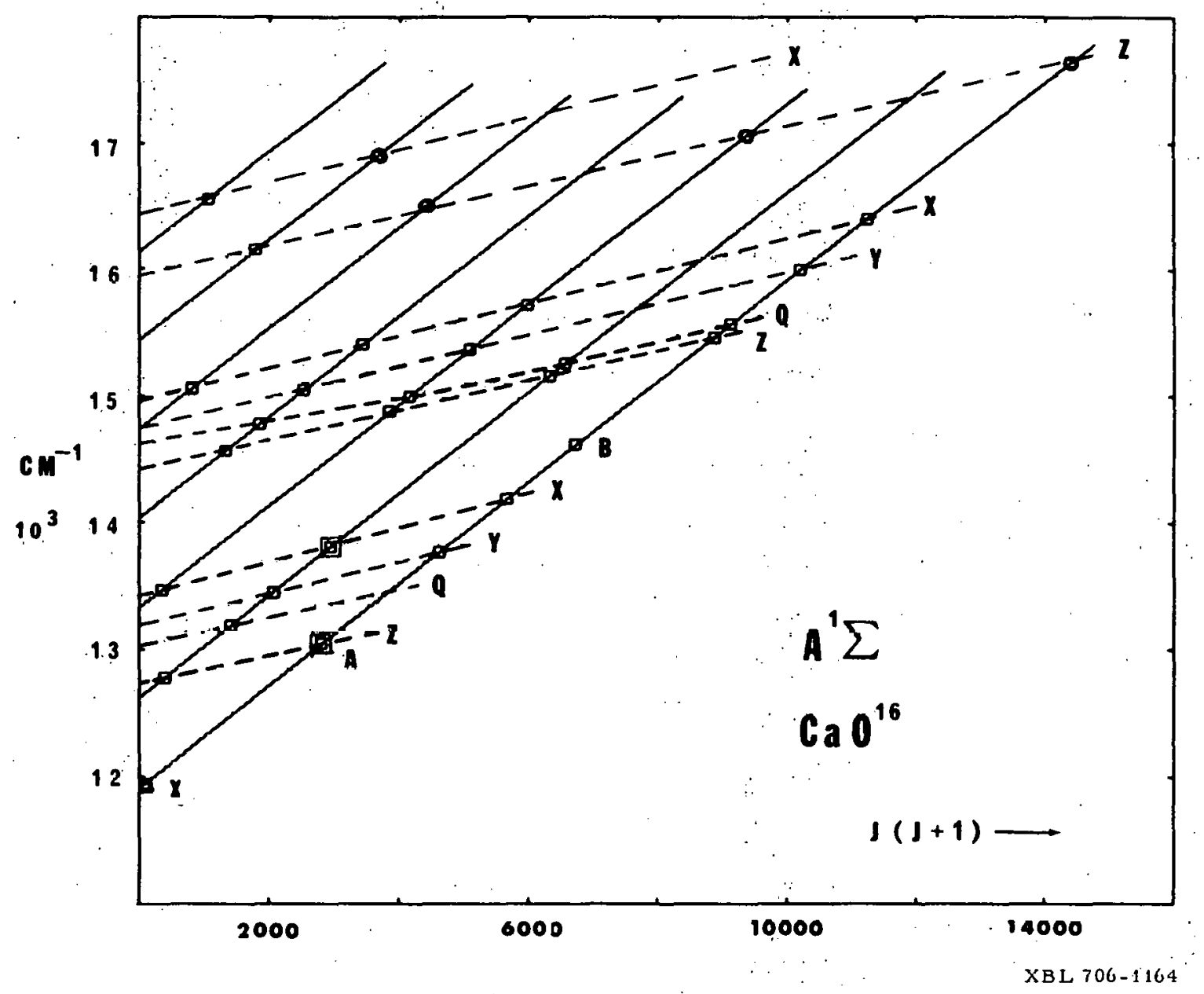

F1g. 15. Plot of energy vs $J(J+1)$. The solid lines represent the vibrational levels of the $A^{\prime} \Sigma$ state of $\mathrm{CaO}^{16}$, the squares indicate perturbations, and the dashed lines connect perturbations arising from the same perturbing state. The zero of energy has been taken as the bottom of the $X^{\prime} \Sigma$ potential curve. 


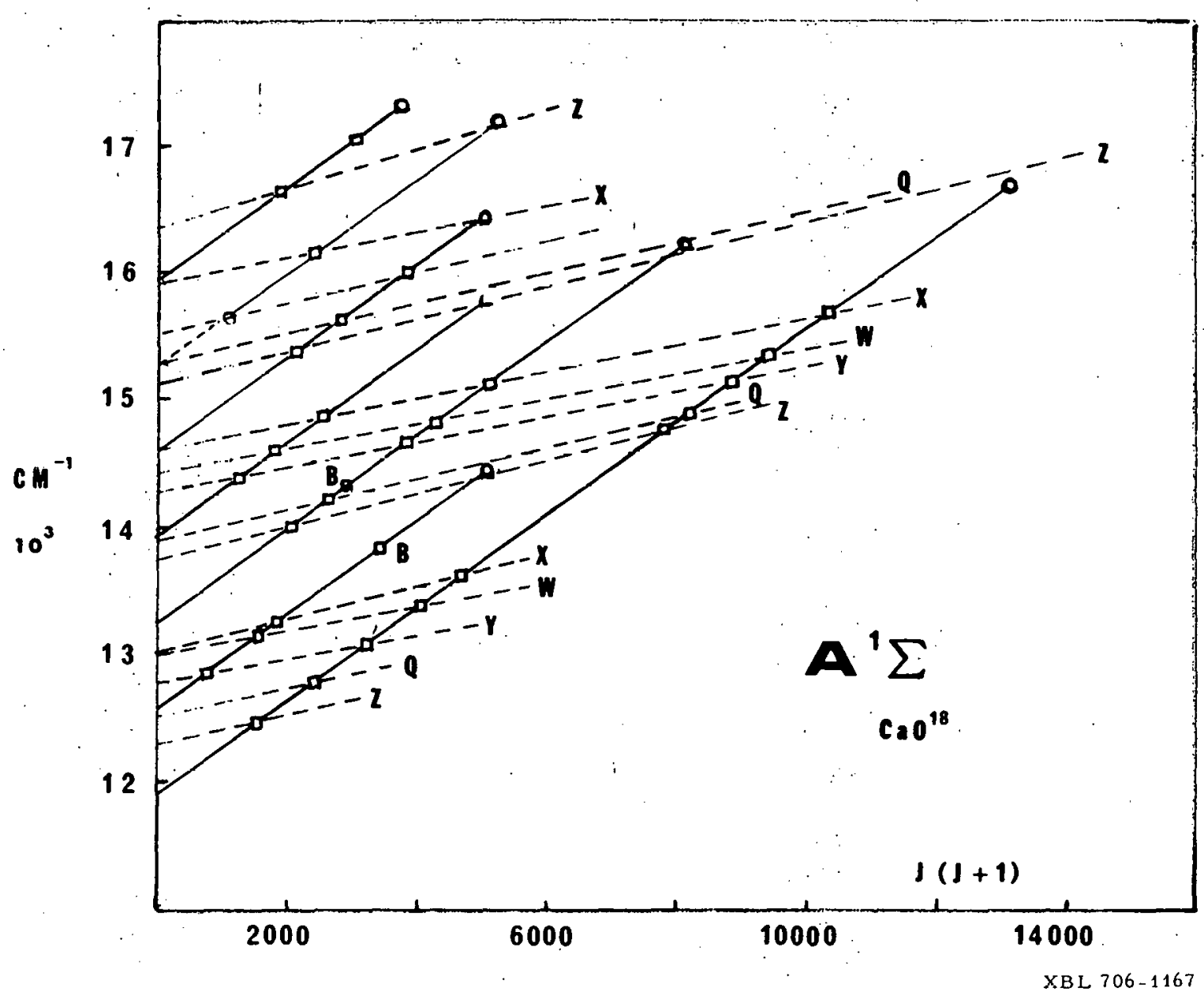

Fig. 16. Plot of energy vs $J(J+1)$. The solid lines show the vibrational levels of the $A^{\prime} \sum$ state of $\mathrm{CaO}^{18}$, the squares indicate perturbations, and the dashed lines connect perturbations arising from the same perturbing state. The circles indicate the end of the analysis. The zero of energy is the bottom of the $X^{\prime} \Sigma$ potential curve. 


$$
-42-
$$

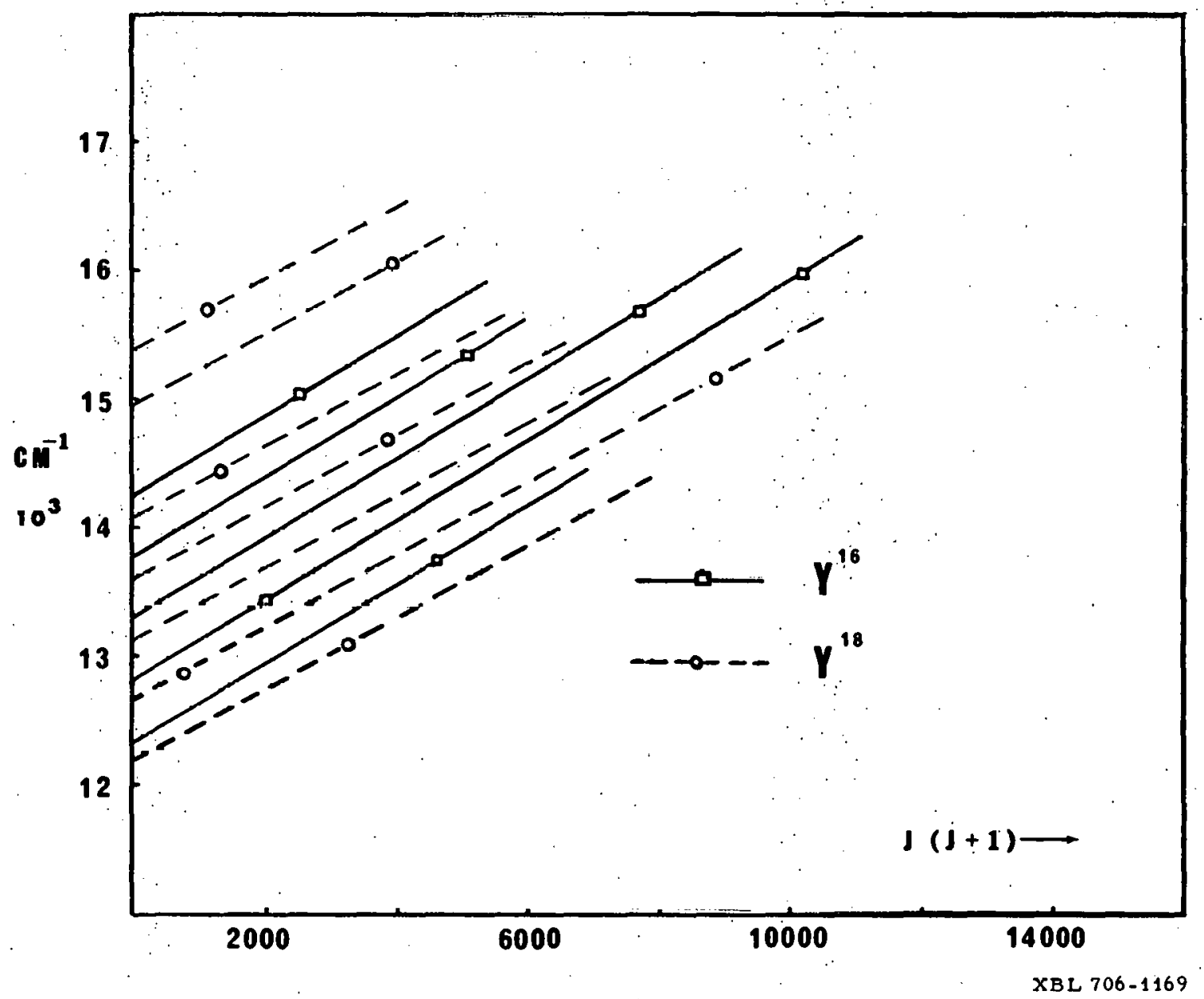

Fig. 17. Plot of energy vs $J(J+1)$ showing the vibrational levels of the $\mathrm{Y}^{16}$ and $\mathrm{Y}^{18}$ perturbing states. 


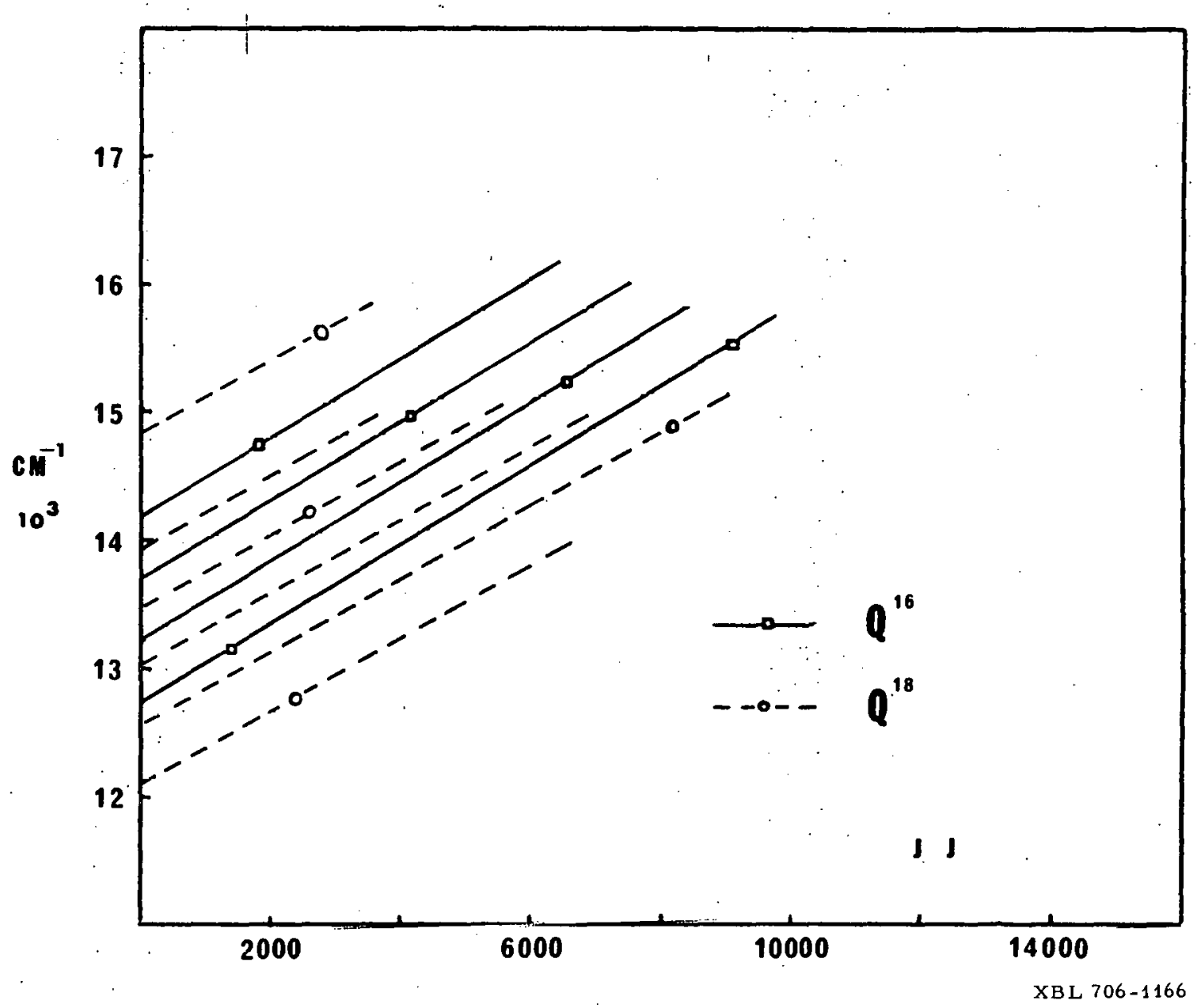

Fig. 18. Plot of energy vs $J(J+1)$ showing the vibrational levels of the $Q^{16}$ and $Q^{18}$ perturbing states. 


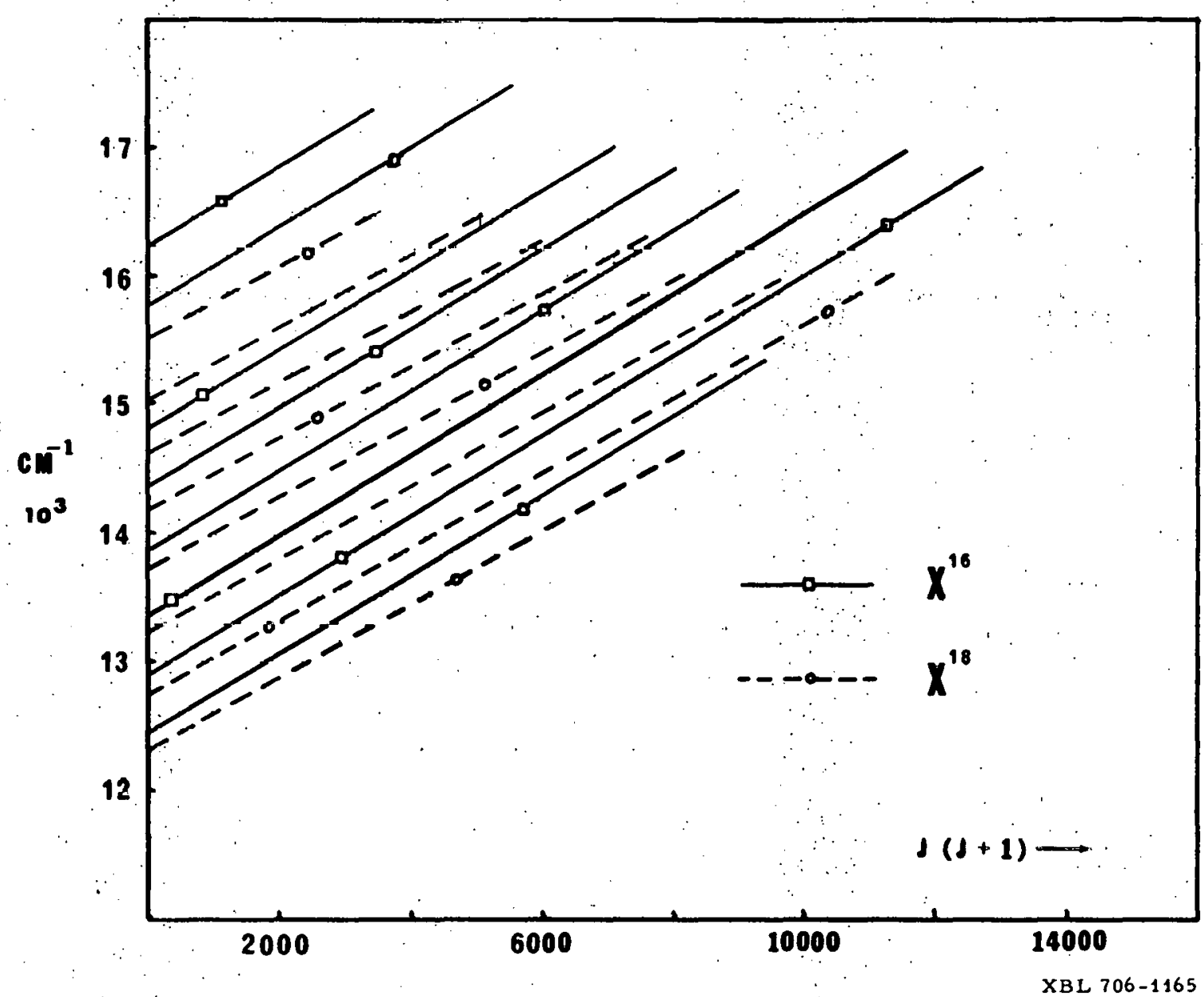

Fig. 19. Plot of energy vs $J(J+1)$ showing the vibrational levels of the $X^{16}$ and $x^{18}$ perturbing states. 


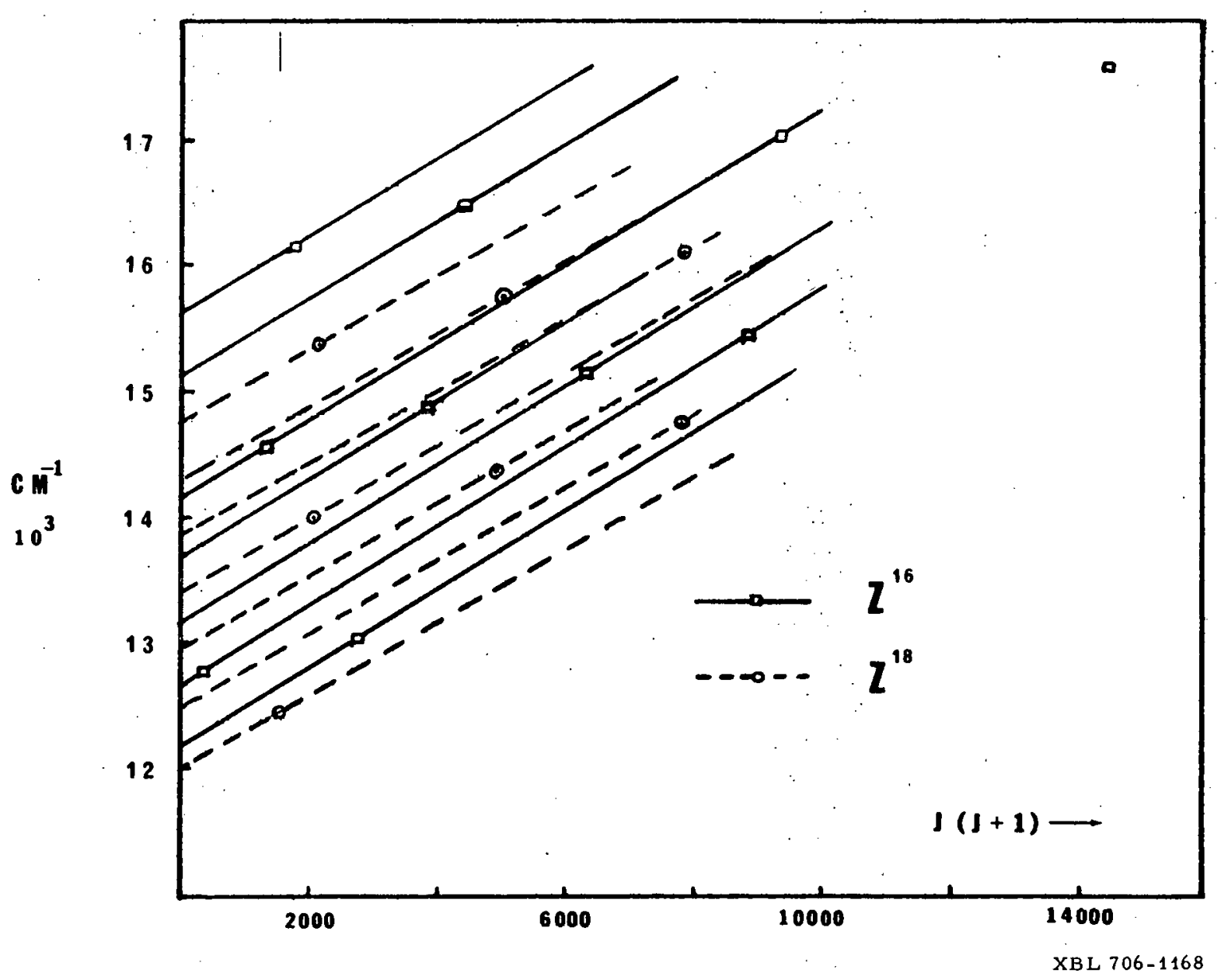

Fig. 20. Plot of energy vs $\mathrm{J}(\mathrm{J}+\mathrm{I})$ showing the vibrational levels of the $\mathrm{z}^{16}$ and $\mathrm{z}^{18}$ perturbing states. 
IV. CORREIATION OF THE PERTURBING STATES OF $\mathrm{CaO}^{16}$ AND $\mathrm{CaO}^{18}$ Hultin and Lagerqvist found six perturbing states in $\mathrm{CaO}^{16}$, four called $X, Y, Q$ and $Z$, having $B_{v} \sim 0.33$ and $\omega_{e} \sim 500$ and two, called $A$ and $B$ with $B_{V} \sim 0.38$ and $\omega_{\mathrm{e}} \sim 600$. In $\mathrm{CaO}^{18}$ six perturbing states have also been found. However five of them have $\mathrm{B}_{\mathrm{v}}$ values of 0.30 (comparable to 0.33 in $\mathrm{CaO}^{16}$ ) and only one has ${ }^{\mathrm{B}_{\mathrm{v}}}$ value of .35 (comparable. to 0.38 in $\left.\mathrm{CaO}^{16}\right)$. The $\mathrm{A}^{16}$ state is indicated by only one overlapped perturbation near a region where a $Q$ perturbation is expected but not observed. It is possible then that the $B_{V}$ value estimated for $A$ is incorrect and that the set of $\mathrm{z}^{16}$ perturbations are really due to two perturbing states with $B_{y} \sim 0.33$. It is even possible that the $A^{16}$ perturbation is really due to the missing (Q-I) level since other states predicted in this region could shift it without interacting with $A^{l} \Sigma$

(i.e. nine points of perturbation are possible between $3_{i n}$ and ${ }^{3} \Sigma$ components in case $(a), I_{\Delta}$ is probably present but invisible to a ${ }^{l_{\mathrm{V}}}$ state, etc. See Kovacs (1969) for a listing of possible interactions.) In this case the $X^{16}$ or $Y^{16}$ state may be due to two sets of perturbing. levels.

First the two B-states, $\mathrm{B}^{16}$ and $\mathrm{B}^{18}$, are correlated on the basis of their $\mathrm{B}_{\mathrm{v}^{\prime}}$-value 3. Using the $\mathrm{x}^{1} \Sigma$ constanto given in Hultin and Lagerqvist (1950), the first thirty levels of that state were calculated for $\mathrm{CaO}^{16}$ and $\mathrm{CaO}^{18}$ and compared to the $\mathrm{B}$ state. The results were encouraging and so the constants found in Brewer and Hauge (1968) (which are based on higher experimental values and therefore should be better in the region of interest) were also tried. The comparison is shown in Table 7. There is good agreement between the experimental and 
and calculated values of $B_{v}$ found at the same energy. Since $B$ is the only perturbing state with $\mathrm{B}_{\mathrm{V}}$ and $\Delta \mathrm{G}$ values in this range, it is probably the $X^{1} \sum$ state. : Since the four vibrational levels found correlate to $V=18,19$ in $\mathrm{CaO}^{16}$ and $\mathrm{V}=20,21$ in $\mathrm{CaO}^{18}$, the isotopic shift cannot be directly dalculated. Extrapolated values for $v^{18}=18,19$ and $v^{16}=21$ give isotopic shifts quite close to the calculated ones and a vibrational numbering which is only off by one quantum number. The $\mathrm{V}^{18}=20$ level appears to be perturbed.

The $\mathrm{X}^{18}, \mathrm{Y}^{18}, \mathrm{Z}^{18}, \mathrm{Q}^{18}, \mathrm{~W}^{18}$, and $\mathrm{X}^{16}, \mathrm{Y}^{16}, \mathrm{Z}^{16}, \mathrm{Q}^{16}$ states will now be considered. The energy levels of $\mathrm{CaO}^{18}$ will be lower in energy than the corresponding levels in $\mathrm{CaO}^{16}$. See Fig. 17 for example. If one compares the $Y^{16}$ and $Y^{18}$ electronic states, it is possible for $\left(Y^{16}+3\right)$ to have the same vibrational quantum number as $\left(Y^{18}\right),\left(Y^{18}+1\right)$, or $\left(Y^{18}+2\right)$. In the following discussion, only the first two sets of levels lower in energy will be considered $\left(i . e .,\left(Y^{16}+1\right) \rightarrow\left(Y^{18}\right)\right.$, $\left(Y^{16}, \varepsilon\right) \rightarrow\left(Y^{18}+1\right),\left(Y^{16}+3\right) \rightarrow\left(Y^{18}+2\right)$, etc. and $\left(Y^{16}+1\right) \rightarrow\left(Y^{18}+1\right)$, $\left(Y^{16}+2\right) \rightarrow\left(Y^{18}+2\right),\left(Y^{16}+3\right) \rightarrow\left(Y^{18}+3\right)$, etc $)$. The sets at lower energies (i.e. $\left(Y^{16}+2\right) \rightarrow\left(Y^{18}\right) \cdots$ or $\left(Y^{16}+3\right) \rightarrow\left(Y^{18}\right) \cdots$ etr. $)$ can also form possible combinations, however (since the isotopic shifts would be larger in this case) they would put the origins of the perturbing states at least $8000 \mathrm{~cm}^{-1}$ below $X^{1} \sum$ state. It is more important to check if these states are above or near $x^{l} \Sigma$ in order to determine the ground state of $\mathrm{CaO}$. Also the larger the shifts, the harder it is to extrapolate to a meuringful v-value. It is important although to remember that lower origins are possible. Since we have five $\mathrm{CaO}^{18}$ states, four $\mathrm{CaO}^{16}$ states, and two 
possibilities for each combination, there are forty. ways to correlate the nine states. The comparison of $\mathrm{Y}^{16}$ with the next lowest set of $\mathrm{Y}^{18}$ levels will be called $\left(\mathrm{Y}^{16} \mathrm{Y}^{18}\right)$; the comparison with the second lowest set $\left(Y^{16} Y^{18} d\right)$. The shifts calculated for all forty combinations are listed in Table A-l.

Equation (I) shows the relationship between $v, \omega_{e} x_{e}, \omega_{e}$ and the energy shifts. If the shifts are plotted vs $v$, the curve should intersect the $x$-axis at $v=-\frac{1}{2}$. At low $v$ the slope is $\sim\left(\omega_{e} /(1-\rho)\right)$ : at higher $v$, the slope decreases in response to the $\omega_{e} x_{e}$ terms. The vibrational quantum numbers for any of the forty combinations mentioned can be obtained by plotting the shifts vs a relative $\mathrm{v}$ and extrapolating to zero. Figure 24 shows sample plote of the shift ve $v$ for various values of $\omega_{P_{P}} x_{P}$ and $\omega_{P}$. Similar plots were used as aids in extrapolating the experimental values. The plots for all the $\mathrm{Y}^{18}$ combinations are shown in Fig. 21.

of the 40 combinations plotted, 28 were rejected. Table A- 2 shows the comparisons. One of three reasons is given for rejecting a correlation.

(1) $v_{p}$ too high. Same discussion as above applies here. These combinations are possible, but correlations giving states above $x^{l} \Sigma$ should be considered first.

(2) Scattered. Trends in energy away from the calculated shape of the curve (Fig. 24) were used as criteria, rather than one or two points being out of line. For example, an increase in slope at higher v-values (concave). would not be acceptable.

(3) $\omega_{e} x_{e}(a-b) . \omega_{e}$ and $\omega_{e} x_{e}$ values can be obtained from the shift vs $v$-plot and also from the energy separations of the vibrational 
levels and the v-quantum numbers. If the values from these two methods do not agree, that correlation is rejected.

An example can best clarify this method. Consider the $\left(Q^{16} Y^{18}\right)$ correlation. Various combinations of $\omega_{e}$ and $\omega_{e} x_{e}$ can fit the points. The lowest possible $\omega_{e}\left(\omega_{e} x_{e}=0\right)$ value from the shift vs $v$ plot can be obtained from the slope divided by (1-P). (A higher $\omega_{e}$ is possible since $\omega_{\epsilon} x_{\epsilon}$ can decrease the slope, however a lower one is not for the same reason. $\omega_{\mathrm{e}} \mathrm{x}_{\mathrm{e}}$ would only decrease the slope further.) In this casc $\omega_{e}=675$. The highest $\omega e_{e} e$ which could be used is under ten. The quantum number for the $Q^{16}$ level is $v=2$. The difference between the $v=2$ and $v=3$ levels of $Q^{16}$ is calculated from these constants as follows :

$$
\begin{aligned}
G(3.2) & =\omega_{e}(3.5)-\omega_{e} x_{e}(3.5)^{2}-\omega_{2}(2.5)+\omega_{\epsilon} x_{e}(2.5)^{2} \\
& =\omega_{\epsilon}-6 \omega_{e} x_{e}=675-6(10)=615
\end{aligned}
$$

The difference between the $\left(Q^{16}\right)$ and $\left(Q^{16}+1\right)$ levels is 500 so this correlation is wrong. $\omega_{\mathrm{e}} \mathrm{x}$ would have to be 29 instead of 10 in order for $\omega_{e}$ to equal 675. A higher $\omega_{e}$ value would make $G(3-2)$ still larger without substantially increasing the needed $\omega_{e} x_{e}$ value. The comment for this correlation in Table A-2 is $\omega_{e} x_{\epsilon}(10-29) \cdot$ where 10 and 29 are the $\omega_{\mathrm{e}} \mathrm{x}$ values needed for the two methods.

Table $8(a)$ shows the 12 possible correlations left. If it is assumed that all the $\mathrm{CaO}^{18}$ states are used just, once; then the. $\left(x^{16} x^{18} d\right)$ correlation is correct. The $Q^{16}$ state has a small matrix element in comparison to the $\mathrm{x}^{16}, \mathrm{Y}^{16}$, and $\mathrm{z}^{16}$ states. It is unlikely to be correlated to more than une (ias) ${ }^{78}$ state. $Y^{18}$ can ve combined with either $Y^{16}$ or $Q^{16}$. The $Y^{18}$ perturbations are much stronger than 
those of $Q^{16}$ so the $\left(Y^{18} Y^{16}\right)$ correlation appears to be the currcet one. The $\mathrm{Q}^{16}$ and $\mathrm{z}^{16}$ states both go to $\mathrm{Q}^{18}$ and $\mathrm{Z}^{18}$. This is reasonable since the $Q$ and $Z$ perturbations are very close to each other in both isotopes. The $\mathrm{Z}$ perturbations are much stronger in both cases, which indicates combinations of $\left(Q^{16} Q^{18} d\right)$ and $\left(z^{16} z^{18} d\right)$. At this point all the $\mathrm{CaO}^{16}$ states and all the $\mathrm{CaO}^{18}$ states except. $\mathrm{W}^{18}$ have been used. The three possiblc combinations using $w^{18}$ are shown in Table $8(\mathrm{~b})$ by dashed lines, Either $\left(x^{3.6} W^{18} d\right)$ or $\left(y^{16} W^{18} d\right)$ would put $W^{18}$ below $X^{1} \Sigma$ along with $Q^{18}, Z^{18}$ and $X^{18}$. The $\left(Y^{16} W\right)$ correlation would put $W^{18}$ at $\sim 11080 \mathrm{~cm}^{-1}$. The two possibilities for $W^{18}$ are shown as dashed Iines in Fig. 22. Among the states predicted to be in this region: ${ }^{3} \pi, 3^{3}$, $I_{\Pi}, I_{\Delta}$, the following states or substates can perturb a ${ }^{I_{\Sigma}}{ }^{+}:{ }^{3} \Pi_{1},{ }^{3} \Pi_{0}$, ${ }^{1} \Pi,{ }^{3} \Sigma_{J+1}^{-},{ }^{3} \Sigma_{J-I}^{-}$. Assuming Hund's case (a) the five states should be grouped as two, two, one, since four of them are predicted to be substates of triplet electronic states. If $\mathrm{W}$ and $\mathrm{Y}$ are components of a triplet, the splitting would be on the order of $3000 \mathrm{~cm}^{-1}$. This seems too large. (The doublet splitting in AsO, a much heavier molecule, is. $1025 \mathrm{~cm}^{-1}$. The splitting here would not be expected to be larger.) If $\left(Y^{16} W^{8}\right)$ is not. true, then $W$ would be found at approximately $-2500 \mathrm{~cm}^{-1}$ relative to $x^{\perp} \Sigma$. A summary of the perturbing states and their constants is 'tound in l'able $y$ for the best currelaliuns.

If any of the above assumptions are wrong, other sets of correlations become possiblc. The assumptions are:

(1). There is a one to one correlation between the states perturbing $\mathrm{A}^{1} \Sigma$ in $\mathrm{CaO}^{16}$ and $\mathrm{CaO}^{18}$.

(2) The perturbing states are $x^{1} \Sigma, I_{\Pi}, 3_{\Pi}, 3_{\Pi}, 3_{\Sigma} \Sigma_{J+1}$, 
and ${ }^{3} \Sigma_{\mathrm{J}-1}^{-}$. These states are predicted to be low-lying by analogy to the isoelectronic $C_{2}$ states (Brewer, 1962), and are able to perturb a ${ }^{1} \Sigma^{+}$(Kovacs, 1969). A recent paper (Carlson, et al., 1970) suggests a low-lying ${ }^{3} \Sigma^{+}$state. The predicted ${ }^{1} \Delta$ also would not perturb a ${ }^{1} \Sigma$. Perturbations between $a^{3} \Sigma^{+}$and $a^{1} \Sigma^{+}$state are predicted to be very weak (Kovacs, 1969) and so it would be difficult to find an indication of ${ }^{3} \Sigma^{+}$in this study. Also six perturbing states and substates are predicted considering just ${ }^{3} \pi,{ }^{3} \Sigma,{ }^{1} \pi$, and $x^{1} \Sigma$ perturbing states and six are found. If the ${ }^{3} \Sigma^{+}$state is included, one of the above states must be discredited, which would make it difficult to account for all of the sets of perturbations found. Two sets of perturbations are expected from both the ${ }^{3} \Pi$ and the ${ }^{3} \Sigma$ states, the $x^{1} \Sigma$ state is well assigned to the B-perturbing state, and the ${ }^{1} \Pi$ state has low-lying counterparts in $\mathrm{C}_{2}, \mathrm{BeO}$, and $\mathrm{MgO}$ as well as coming from the same molecular orbital configuration as the $3 \pi$ state. So it would be hard to re-assign just one of the perturbing sets of perturbations to a ${ }^{3} \Sigma^{+}$. The two weak sets, $B$ and $Q$, are easily correlated with $X^{I} \Sigma$ and $3_{I_{1}}$ : The perturbation at $v^{\prime}=1, J=57.9$, which is assigned to the $B^{18}$ state, is out of line however from the other $B$ perturbations and might be due to a low ${ }^{3} \Sigma^{+}$ state.

(3) The origin of the perturbing states is not below $8000 \mathrm{~cm}^{-1}$. It is possible that this assumption ie false and that lower origins exist. However since there are too many correlations giving lower values to be able to pick out a consistent set and because of the difficulty in extrapolating larger shifts, it is not possible to come to drly detinite conclusions. 
(4) The $\omega_{e} x_{e}$ and the scattering criteria are assumed to be correct. There are at least three perturbing states below $X^{1} \Sigma$ if they are true.

(5) The splitting between ${ }^{3} \Pi_{0}$ and ${ }^{3} \Pi_{1}$ is less than $1000 \mathrm{~cm}^{-1}$. This is based on a comparison of splittings found in other molecules (i.e. AsO, PO).

(6) The size of a perturbation will not change drastically with a change of isotope, i.e. $Q^{16} \rightarrow Q^{18}$.

All the assumptions appear to be reasonable. Also a supporting piece of evidence for the assignment in Table 9 is found in a lowtemperature matrix isolation study of CaO (Wang, 1969). Bands were found starting at $20,367 \mathrm{~cm}^{-1}$ and identified as $\mathrm{CaO}$ by their isotope shift $\left(\mathrm{CaO}^{18}-\mathrm{CaO}^{16}\right)$. The transition does not correspond to any known singlet transition and therefore indicates the possibility of a lowlying triplet state. It has been included in F'ig. 23.

Also the splittings between states coming from the same molecular orbital configuration can be compared. For the ten-electron molecules $\left(N_{2}, A l C l\right.$, etc.) the splittings between the ${ }^{3} \Pi$ and ${ }^{1} \Pi$ states from the XowI ${ }^{4} \mathrm{VI}$ configuration are between $6000-16000 \mathrm{~cm}^{-1}$ for a wide range of molecular weights (Brewer, 1962). For the eight electron molecules the splitting between the ${ }^{1} \Pi$ and ${ }^{3} \Pi$ states of the $y \sigma^{2} x \sigma \omega \pi^{3}$ configuration is $12000 \mathrm{~cm}^{-1}$ for $\mathrm{CsO}$ and $7600 \mathrm{~cm}^{-1}$ for $\mathrm{C}_{2}$. This fite in quite well with our expectations from the ten-electron molecule case: 
Table 7. Comparison of the $E$ state and $X^{I} \sum$

\begin{tabular}{|c|c|c|c|c|c|c|c|c|}
\hline & B Stat & & & & $x^{1} \Sigma$ & lated & & \\
\hline . & $v$ & $\begin{array}{c}G(\nu) \\
\mathrm{cm}^{-1}\end{array}$ & $\Delta \mathrm{G}$ & BV & $v$ & $\begin{array}{c}\mathrm{G}(\nu) \\
\mathrm{cm}^{-1}\end{array}$ & $\Delta \mathrm{G}$ & BV \\
\hline $\mathrm{CaO}^{16}$ & $\begin{array}{c}B \\
B+1\end{array}$ & $\begin{array}{l}12113 \\
12694\end{array}$ & 581 & . 381 & $\begin{array}{l}18 \\
19\end{array}$ & $\begin{array}{l}12039 \\
12619\end{array}$ & 580 & .382 \\
\hline $\mathrm{CaO}^{18}$ & $\begin{array}{c}B \\
B+1\end{array}$ & $\begin{array}{l}12650 \\
13322\end{array}$ & 672 & $\begin{array}{l}\sim .35 \\
\sim .35\end{array}$ & $\begin{array}{l}20 \\
21\end{array}$ & $\begin{array}{l}12716 \\
13268\end{array}$ & 575 & $\begin{array}{l}.348 \\
.346\end{array}$ \\
\hline
\end{tabular}


Table 8. Correlations Between the 2erturbing States of $\mathrm{CaO}^{18}$ and $\mathrm{CaO}^{16}$

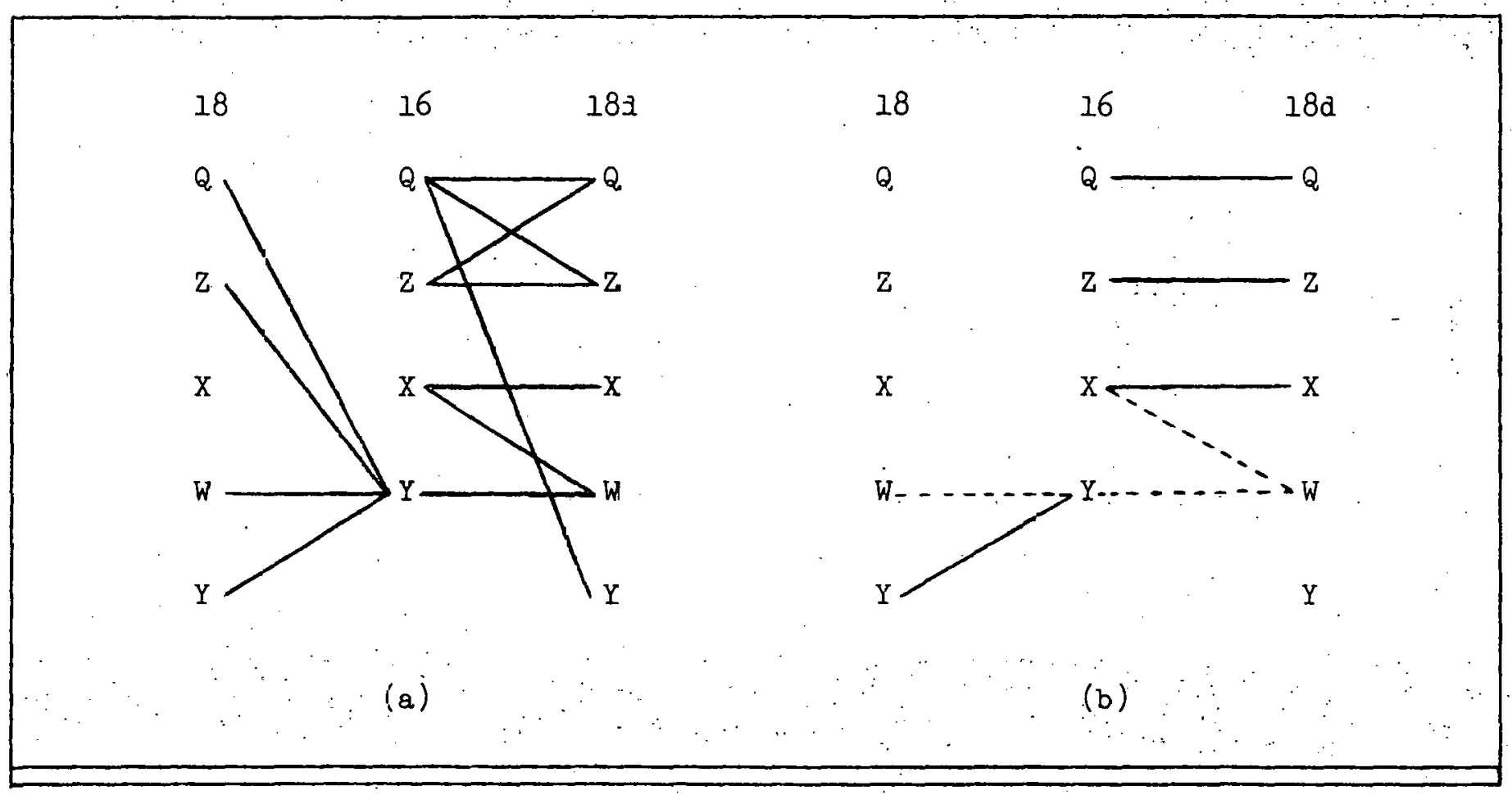


Table 9. Summary of Constants

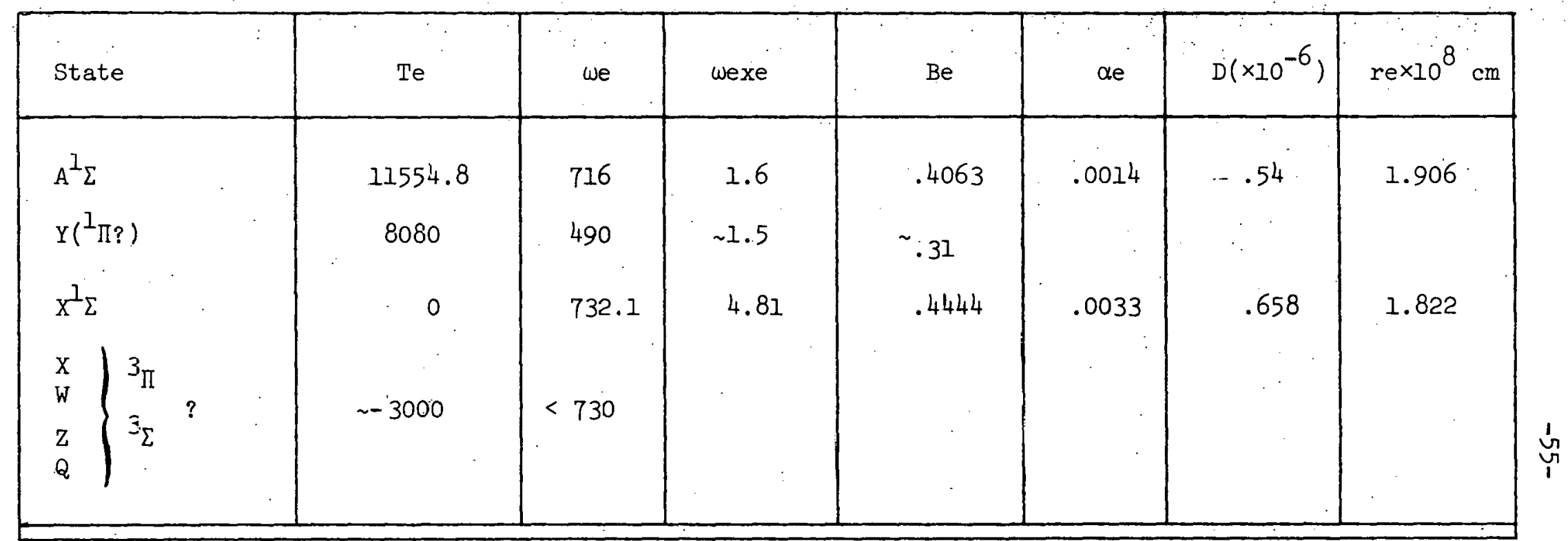


Table 10. Predicted and Observed Transitions in Ca., $3500-12,000 \AA$

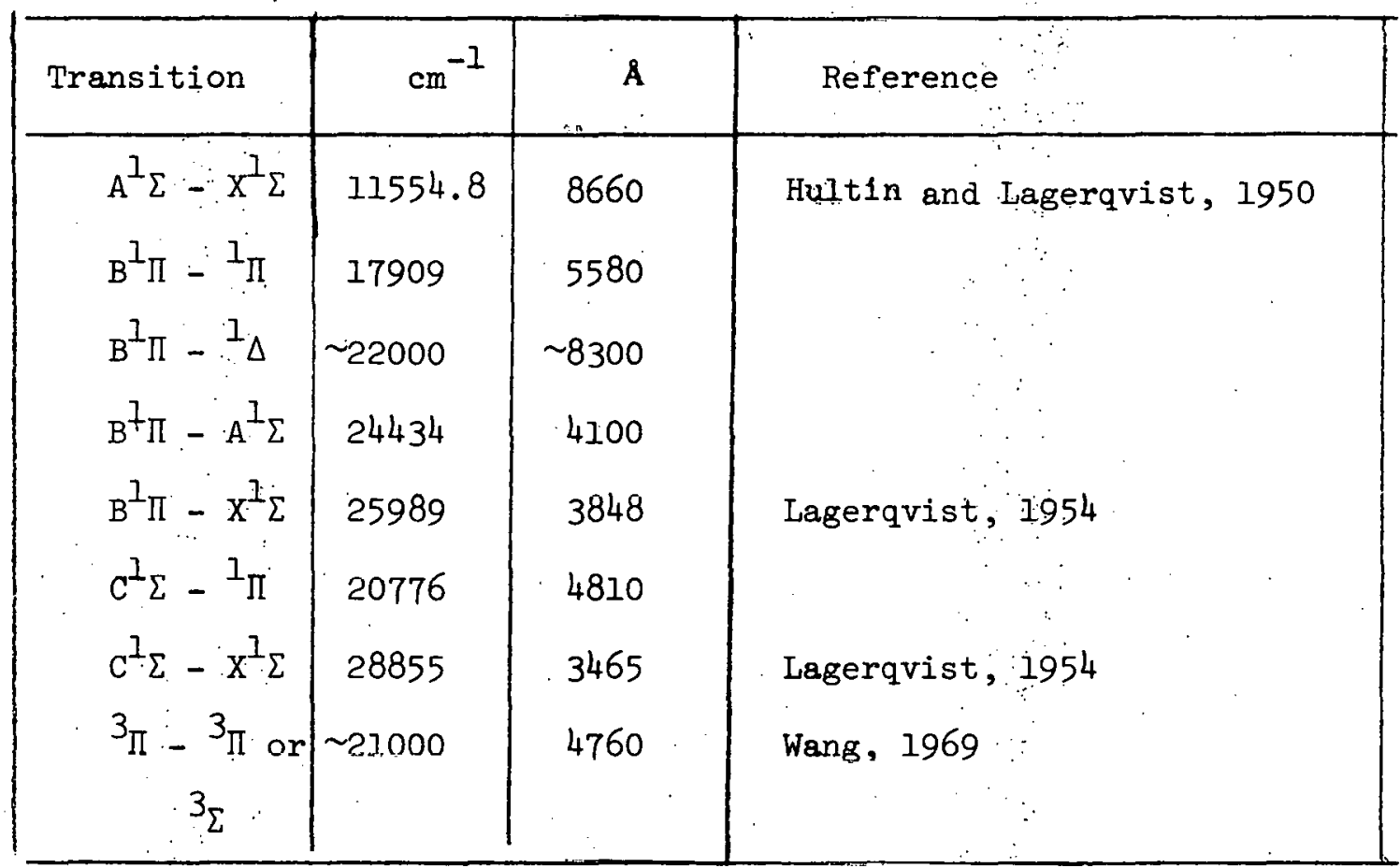




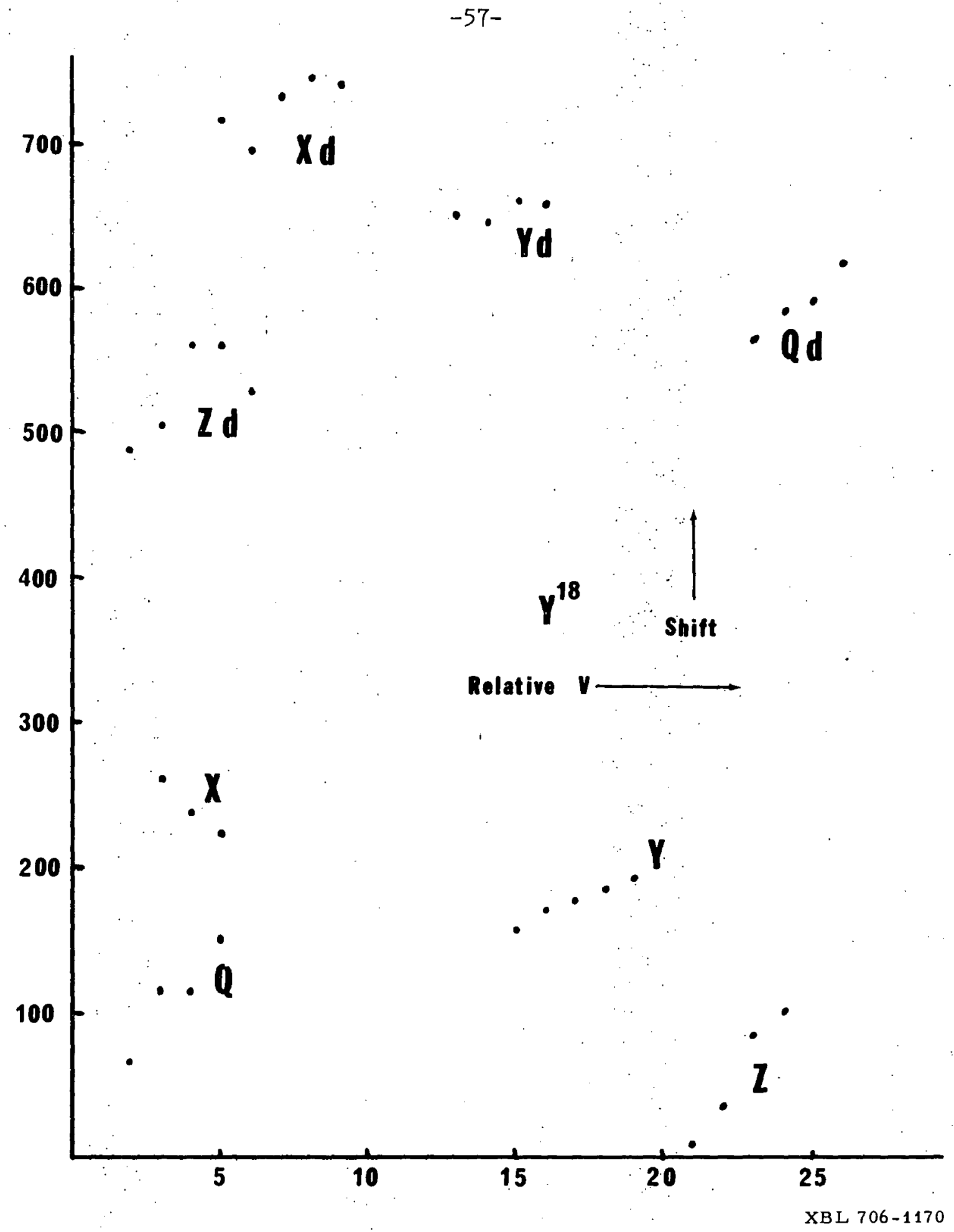

Fig. 21. Plot of the shift vs a relative vibrational numbering for all the correlations involving $\mathrm{Y}^{18}$. 
$-58-$

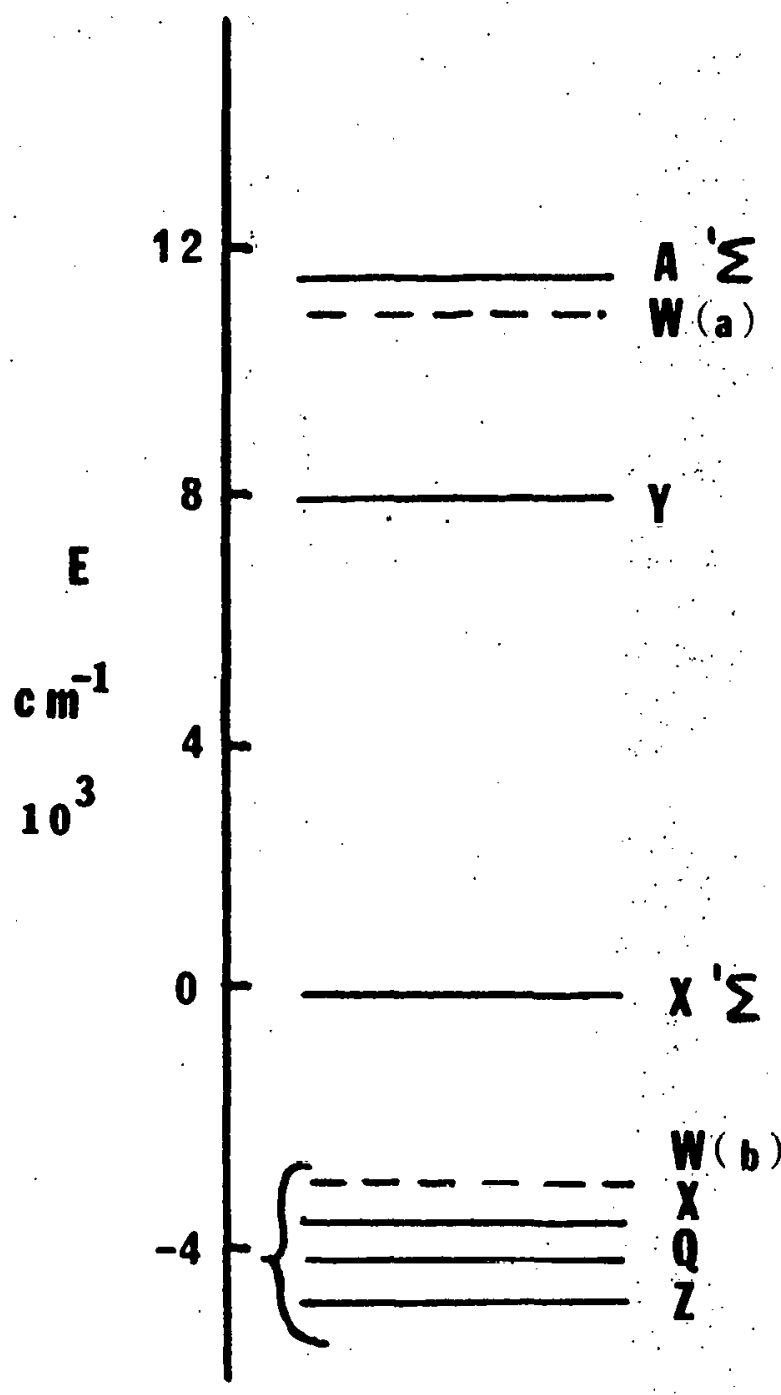

XBL $70.7-1377$

Fig. 22. Relative energy scale for the perturbed and perturbing states. 
ENERGY LEVELS OF CaO

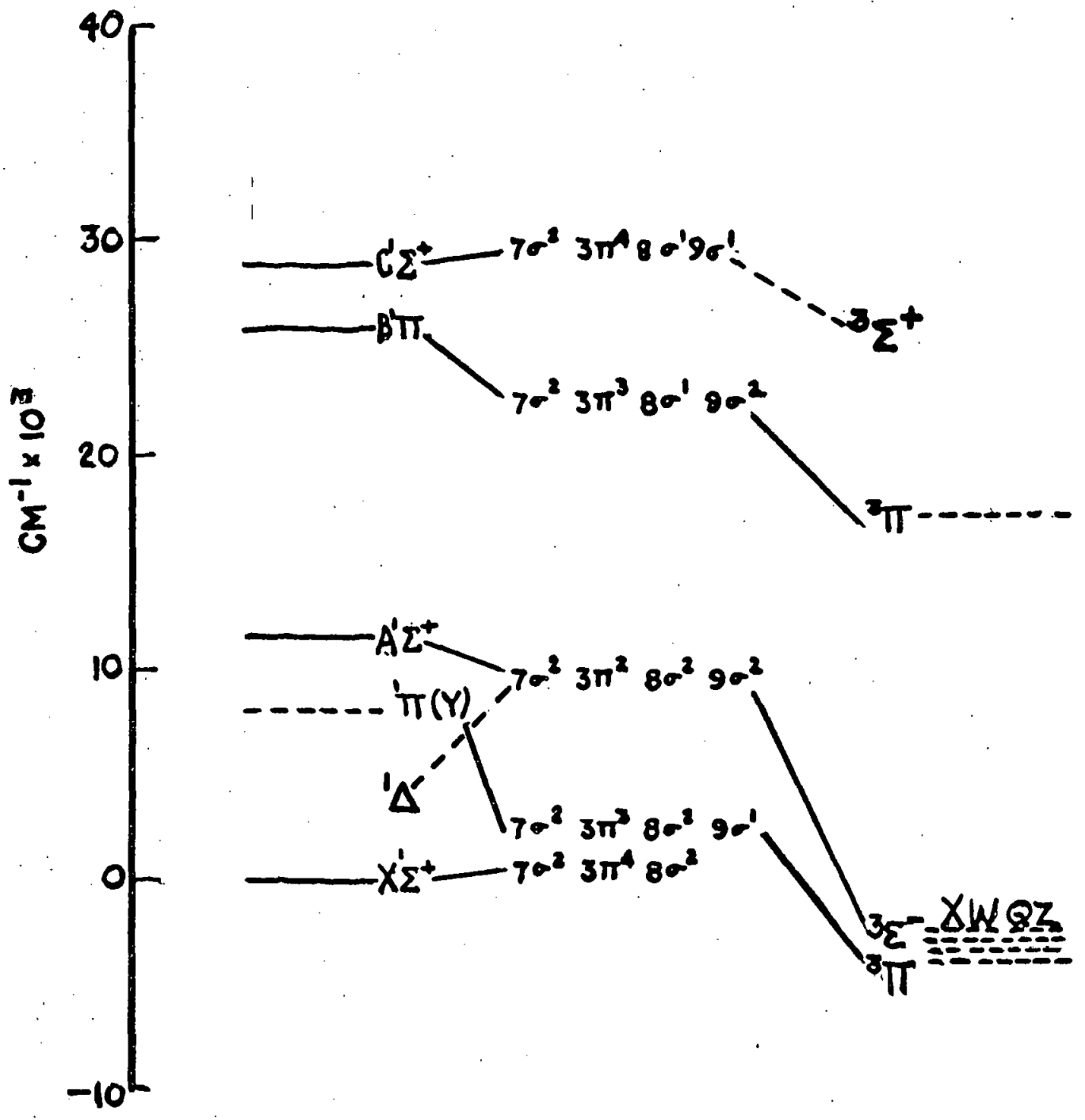

XBL 707-1374

Fig. 23. Low-lying energy levels of CaO. 
$-60-$

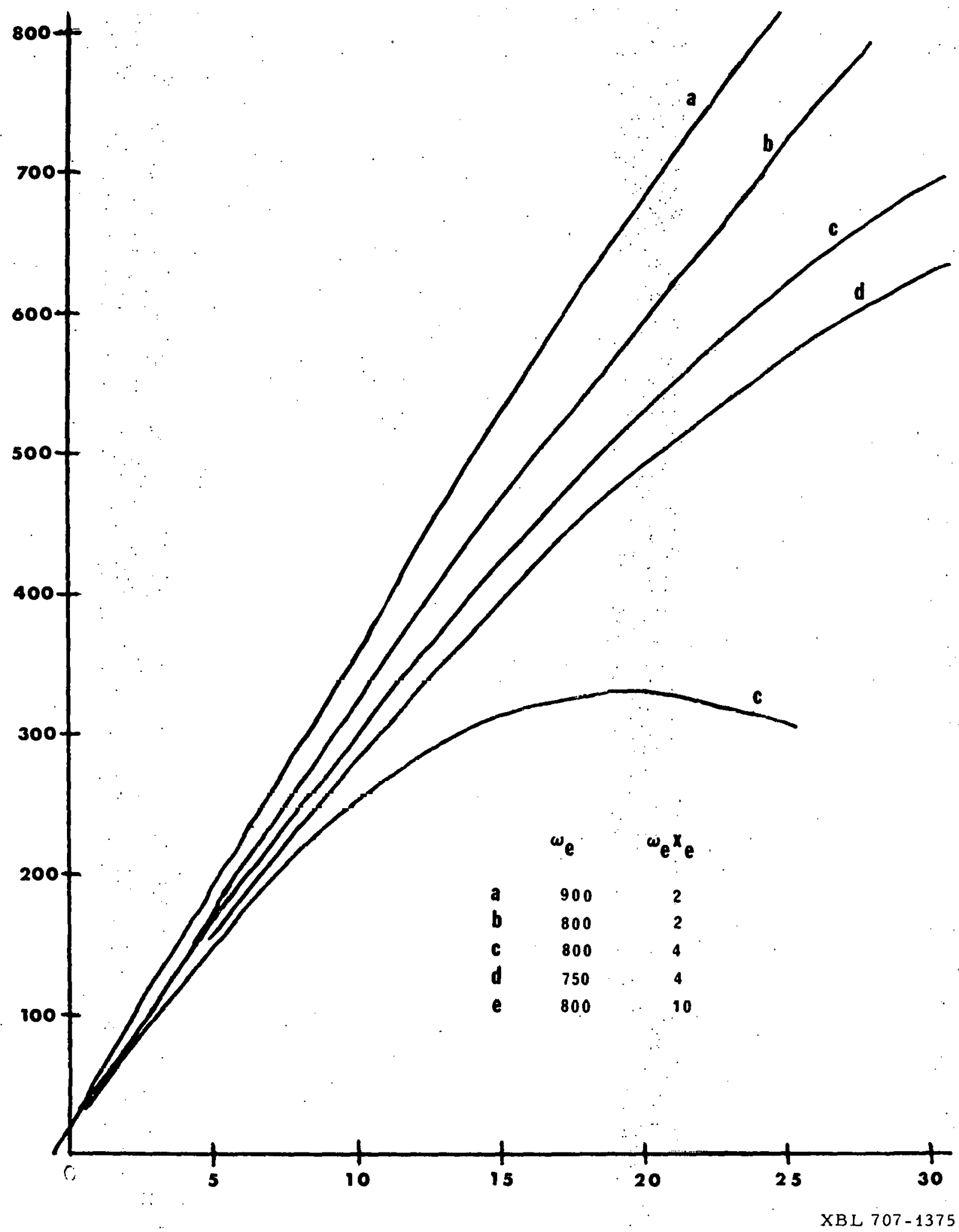

Fig. 24. Calculated plots of the vibrational isotopic shift vs the vibrational quantum number $v$ for several combinations of $\omega_{e}$ and $\omega_{e} x_{e}$. 


\section{CONCLUSION}

The above comparison of $\mathrm{CaO}^{16}$ and $\mathrm{CaO}^{18}$ perturbations gives a good qualitative description of some of the low-lying electronic states of $\mathrm{CaO}$ and shows that the $\mathrm{X}^{\mathcal{I}} \Sigma$ is not the ground state. It is hard to determine exact origins for $X, Q, Z$, and $W$ because of the long extrapolations involved. The value given for all four is $-3000 \mathrm{~cm}^{-1} \pm 2000 \mathrm{~cm}^{-1}$. The $Y$ state has a much shorter extrapolation and is found to be at 8080 I $500 \mathrm{~cm}^{-1}$. Since the lowest ${ }^{1} \Sigma^{+}$state in $\mathrm{C}_{2}, \mathrm{BeO}$, and MgO has the largest $\omega_{e}$ value, the $\omega_{e}$ value for the $X, Q, Z, Y$, and $W$ states is expected to be below 730 .

The $B$ state has been assigned to $X^{1} \Sigma$. However it is difficult to assign $W, X, Q, Z$ and $Y$ to specific states. $Y$ should be $a^{l} \Pi$ since $i t$ stands by itself and the other possible singlet, ${ }^{1} \Delta$, cannot perturb a ${ }^{1} \Sigma$. Hultin and Lagerqvist (1950) indicate that $x$ may, be the ${ }^{3} \Pi_{0}$ substate since its matrix element is independent of $\mathrm{J}$. The $Q$ perturbations are small and could be due to a ${ }^{3} \Pi_{1}-{ }^{I_{\Sigma}}{ }^{+}$interaction which has a small matrix element. That leaves $W$ and $z$ to be assigned to ${ }^{3} \Sigma_{\mathrm{J}+1}$, and ${ }^{3} \Sigma_{\mathrm{J}-1}$.

It would be useful to determine the spectroscopic constants and origins of these states more accurately since the low-lying states of a molecule are needed for thermochemical calculations. Further experiments might include searching for calculated transitions (Table 10). For example, the $B^{I} \Pi-Y$ transition is predicted to be at $\sim 5580 \AA$, quite close to a strong, unanalyzed system at $5555 \AA$. Another possibility, the molecular beam electric resonance technique used to measure the rotational ronstante of the guund state of' BaO (Wharton and Klemperer, 1963), is probably not practical for CaO because of the difficulty of 


$$
-62-
$$

obtaining a CaO beam. Matrix fluorescence experiments could give the vibrational constants of the lower state of the transition found by Wang (1969): Electron spin resonance might also be done in a matrix to determine which is the lowest state, ${ }^{3} \Pi$ or ${ }^{3} \sum$ (Kasai, 1968). Also the perturbations of another isotopic molecule, such as $\mathrm{Ca}^{44} \mathrm{O}^{16}$, could be analyzed to confirm the correlations made in this paper. 
$-63-$

APPENDIX A

COMPARISON OF $\mathrm{CaO}^{16}$ AND $\mathrm{CaO}^{18}$ 
Table A-1. Shifts Between the Perturb-rg Vibrational Levels of $\mathrm{CaO}^{18}$ and $\mathrm{CaO}^{16}$

\begin{tabular}{|c|c|c|c|c|c|c|c|c|c|c|}
\hline $\mathrm{z}^{16}$ & $\begin{array}{l}-5 \\
10 \\
35 \\
85 \\
90\end{array}$ & $\begin{array}{l}490 \\
505 \\
560 \\
560 \\
530 .\end{array}$ & $\begin{array}{l}360 \\
425 \\
470 \\
450 \\
430 \\
520 \\
625\end{array}$ & $\begin{array}{l}855 \\
950 \\
945 \\
885 \\
965\end{array}$ & $\begin{array}{r}65 \\
95 \\
120 \\
195 \\
215\end{array}$ & $\begin{array}{l}560 \\
590 \\
645 \\
670 \\
650\end{array}$ & $\begin{array}{l}390 \\
435 \\
490 \\
510 \\
485 \\
605 \\
690\end{array}$ & $\begin{array}{r}885 \\
960 \\
965 \\
940 \\
1020 \\
1115\end{array}$ & $\begin{array}{l}155 \\
180 \\
210 \\
275 \\
275 \\
290 \\
370 \\
435 \\
\end{array}$ & $\begin{array}{l}650 \\
675 \\
735 \\
750 \\
710 \\
825 \\
880\end{array}$ \\
\hline$Q^{16}$ & $\begin{array}{r}85 \\
115 \\
115 \\
150\end{array}$ & $\begin{array}{l}565 \\
585 \\
590 \\
615\end{array}$ & $\begin{array}{r}5 \\
25 \\
5 \\
50\end{array}$ & $\begin{array}{l}435 \\
505 \\
500 \\
505\end{array}$ & $\begin{array}{l}170 \\
200 \\
225 \\
270\end{array}$ & $\begin{array}{l}635 \\
670 \\
675 \\
725\end{array}$ & $\begin{array}{r}15 \\
45 \\
65 \\
105\end{array}$ & $\begin{array}{l}465 \\
515 \\
520 \\
565\end{array}$ & $\begin{array}{l}255 \\
290 \\
305 \\
330\end{array}$ & $\begin{array}{l}725 \\
755 \\
765 \\
805\end{array}$ \\
\hline $\mathrm{Y}^{16}$ & $\begin{array}{l}155 \\
170 \\
175 \\
185 \\
190\end{array}$ & $\begin{array}{l}650 \\
645 \\
660 \\
655\end{array}$ & $\begin{array}{l}25 \\
90 \\
85 \\
75 \\
90\end{array}$ & $\begin{array}{l}520 \\
565 \\
570 \\
545\end{array}$ & $\begin{array}{l}225 \\
255 \\
260 \\
295 \\
310\end{array}$ & $\begin{array}{l}720 \\
730 \\
745 \\
765\end{array}$ & $\begin{array}{r}55 \\
100 \\
105 \\
135 \\
145\end{array}$ & $\begin{array}{l}550 \\
575 \\
590 \\
605\end{array}$ & $\begin{array}{l}315 \\
340 \\
350 \\
375 \\
370\end{array}$ & $\begin{array}{l}810 \\
815 \\
835 \\
845\end{array}$ \\
\hline \multirow[t]{2}{*}{$x^{16}$} & $\begin{array}{l}260 \\
235 \\
225 \\
245\end{array}$ & $\begin{array}{l}715 \\
695 \\
730 \\
745 \\
740\end{array}$ & $\begin{array}{l}130 \\
155 \\
135 \\
145 \\
180 \\
195 \\
270 \\
285\end{array}$ & $\begin{array}{l}585 \\
615 \\
642 \\
635 \\
640 \\
675 \\
755 \\
740\end{array}$ & $\begin{array}{l}330 \\
320 \\
310 \\
365 \\
400\end{array}$ & $\begin{array}{l}785 \\
780 \\
815 \\
855 \\
860\end{array}$ & $\begin{array}{l}160 \\
165 \\
155 \\
205 \\
235 \\
280 \\
340\end{array}$ & $\begin{array}{l}615 \\
625 \\
660 \\
695 \\
695 \\
778\end{array}$ & $\begin{array}{l}420 \\
405 \\
400 \\
445 \\
460 \\
500\end{array}$ & $\begin{array}{l}875 \\
865 \\
905 \\
935\end{array}$ \\
\hline & $\mathrm{Y}^{18}$ & $\mathrm{Y}^{18} \mathrm{~d}$ & $x^{18}$ & $x^{18}$ & $Q^{18}$ & $Q^{18} d$ & $\mathrm{w}^{18}$ & $w^{18} d$ & $\mathrm{z}^{18}$ & $\mathrm{z}^{18}$ \\
\hline
\end{tabular}


Table A-2. Comparison of Perturbing States: $\mathrm{CaO}^{16}, \mathrm{CaO}^{18}$

\begin{tabular}{|c|c|c|c|c|}
\hline & $x^{16}$ & $Y^{16}$ & $Q^{16}$ & $\mathrm{z}^{16}$ \\
\hline $\mathrm{Y}^{18}$ & scattered & maybe & wexe $(10-29)$ & wexe $(3-177)$ \\
\hline$y^{18} d$ & Vp too high & Vp too high & maybe & scattering \\
\hline$x^{18}$ & $\begin{array}{l}\text { scattered } \\
\text { (concave) }\end{array}$ & scattered & scattered & scattered \\
\hline$x^{78}$ & maybe & scattered & scattered: & Vp too high \\
\hline$Q^{18}$ & scattered & maybe & wexe $(29-5)$ & wexe $(1-100)$ \\
\hline$Q^{18} d$ & Vp too high & $\begin{array}{l}\text { scattered } \\
\text { (concave) }\end{array}$ & maybe & maybe \\
\hline$w^{18}$ & scattered & maybe & wexe $(10-125)$ & wexe (2-29) \\
\hline$w^{18} d$ & maybe & maybe & wexe $(1,15)$ & Vp too high \\
\hline$z^{18}$ & scattered & maybe & wexe $(6,30)$ & wexe $(2-50)$ \\
\hline$z^{18} d$ & Vp too high & Vp too high & maybe & maybe \\
\hline
\end{tabular}




\section{APPENDIX B}

This appendix contains the listings for the computer programs used to analyze the data. They were written for operation on the CDC computers at the Lawrence Radiation Laboratory at Berkeley. The program language is CDC's Chippewa Fortran which is nearly identical to Fortran IV.

\section{STAND}

Program STAND uses the measured spectral standard lines to calculate the wavelength and energy $\left(\mathrm{cm}^{-1}\right)$ for all the measured lines. Both the standard Th-lines and the CaO molecular lines were measured and recorded one to a card by a semi-automatic comparator (lent by Dr. John Phillips, University of California at Berkeley, Astronomy Department). Each card contained the relative position of the line, its relative intensity, and a code number indicating the type of line (standard, atomic, molecular, etc.) .

The data deck consists of:

(a) TOY (I) indicates whether the measured line lies between 0-100 mm, $100-200 \mathrm{~mm}$, or $200-300 \mathrm{~mm}$ on the measuring scale. The first data card reads $-J 1$ with a $3 A 1$ format.

(b) N, NLAST, and NU (format 3I5) where

$$
\begin{aligned}
& N \quad=\text { order of fit }+1 \\
& \text { NU } \quad=\text { number of slastdard lines } \\
& \text { NLAST }=\text { the find value of } N
\end{aligned}
$$

(c) ETOL (format $8 F 10.5$ ) is the tolerable error in calculating standard lines,

(d) SHIFT (format FI0.2) relates the standard lines to the unknown lines. It is usually zero. 


$$
-67-
$$

(e) Assigned standard line values $Y Y(I)$ (format Fl0.3).

(f) Deck of measured lines, with all the standard lines first in the same order as their assigned values in $(e)$.

\section{(g) Blank card.}

When. $N$ equals NLAST, one card is punched for each measured line with its wavelength, energy $\left(\mathrm{cm}^{-1}\right)$, relative intensity.

This program was written by Dävid Green and Joel Tellinghuisen. 


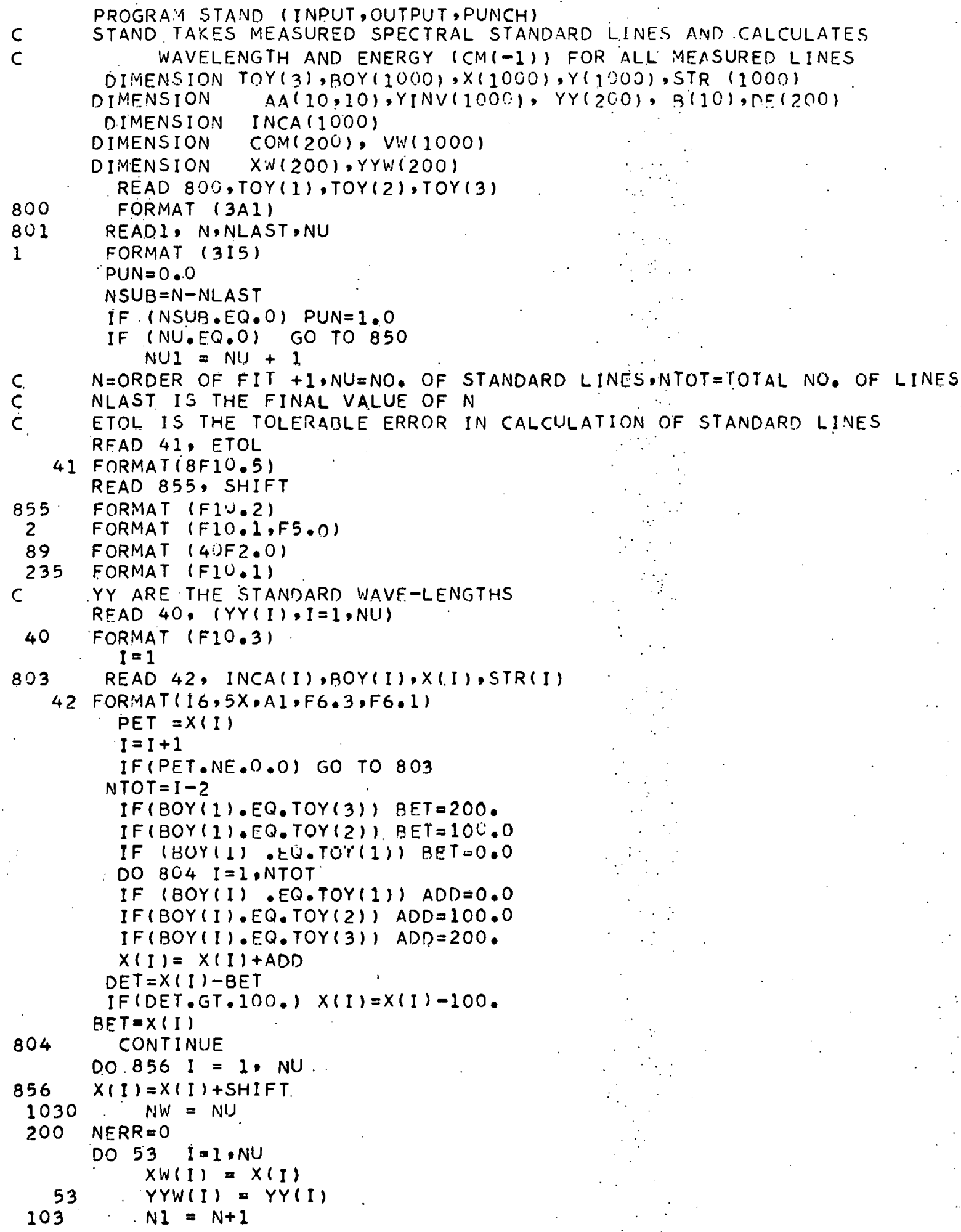




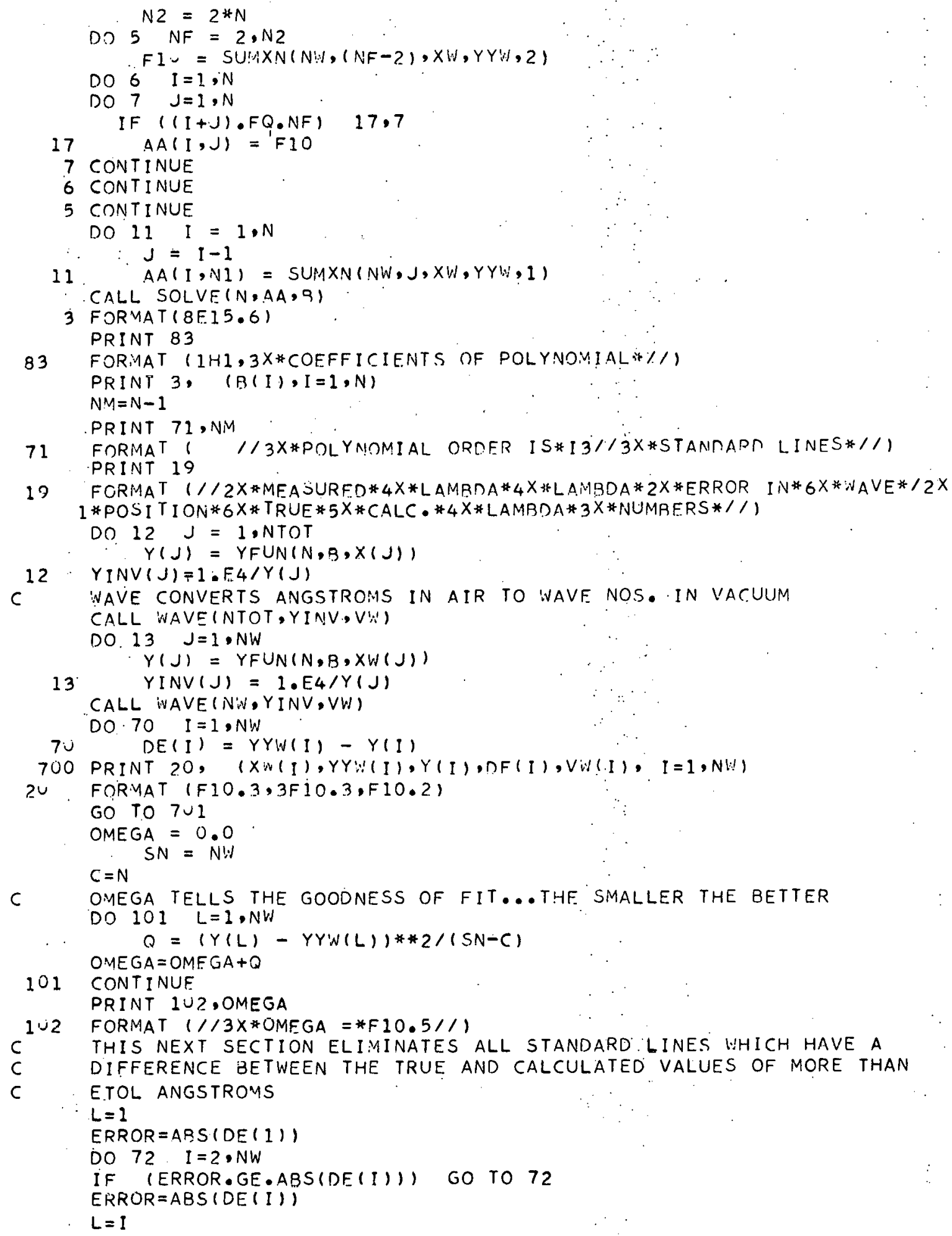


72 CONTINUE

IF. (ERRDR.GE.ETOL) SO TO 73

GO TO $7 \cup 1$

$73 \quad L I=L+1$

$N E R R=N E R R+1$

IF (NERR.EQ.5) GO TO 555

DO $74, J=L I, N W$

$J I=j-1$

TENPO = YYW!(J)

YYW(JI) = TEMPO

TEMPO $=X W(J)$

$X W(J I)=$ TEMPO

74 CONTINUE

$N W=N$ N -2

$N S:=N W-2$

IF (NLAST.EQ.NS) GO TO 525

GO TO $1 \cup 3$

555 PRINT 556

556 FORMAT (1.H1.3X*THERF. ARE MORE THAN 5 ERRORS*1/) GO TO 701

525 PRINT 526

526 FORMAT. (1/3X*THERE ARE TOO FEW GOOD LINES*//1)

701 PRINT 85

85 FORMAT 1 //3X*OBSERVATIONS*//2X*MEASURFD*4X*LAMDDA*6X*WAVE*3X 1 *COMMENT*/2X*POSI TION*5X*CALC * * X*NUMBERS* / $)$

PRINT 86, $(X(I), Y(I), V W(I), I N C A(I), S T R(I), I=N U I, N T O T)$

86 FORMAT (2FIU.3,F.10.2,110,F6.1)

IF (PUN.EQ.U.0) GO TO 880

PUNCH 87I, (VW(I),Y (I),STR(I),INCA(I),X(I), I =I,NTOT)

880

871 FORMAT $(10 X, 3 F 10.2,110,10 X, F 10.3)$. CONT INUE

$\mathrm{N}=\mathrm{N}+1$

566 IF (N.LF.NLAST) GO TO 1030

GO TO 801

850 CONTINUE

END

FUNCTION SUMXN(NT,N,X,Y,JJ)

DIMENSION $X(1000), Y(1000)$ $S=1,-1$

IF $(J j . E Q .1) 1.3$

1 DO $2 \quad I=1, N T$

$2 \quad S=S+Y(I) * X(I) * N$ GO TO 20

3 DO $4 \quad I=1, N T$

$4 \cdot S=S+X(1) * * N$

RETURN

END

SUBROUTINE SOLVE (N,A,R)

DIMENSION $A(10,10), B(10)$ $N 1=N+1$

DO. $3 \quad I=1, N$ $A T E M=A(I, I)$

DO $4: J=1, N 1$

4

$A(I, J)=A(I, \nu) / A T E M$

DO $5, K=1, N$

If $(K-I) \quad 51,5,51$

XBL 707-1392 


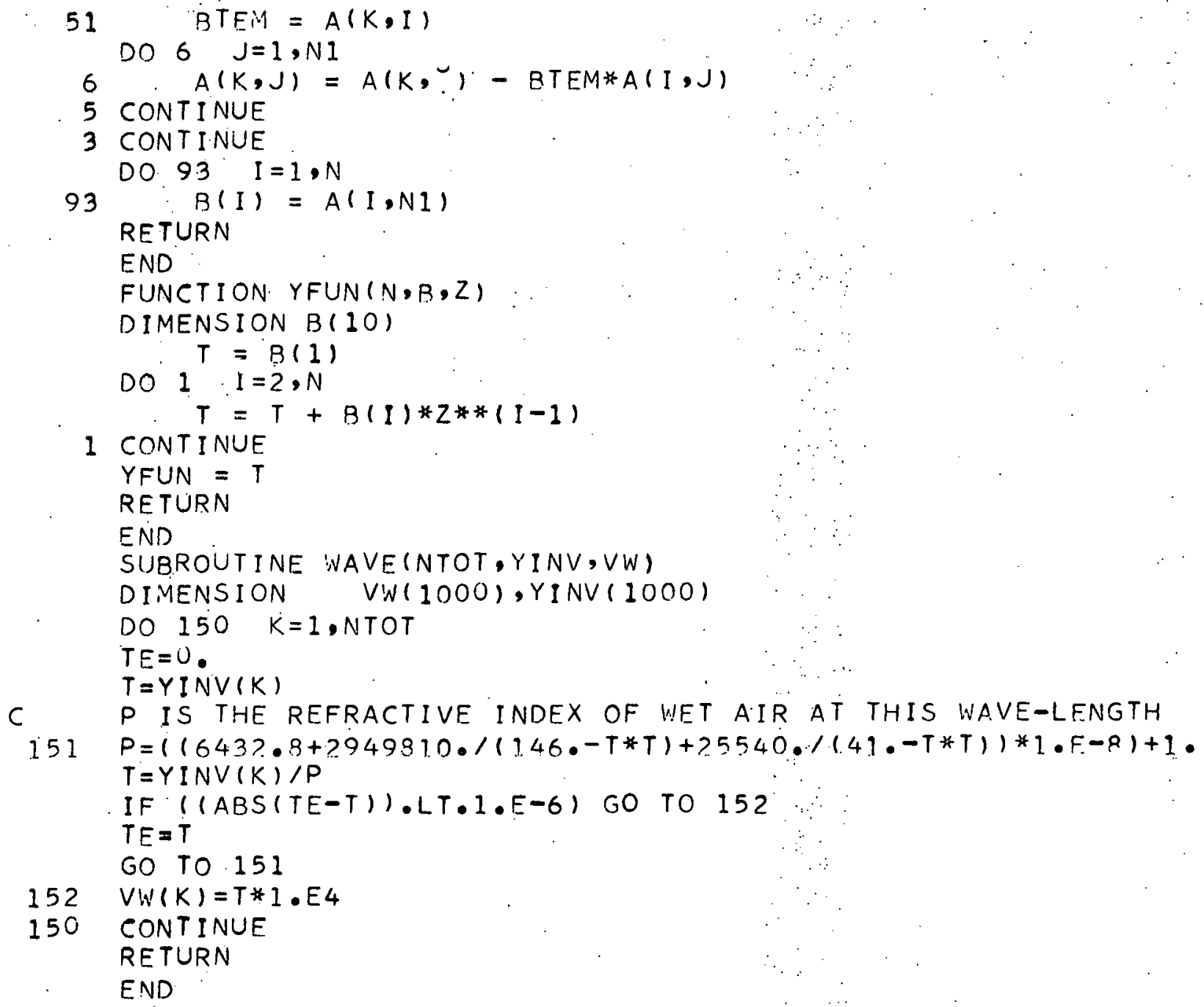


2. STNPLOT uses the cards punched by program STAND to plot the measured lines on a graph of energy $\left(\mathrm{cm}^{-1}\right)$ vs relative intensity. The end of the deck is signaled by a card with 88 in columns 49 and 50. The dispersion in $\mathrm{cm}^{-1}$ per inch is given on the next card (format 8F10.5). See Figure $(B-1)$ for a sample plot. The program was written by Joel Tellinghuisen. 


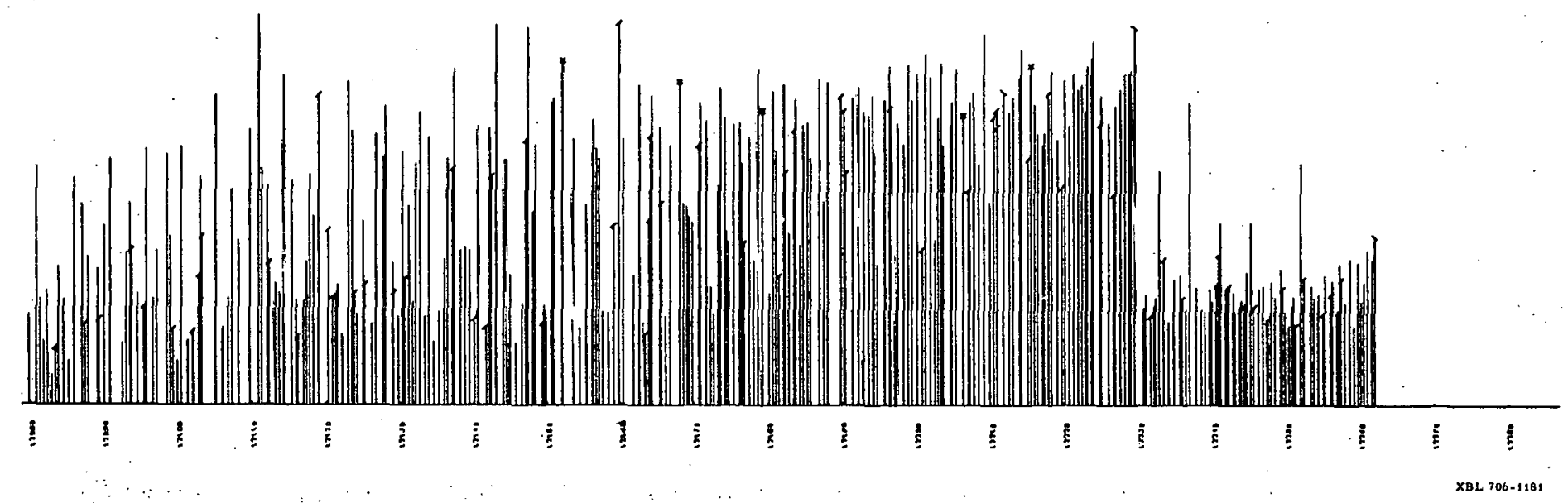

Fig. B-1. Sample plot of energy $\left(\mathrm{cm}^{-1}\right)$ vs relative intensity from the program STN PLOT. Lines with bars slaniing to the left ( ) indicate overlapped lines, bars slanting to the right ( ) red-degraded heads, and crosses ( ) two lines too close to be resolved. 
PROGRA:- STNPLUT (INPUT, OUTPUT, TAPE98, PLOT, T.APE99=PLOT)

DIMENSION VWI (1ODO), Y (1000), STR(1000), INCA IIORO)

$c$
$c$
$c$
$c$
$c$
$c$

THE FOLLONING CODE HAS BEEN USED FOR INCA. .

. 0 AND 1 - . ATOMIC LINES

2 - 2 RED-DEGRADED BAND HEAD

3 - . VIOLET-DEGRADED BAND HEAR

- - sPike mensured on center

INTEGERS 5 THRU 0 RESULT IN NO SYMBOLS. ON PLOTTED LINES.

1 FORMAT $(8 F 10.5)$

2 FORMAT $(10 X, 3 F 10,2,110)$

3 FORMATI/////2OX,*INPUT DATA*///1

4 FORMATI///*PLOT DISPERSION $=$ *F5.0, CM-I PER INCH*//1) CONTINUE

DO $11 \quad I=1.1000^{\circ}$

READ 2, VW(I),Y(I),STR(I),INCA(I)

IF (INCA I ).EQ.88) GO TO 12

11 CONTINUE

12

PRINT 3

PRINT 2, (VW I ),Y(I),STR(I),INCA(I),I =I, NTOT)

READ 1;, DISP

PRINT 4, DISP

CALL GRAPHX (VW, STR, INCA, NTOT,DISP)

READ 500, ISTOP

500

FORMAT (I5)

IF (ISTOP.NE.O) GO TO 501

CALL CCEND

END.

SUBROUTINE GRAPHX(X,Y, IND, NT, DISPI

COMMON/CCPOOL / XL,XH,YL,YH,CXL,CXH, CYL, CYH

DIMENSION $X(50 U), Y(500), I N D(500), X P(3), Y P(3)$

$X M I N=$ TMIN(NT, X) \& XPAAX $=$ FMAX $(N T, X)$

$I A=X M I N / 100$

$I B=\operatorname{ximAX} / 100$

$X L=100 . * I A \quad \$ \quad X H=100 . * I B$

DELTX $=(X H-X L) / D I S P * 100$.

$C X L=100 . \$ C X H=D E L T X+100$.

$Y A=F M I N(N T, Y)$

$Y L=0.0 \quad \$ . Y H=120 .-Y A$

$C Y L=300 . \$ C Y H=900$.

$G L=D E L T X / 100 \cdot+.1$

$N X L=G L$

CALL CCGRID $11, N X L, 6 H N O L B L S, 1,6)$

CALL CCLBL $(N X L, 1)$.

DO $11 \quad I=I, N T$

$$
\begin{gathered}
X P(1)=X(1) \$ X P(2)=X(1 .) \quad Y P(2)=0.0 \\
Y P(1)=105 .-Y(1)
\end{gathered}
$$
$N S Y M=0$

IF (INDII).EQ.1) NSYM $=8$

IF (INDII) $E$ EQ.2) NSYM $=4$

IF (IND(I),EQ.3) N.SYM $=5$

IF. (IND(I).EQ.4) NSYM $=2$

CALL CCPLOT (XP,YP, 2, 4HJOIN,NSYM, 5)

11 CONTINUE

CALL CCNEXT

RETURN

END

XBL $707-1388$ 


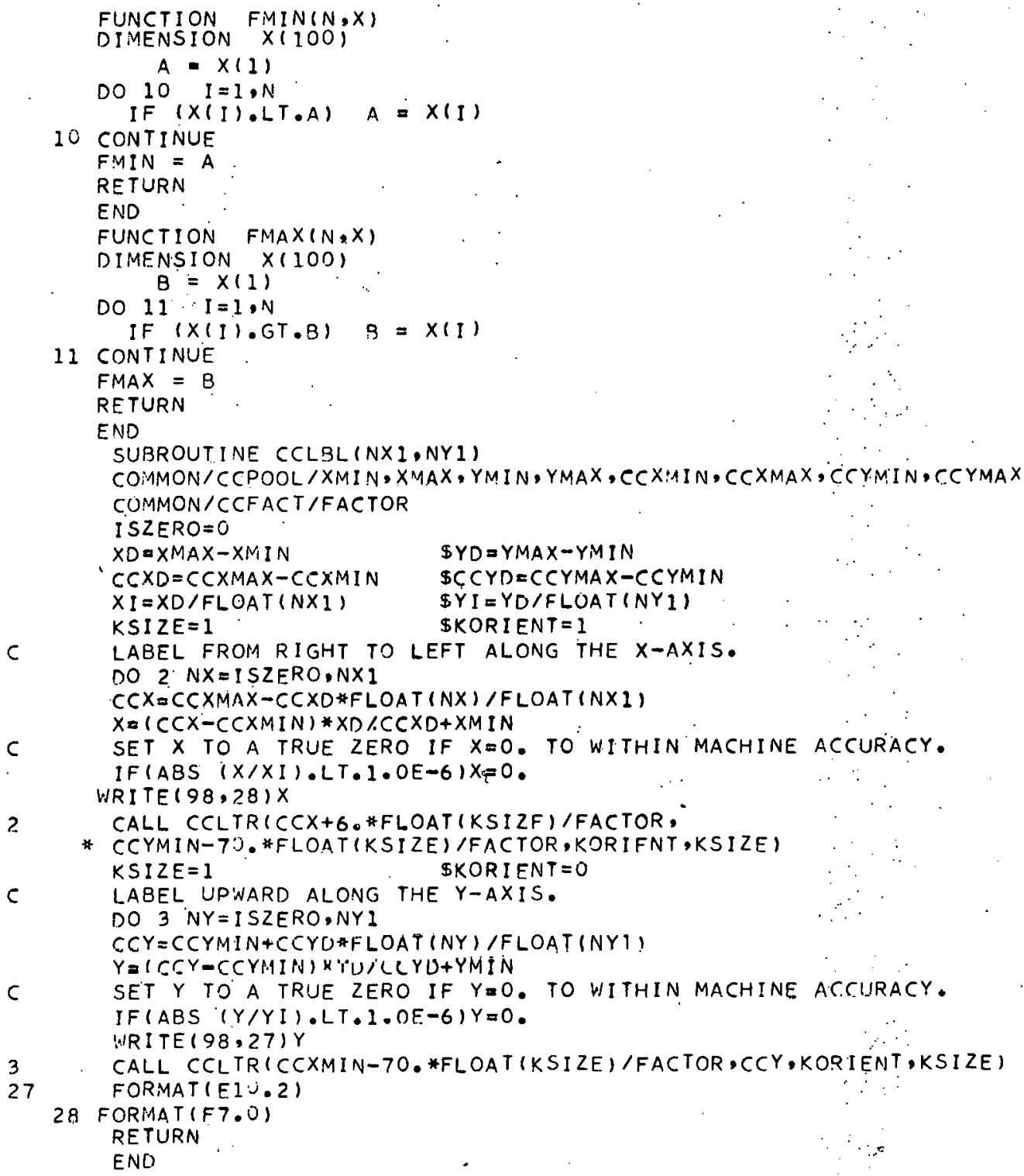


3. NOSORT calculates the combination differences, $\Delta_{2} F^{\prime \prime}(J)$, for $\mathrm{CaO}^{18}$ from the spectroscopic constants of $\mathrm{CaO}^{16}$ and $\rho$. As illustrated in Figure B-2

$$
\Delta_{2} F^{\prime \prime}(J)=R(J-\dot{I})-P(J+I)=F_{v}^{\prime \prime}(J+I)-F_{v} "(J-I)
$$

where $F_{v} "(J)$. is the energy of the J-rotational level of the lower vibrational state. Thus the energy difference between one line in the $R$-branch and one $\perp$ ine in the P-branch is known. The energy of $R(J-I)$ is calculated and every line in the region [SCAN. $+R(J-1)]$ to $[R(J-I)-S C A N]$ is assumed to be a possible candidate for $R(J-1)$. Whe combination difference $\Delta_{2} F^{\prime \prime}(J)$ (IERR) is added to the possible $R(J-1$ ) lines and the program searches for $P(J+1)$. If a pair of lines with the proper energy difference is found, a relative energy for the $F_{v}^{\prime}(J)$ level (called EAVE) is calculated using the energies of $P(J+I)$ and $R(J-I)$ plus the spectroscopic constants of the lower vibrational state. All the EAVE's

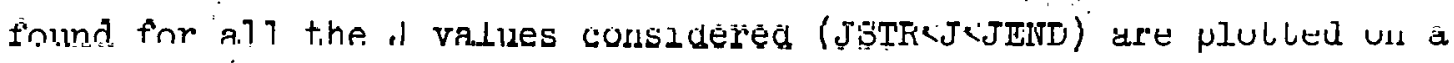
scale of relative energy vs $J(J+1)$. (see Figure $B-3)$. The quantity $S L^{*} J^{*}(J+1$ ) was substracted from EAVE so that the plot would be horizontal and graph paper not wasted. The numbers plotted in each case represent the relative intensities of the $\mathrm{P}$-line, the A's indicate the calculated energy of $P(J+I)$, and the circled numbers indicate combinations which have been assigned to the $(0,0)$ band. Notice the perturbation at $\mathrm{J} 38$. A similar program is described in Kopp, et $47 ., 1965$. 


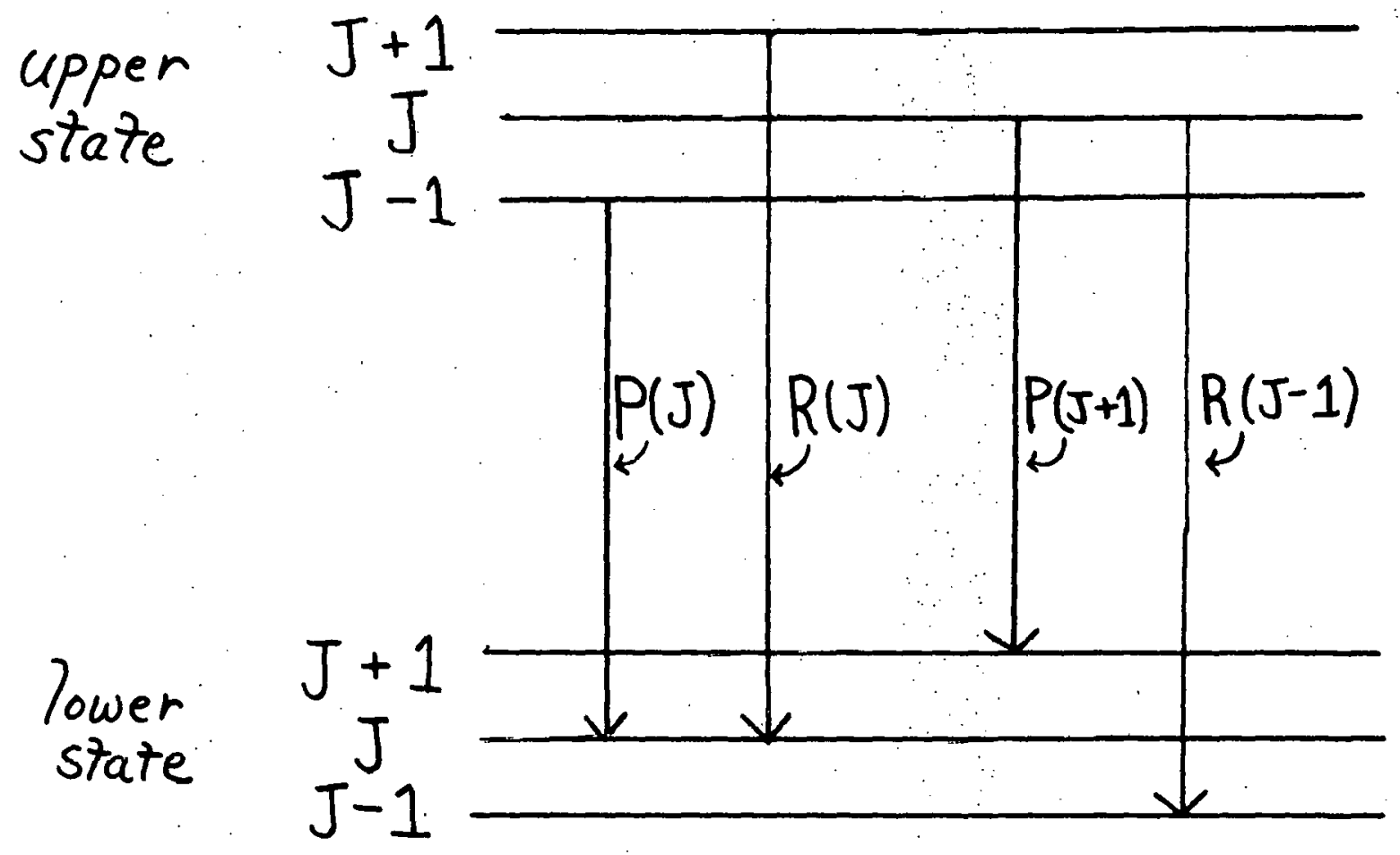

XBL 707-1376

Fig. B-2. Plot illustrating the equations

$$
\begin{aligned}
& \Delta_{2} " F(J)=R(J-I)-P(J+I)=F_{V}^{\prime \prime}(J+I)-F_{V}^{\prime \prime}(J-I) \\
& \Delta_{2}^{\prime} F(J)=R(J)-P(J)=F_{V}^{\prime}(J+I)-F_{V}^{\prime}(J-I)
\end{aligned}
$$




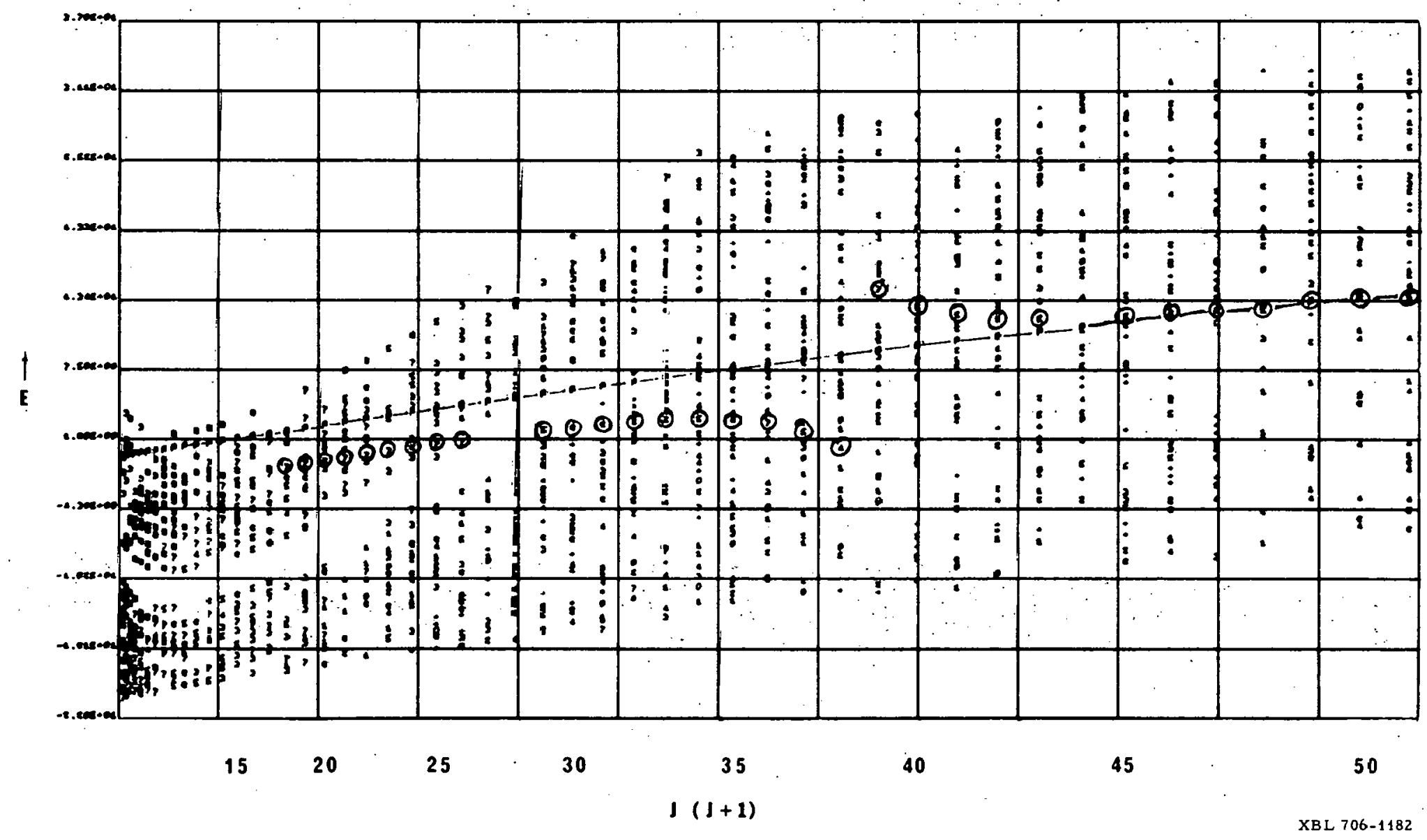

Fig. B-3. Sample plot of the program NOSORT. The coordinates Ere energy vs $J(J+l)$. Each number represents a possible assignment of $P(J+I)$ and $R(J-I)$, the $A^{\prime} s$ indicate the calculated energy of the $J$ rotational level and the circled numbers show the combinations which have been assigned to the $(0,0)$ band. 


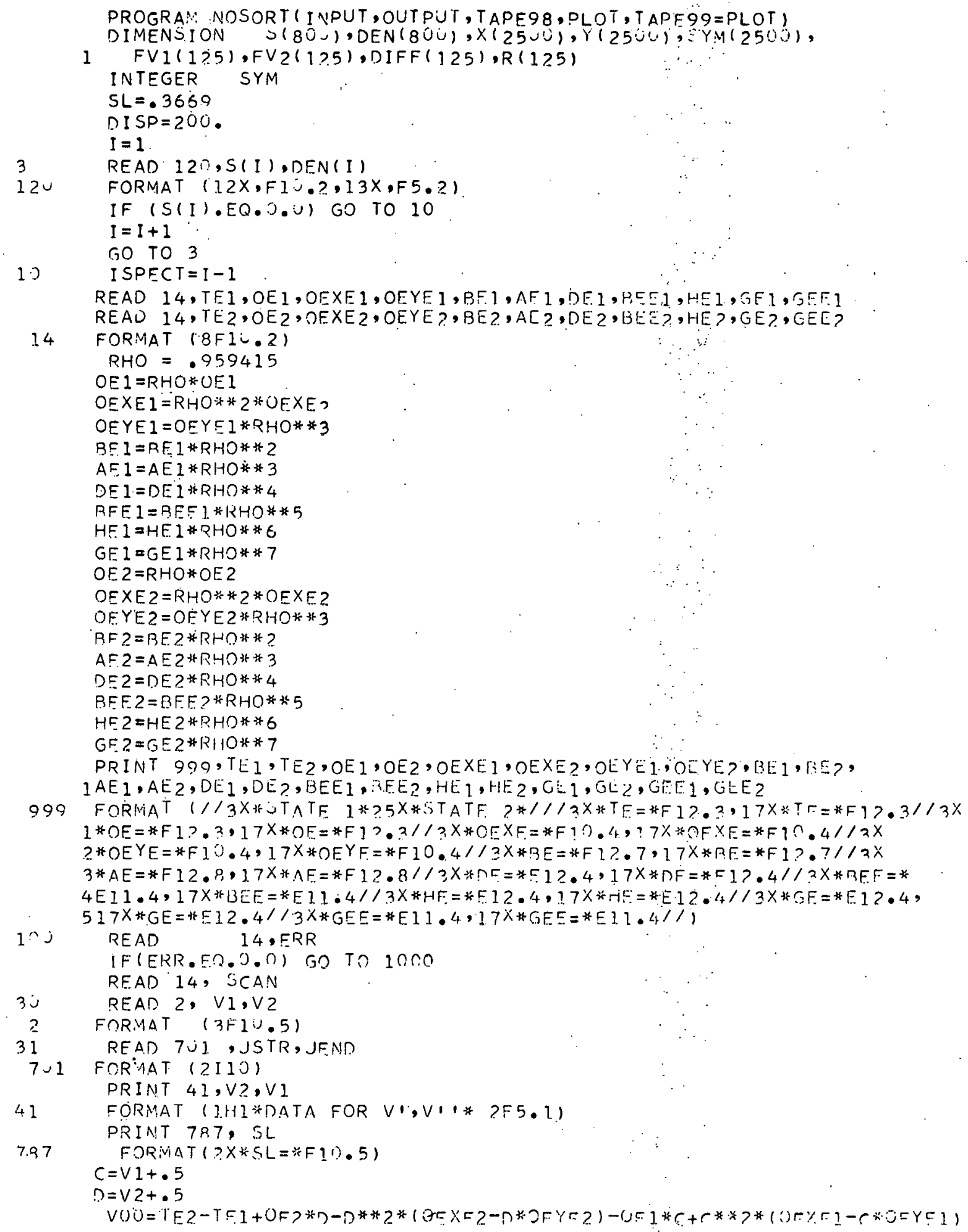

XBL $707-1396$ 


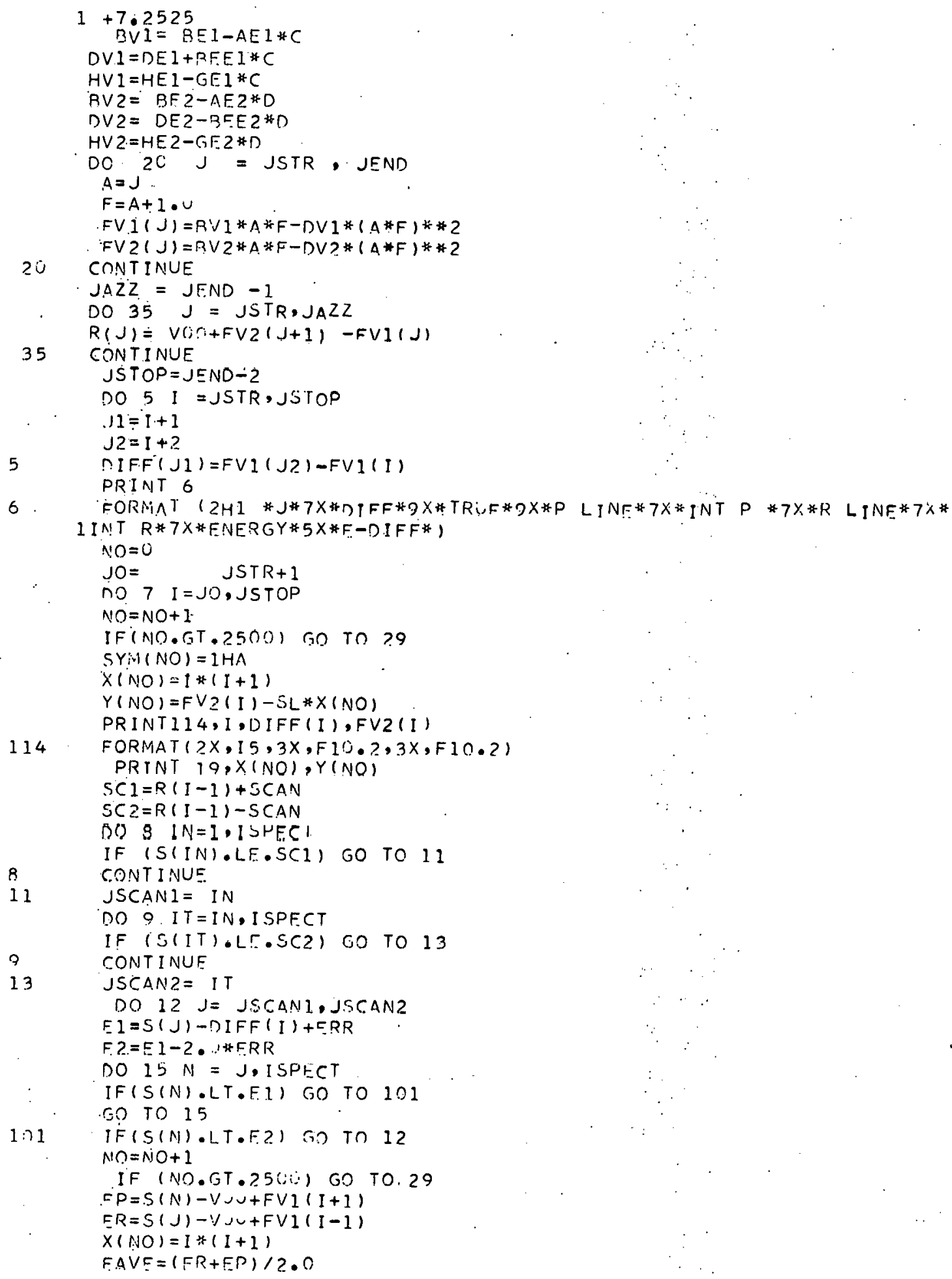


FDIFF=EAVE- FV $2(I)$

$Y(N O)=E A V E-S L \# X(N O)$

NDEN $=(D E N(N)+5.0) * .1$

SYM $(N O)=10-N D E N$

$S Y M(N O)=S Y M(N O)+33 B$

$5 Y M(N O)=L E F T(S Y M(N O), 54)$

PRINT $19, S(N), D F N(N), S(J)$, DFN (J), EAVE, EDIFF, Y (NO)

19

FORMAT $(33 X, 7(3 X, F 10.2)$

CONTINUE

$\begin{array}{ll}12 & \text { CONTINUE } \\ 7 . & \text { CONTINUE }\end{array}$

GO TO 40

29

$M O=N O-1$

4U CALL GRAPH $(X, Y, S Y M, N O, D I S P)$

GO TO IUU

IOUC CONTINUF

CALL CCENIO

END

SUBROUTINE GRAPHI $X, Y, S Y M, N T, D I S P$

COMINON/CCPOOL / XL, XH,YL,YH, CXL, CXH, CYL, CYH

DIMENSION $X(3750), Y(3750)$, SYM( 3750$)$

$X M I N=F M I N(N T, X)$ S XMAX $=F A X(N T, X)$

$I A=X M I N / 100$

$I B=X M A X / I \cup O+1$

$X L=1 U U^{*}$ *IA $\$ \quad X H=100 * 1 R$

DE.LTX $=(X H-X L) / D I S P * 100$.

$C X L=1$ IUD. $\$$ S $C X H=D E L T X+100$.

$Y M \perp N=F M I N(N T, Y) \quad \$ \quad Y M A X=F M A X(N T, Y)$

$I A=Y M I N-2 \cdot U$

$I B=Y M_{A} A X+2 \cdot U$

$Y L=I A$

$Y H=I B$

$C Y L=20 \%$. $\quad$ CCYH= 900.

$G L=D E L T X / 100+\cdots 1$

$N X L=G L$

NYL $=10$

CALL CCGRID (NXL, 6HLABELS,NYL)

nO $11 \mathrm{I}=1$. NT

$Y P=(Y(I)-Y L) *(C Y H-C Y L) /(\quad Y H-Y L)+C Y L$

$X P=(X(I)-X L) *\left(C X_{H}-C X_{L}\right) /\left(X_{H}-X_{L}\right)+C X_{L}$

CALL CCLTR(XP,YP,O,1, SYYA(I), I)

11 CONTINUF

CALL CCNEXT

RFTURN

END

FUNCTION FMIN $(N, X)$

DIMENSION $X(1 \mathrm{CO})$

$A=X(1)$

DO $10 \quad I=1, \mathrm{~N}$

IF $(X(I) \cdot L T \cdot A) \quad \Delta=X(I)$

10 CONTINUF.

$F \because I N=A$

RETURN

END

FUNCTION FMAX $(N, X)$

DIMENSION $x(100)$

$B=\times(1)$

DO $\left.1 I^{2}(x I=I)=0 T \cdot B\right) \quad R=X(1)$

11 CONTINUE

FMAX $=B$

RETURN

$E N D$

XBL $707-1398$ 
4. BOTH is basically the same program as NOSORT only after an $R(J-I)$ and $P(J+1)$ is found to satisfy the lower state combination difference, a $P(J-I)$ must also be found to satisfy the upper state combination difference for $(J-I)$. The upper state differences, (DI) are read in by statement 38 . 
PROGRAY 3OTH (I NPUT, OUTPUT, TAPE98, PLOT, TAPE99=PLOT)

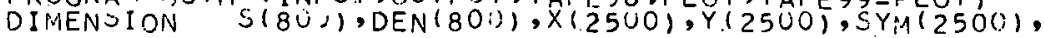

$1 \quad F V 1(125), F V_{2}(125), D I F F(125), R(125)$

DIMENSION DIF (125)

INTEGER SYM

$S L=.3655$

II $S P=24 \%$

$I=1$

READ $120, S(1), D E N(I)$

12 FORMAT $(12 X, F 1 \cup .2,13 X, F 5.2)$

IF (S(I).EQ.0.ن) GO TO 10

$I=I+1$

GO TO 3

I SPECT $=I-1$

REAO 14,TE1, OE 1, OEXE1, OEYE 1, BE 1, AF 1, DE 1, BEE 1, HE 1, GE 1, GEE 1

REAO 14, IE2, OE 2, OEXE2, OEYE2, BE2, AE?, DE?, UEE2, HE?, GE?, GEE?

14

FORMAT (BFIU.?)

RHO $=.059415$

$O F .1=R H O * O E 1$

OEXE $1=R H O * * 2 * O E X E K$

OEYE $1=O E Y E I * R H D * * 3$

$B E .1=Q E 1 *\{R H O *$ ?

$A F I=\triangle E 1 * R H O * * 3$

$D F I=D E I * R H O * * 4$

BEE I $=$ REF I RHO**5

$H E I=H[1 * R H O * 6$

GF $1=G E 1 * R H O * * 7$

OE $2=R H O * O E 2$

$O F X E 2=R H O * * 2 * O E X F 2$

OFYEZ =OFYF $2 \times R+10 * 3$

$B=2=R F .2 * R H O * 2$

$A F 2=A E 2 * R H O * * 3$

$D F 2=D E 2 * R H O * 4$

$B E E 2=B E F .2 * R H O * * 5$

$H F .2=H E 2 * R H O * 6$

$G F ?=G E 2 * R H O * * 7$

PRINT 999,TE1,TE? OE 1, OE?, OEXE1, OEXE?, OEYE 1, DEYE?,BE 1, BE?,

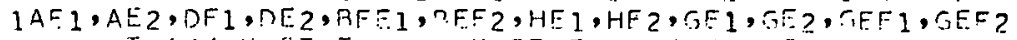

999 FORMAT (//3X*STATE 1 *25X*STATF 2*///3X*TF=*F $12.3,17 X * T F=* F 12.3 / / 3 X$

$1 * O E=\# F 12 \cdot 3,17 \wedge * O E=\# F 17 \cdot 3 / 13 X * \cap E X E=* F 10.4,17 X * O E X E=* F 10.4 / 13 X$

2*OEYE =*F1U.4.17X*OEYE $=* F 10.4 / 13 X * B F=* F 12.7,17 X * B E=* F 12.7 / / 3 X$

3*AE $=* F 12.8,17 X * A E=* F 12.8 / / 3 X * \cap E=* E 1 ? .4,17 X * D E=* E 12.4 / / 3 X * B E E=*$

$4 E 11.4,17 X * B E E=* E 11.4 / 13 X * H E=* E 1 ? .4,1.7 X * H E=* E 1 ? \cdot 4 / / 3 X * G E=* F .17 .4$,

$517 X * G E=* E 12.4 / / 3 X * G E E=* E 11.4,17 X * G E E=* 511.4 / 1)$ READ 14, ERR

IF (ERR.EQ.C.0) GO TO 1000

RFAD $14, F R R 2$

PEAD 14, SCAN

READ 2, $V 1, V 2$

FOR:AAT (3F10.5)

READ 701 , JSTR, JFND

7U1 FORNAT (?IIU)

PRINT $41, V 2, V I$

41 : FORMAT (IHI \# DATA FOR VI,V1*\# 2F5.?)

PRINT 75?, ERR, ERR?

752 FOR MAT (IX,2FIO.3)

PRINT 787, SL

787 FOR:MAT $(2 X * S L=\# F 10.5)$

$C=V 1+.5$

$D=V 2+.5$

XBL 707-1399 
$V O O=T E_{2}-T E 1+O E_{2} * D-D * 2 *\left(O F X E ?-\cap * O F Y E_{2}\right)-O F 1 * C+C * * 2 *\left(O F \times E 1-C * O F Y E_{1}\right)$

$1+7.2525$

$B \vee 1=B F 1-\Lambda E I * C$

$D V 1=D E 1+B E E 1 * C$

$H V 1=H E 1-G E I * C$

$B \vee 2=B E 2-A E 2 * D$

$D V 2=D E 2-9 E E 2 * D$

$H V 2=H E 2-G F .2 * D$

DO $2 \dot{J} j=$ JSTR, JEND

$A=J$

$F=A+1$

$F \vee 1(J)=B \vee 1 * A * F-D V 1 *(A * F) * * 2$

$F \vee 2(J)=B \vee 2 * A * F-D V 2 *(A * F) * * 2$

CONT INUE

$J A Z Z=J E N D-1$

DO. $35 \cdot J=J S T R, J A Z Z$

35

$R(J)=V O n+F V 2(J+1)-F V I(J)$

CONTINUE

$J S T O P=J E N D-2$

DO $5 I=J S T R, J S T O P$

$J 1=1+1$

5

$J 2=I+2$

$5 \quad \underset{N O=0}{\operatorname{DIF} F(J 1)=F V I(J 2)-F V I(I)}$

$42 \quad N A=0$

$J A P=0$.

38

READ 37,JA,DI

37

FORMAT (I5,F 10.05)

$T O P=J A+D I$

IF (TOP.EQ.0.0) GO TO 39

$N A=N A+1$

I $F(N \dot{A} \cdot E Q .1) \quad J O=J A+1$

$D I F(J A)=U 1$

$J A P=J A$

GO TO 38

$39 \quad J S T O P=J A P+1$

IF (JAP.EQ.U) GO TO 1000

PRINT 6

6

FORMAT

1.7X*DIF LON*7X*DIF UP*7X*P $(J-1) * 1$

DO: $7 \mathrm{I}=\mathrm{JO}, \mathrm{JSTOP}$

$\mathrm{NO}=\mathrm{NO}+1$

IF (NO.GT.2500). GO TO 29

$\operatorname{SYM}(N O)=1 \mathrm{HA}$

$X(N O)=I *(1+1)$

$Y(N O)=F V_{2}(I)-S L * X(N O)$

PRINT 114,I,DIFF(I),FV2(I),DIF( I-1)

114 FORMAT $(2 X, 15,3(3 X, F 10.2))$

PRINT $19, X(N O), Y(N O)$

$S C I=R(I-1)+S C A N$

$S C 2=R(I-1)-S C A N$

DO 8 IN $=1$, ISPECT

IF (S(IN).LE,SCI) GO. TO 11

$8 \cdot$ CONTINUE

11 JSCANI $=$ IN

DO 9 IT $=I N$ ISPECT

IF (S(IT).LE.SC2) GO TO 13 


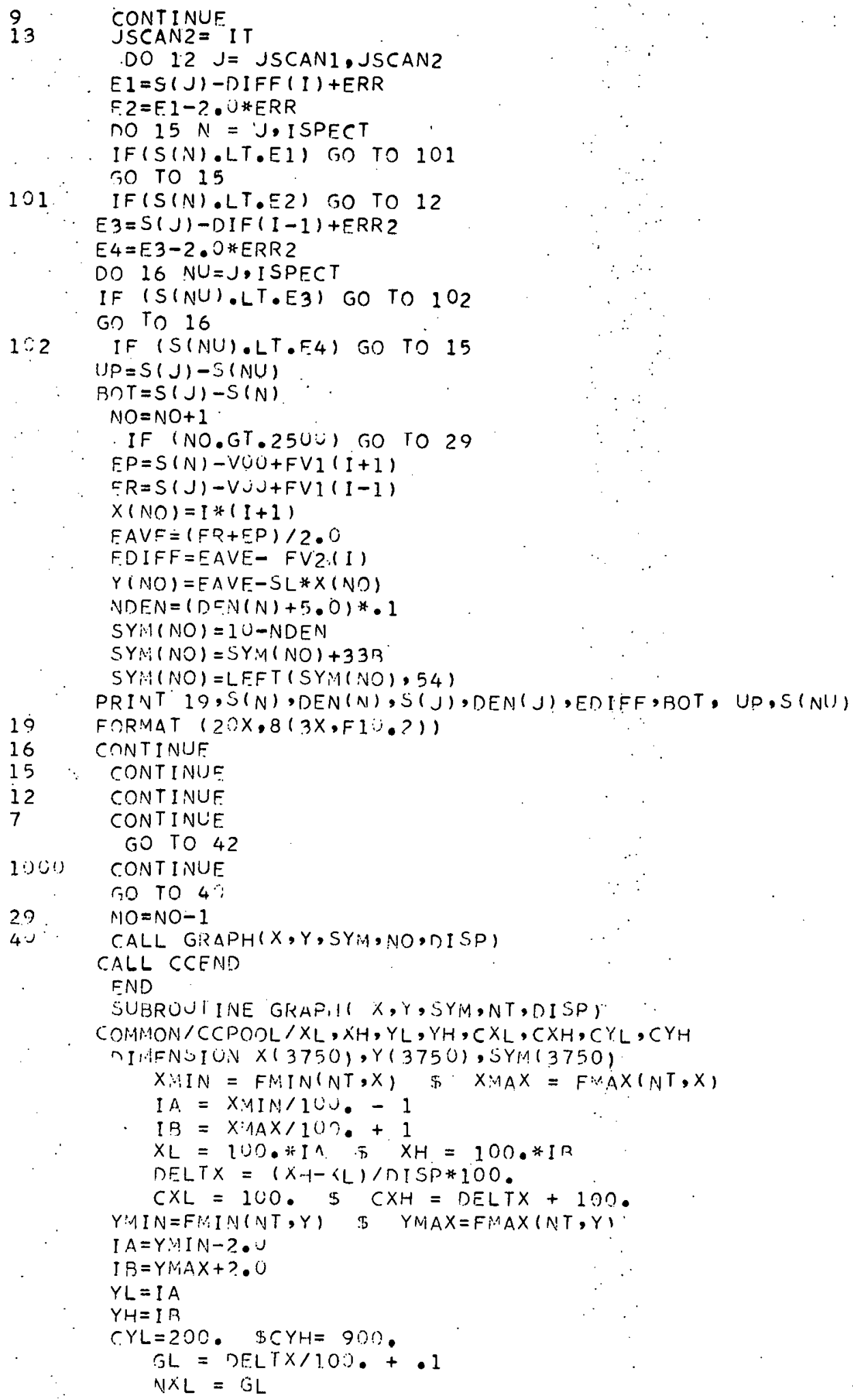


CALLL CCGRID (NXL, GHLAR=LSINYLI)

DO 11 I $I=1, N ! T$

$Y P=(Y(I)-Y L) *(C Y H-C Y L) /(Y Y H-Y L)+C Y L$ $X P=(X(I)-X L) *(C X H-C X L) /(X H-X !)+C X L$

11

CALL CCLTR(XP,YP,O, $1,5 Y A(1), 1)$

CONT INUE

CALL CCNEXT

RETURN

CND

FIINCTION FMIN $(N, X)$

DIMENSION $X(1 \cup O)$

- $A=X(1)$

DO $10 \quad I=1, N$

IU. CONTINUE

IF $(X 1$
NTINUE
IN $=A$

FMIN $=$
RETURN

END

FUNCTION FMAX $(N, X)$

DIMENSION $X(1 \cap$ II)

DO. $\ddot{1}=\mathrm{R}=\mathrm{X}(1)$

IF $(X(I) \cdot G T \cdot B) \quad B=X(I)$

11 CONTINUE

FMAX - R

RFTURN

END

XBL $707-1442$ 
5. TELL I calculates and plots $\Delta_{2} F(J) / 4\left(J+\frac{I}{2}\right)$ vs $\left(J+\frac{1}{2}\right)^{2}$ (see Eq. 3) for both the upper and lower state levels. Sample plots for the $(0,0)$ band are shown in Figures B-4 and B-5. A sample data deck for the $(4,2)$ band is also given. The first card has the vibrational numbering $(4.0,2.0)$, the next has the lowest and highest $J$-numbers for the $R-$ and P-branches up to the first perturbation, then the assigned $R$ and $P$ lines are listed in order, the next set of J-numbers given, etc. The deck is ended by a blank card. Several data decks for different bands can be processed at once. A card with 100. in the first four columns signals the end of the input data. 


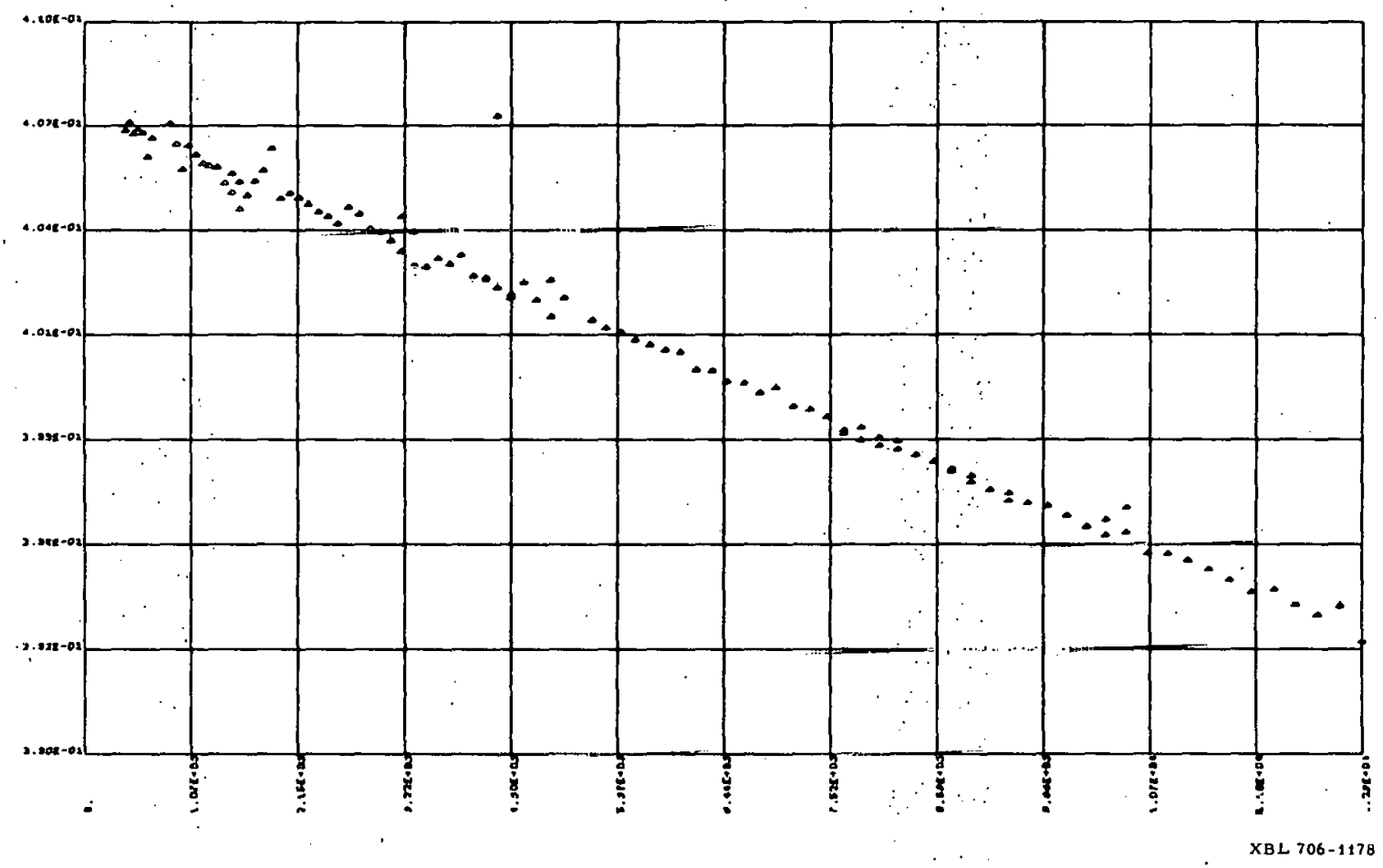

Fig. B-4. Plot of $\Delta_{2}^{\prime \prime} F(J) / 4\left(J+\frac{1}{2^{2}}\right)$ vs $\left(J+\frac{1}{2}\right)^{2}$ for the $(0,0)$ band from program TELL 1. See Eq. 3: 


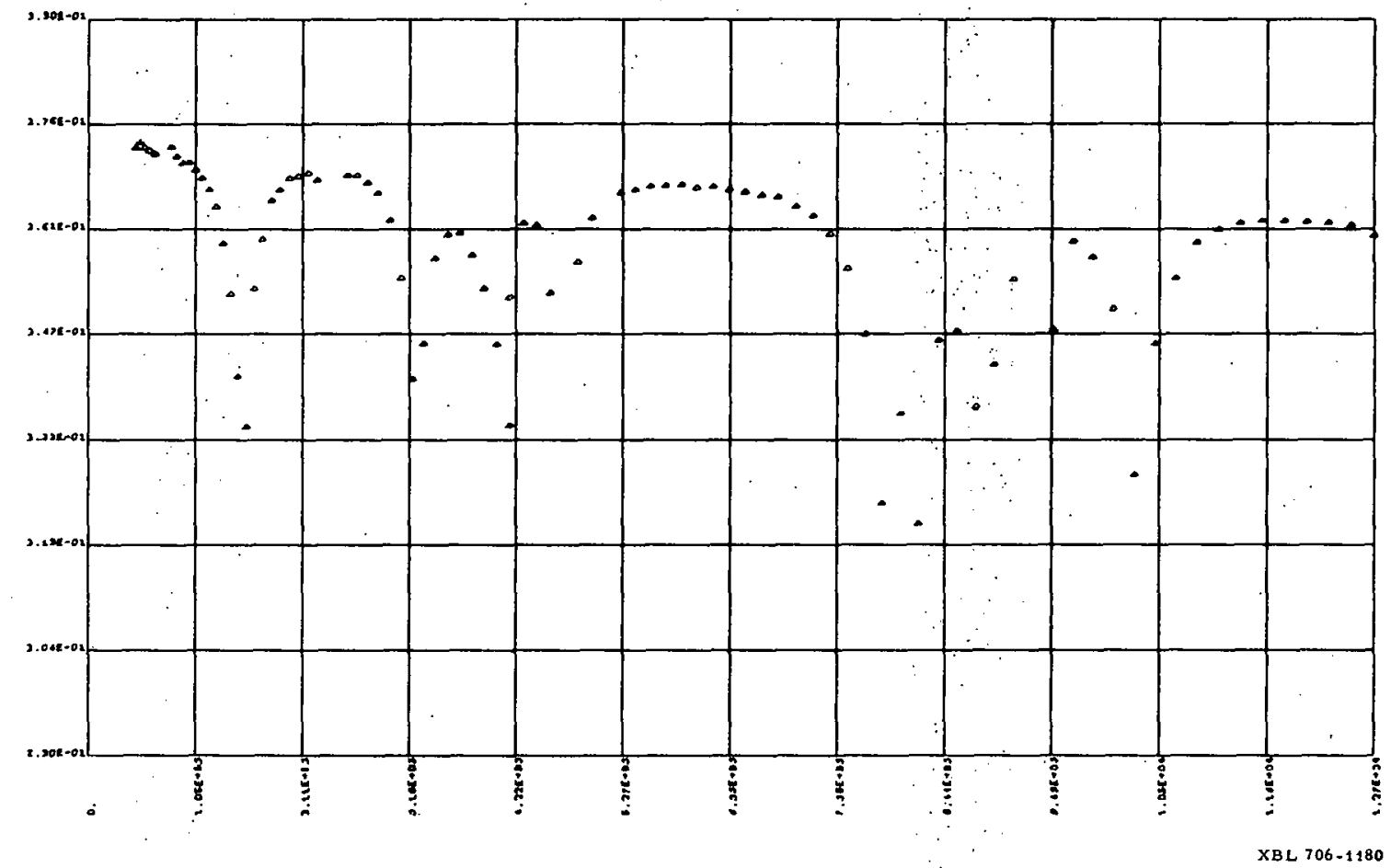

Fig. B-5. Plot of $\Delta_{2}^{\prime} F(J) / 4\left(J+\frac{1}{2}\right)$ vs $\left(J+\frac{1}{2}\right)^{2}$ for the $(0,0)$ band from program TELL 1 . 
PROGRAM TELLI (INPUT, OUTPUT, TAPE98,PLOT: TAPE99=PLOT) DIMENSION XL (150), XH(150)

D.IMENSION JH(150),HDIFF $(150), J L(150), B D I F F(150), P(150), R(150)$

DIMENSION BVH(150),BVL(150),D2L(150),D2H(150)

G- 00157

156 CONTINUE

PRINT $378, V H, V L$

378 FORMAT (IHL*VH,VL $=* 2 F 5.1)$

$101 . I H=0$

$I L=0$

100 READ 1, JRL, JRH, APL, JPH

1 FORMAT (4I5)

. $D=J R L-J R H$

IF $(D . E Q .0 .0)$ GO TO 155

DO $400 I=1,150$

$P(I)=0.0$

$R(\cdot I)=0.0$

400. CONTINUE

READ. $2,(R(I), I=J R L ; J R H)$

READ 2, $(P(I), I=J P L, J P H)$

2

FORMAT $(12 \times \cdot F 10.2)$

$J S=J R L$

IF (JPL.LT•JRL) JS=JPL

$J E=J R H$

IF.(JPH.GT $\bullet J R H) \quad J E=J P H$

PRINT $3,(J, P(J), R(J), J=J S, J E)$

3

FORMAT $(1 X, I 5 ; 5 X, F 10.2,5 X, F 10.2)$

$401 \quad J O \equiv J P L-2$

IF (JO.LE.I) GO TO 403

IF(RIJO) EEQ.0.0) GO TO 402

$I L=I L+I$

$B D I F F(I L)=R(J O)-P(. J P !$.

$J L(I L)=J P L-1$

$X L(I L)=(J L(I L)+.5) * 2$

BVL I IL $)=B D I F F(I L)^{\prime}(4.0 *(J L(I L)+.5))$

$I F(I L, E Q, I) D 2 L(1)=0.0$

IF (IL.EQ.I) GO TO 402

$D 2 L(I L)=0.0$

$J B=J L(I L)-J L(I L-1)$

IF (JB.NE.I) GO.TO 402

$D 2 L(I L)=B D I F F(I L)-B D I F F(I L-1)$

402 IF(R(JPL).EQ.0.0) GO TO 403

$I H=I H+I$

$H D I F F(I H)=R(J P L)-P(J P L)$

$J H(I H)=J P L$

$X H(I H)=(J H(I H)+3) * 2$

$B V H(I H)=H D I F F(I H)(4.0 *(J H(I H)+.51)$

$I F(I H: E Q .1) D 2 H(1)=0.0$

IF (IH.EQ.I)GO TO 403

$D 2 H(I H)=0.0$

$\checkmark B=J H(I H)-J H(I H-1)$

IF ( JB.NE.I) GO TO 403

$\mathrm{O}_{2} H(I H)=H D I F F(I H)=H D I F F(I H-1)$

403

$J P L=J P L+1$

IF (JPL.LE.JPH) GO TO 401

GO TO 100

$155 \therefore$ CONTINUE 
PRINT 181, VH, VL

FORIMAT $I H I * L O N E R$..TATE OF *2F5.1/IX*J*4X*C-DIFF*4X*2ND DIFF*

i $2 X * B V * 1$

PRINT $17,(J L(I), B D I F F(I), D 2 L(I), B V L(I): I=I, I L)$

I $N=0$

DO $19 \mathrm{~J}=1, \mathrm{IL}$

$I N=I N+1$

$B V L(I N)=B V L(J)$

$X L(I N)=X L(J)$

19

IF (BVL $(J) \cdot G T \cdot 0 \cdot 8 \cdot O R \cdot B V L(J) \cdot L T \cdot 0 \cdot 1)$ IN=IN-I

$I L=I N$

CALL GRAPH ( XL,BVL,IL)

CALL LINE. ; XL,BVL,IL)

PRINT $18 \quad, V H, V L$

FORMAT $(1 H I *$ UPPER STATE OF *2F5.1/1X*J*4X*C-DIFF*4X*2ND DIFF* 1. $2 X * B V * 1$

PRINT $17,(J H(I), H D I F F(I), D 2 H(I), B V H(I), I=1, I H)$

17 FORMAT $(1 X, 15,3(5 X, F 10.5))$

IN $=0$

DO $20 \mathrm{~J}=1 \cdot 1 \mathrm{H}$

$I N=[N+1$

$B V H(I N)=B V H(J)$

$X H(I N)=X H(J)$

20

IF (BVH(J).GT.0.B.OR・BVH(J),LT.O.I) IN=IN-I

$I H=I N$

CALL GRAPH ( XH,BVH,IH)

157

CALL LINE

$(X H, B V H, I H)$

READ $5, V H \bullet V L$

FORMAT (2F10.2)

IF $(\mathrm{VH} . \mathrm{LT} .99 .0)$ GO TO 156

END

SUBROUTINE GRAPH $(X, Y, N T)$

COMMON/CCPOOL/XL,XH,YL,YH, CXL, CXH, CYL, CYH

DIMENSION ROUND (4)

DIMENSION $X(150), Y Y(150)$

$X M I N=F M I N(N T, X)$ \& XMAX $=F M A X(N T, X)$

$I R=X M A X+4.0$

$I A=0$

$X L=I A \quad$ \$ $\quad X H=I B$

$N X L=12$

$N Y L=7$

$C X L=100 . \quad \$ C X H=1300$.

$C Y L=200 . \quad \$ \quad C Y H=900$.

NROUND $=4$

ROUND ( 1$): 1.0$

ROUND $(2)=2.0$

ROUND $(3)=2.5$

ROUND $(4)=5.0$

CALL LINEUP (Y,NT,ROUND, NROUND,NYL, YL, YH)

CALL CCGRID (NXL, GHLARELS,NYL)

CALL CCPLOT $(X, Y, N T$, GHNOJOIN,8,1)

CALL CCNEXT

RETURN

END

FUNCTION FMIN $(N, X)$

DIMENSION $X(100)$

$$
A=X(1)
$$


10. CONTINUE

FMIN $=A$

RETURN

END

FUNCTION FMAX $(N, X)$

DIMENSION $X(100)$

$=x(1)$

DO $11 \quad I=1, N$

- IF $(X(I) \cdot G T \cdot B)$ A. $=X(1)$

11 CONTINUE

FMAX = 8

RETURN

END

SUBROUTINE LINE $(X, Y, M)$

DIMENSION X(150), Y (150)

I $A=0$

3

CONTINUE

$S X=0.0$

$S Y=0.0$

$S X Y=0.0$

$5 \times 2=0.0$

DO $1 J=1, M$

$S X=5 X+X(J)$

$S Y=S Y+Y(J)$

$S X Y=S X Y+X(J) * Y(N)$

$5 \times 2=5 \times 2+X(J) * * 2$

1

CONTINUE

$R=M$

$D=R * 5 \times 2-S X * \# 2$

$C 1=(R * S X Y-S X * S Y) / D$

$C 2=\left(S \times 2^{*}+5 Y-S X * 5 X Y\right) / D$

PRINT $2, C 1, C 2$

FORMAT $11 X * L E A S T$ SQUARES FIT OF LINE Cl $X+C 2=\gamma * 110 X * C 1=*$

$1 E 12.5 / 10 X * C 2=* E 12.5)$

IF (IA.GT.U) GO TO 7

TEST $=.015$

$J=0$

IA $=1+I A$

DO $4 I=I, M$

$Y T=C 1 * X(I)+C 2$

$D I=A B S(Y T-Y(I))$

IF (DI.GT.TEST) GO TO 5

$J=J+1$

$X(J)=X(1)$

$Y(J)=Y(I)$

GO TO 4

PRI'NT $6, X(I), Y(I), D I$

FORMAT $(1 / 1 / 40 X, 3 F 15.5)$

CONTINUE

$M=J$

GO TO 3

CONTINUE

RETURN

END 
Sample Data Deck for the $(4,2)$ Band

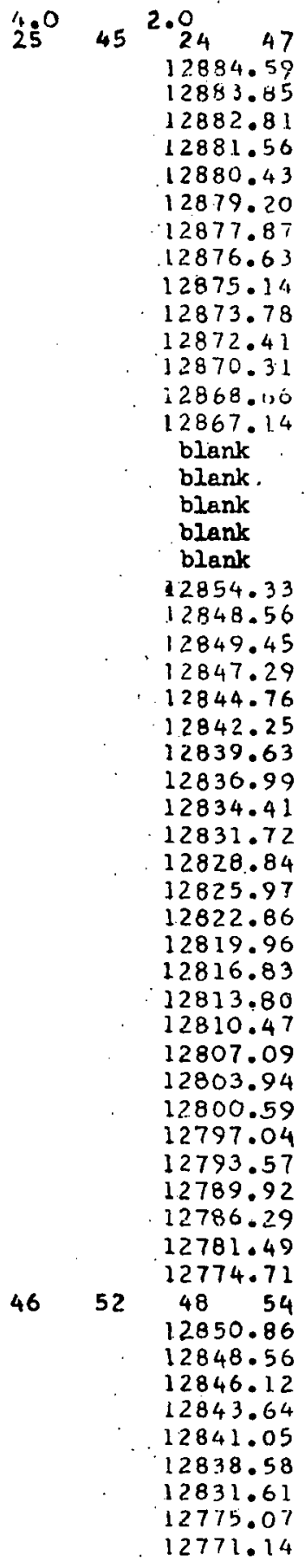

12767.13

12763.17

12759.05

12754.12

12746.49

152 $61 \therefore 54 \quad 63$

12833.40

1.2830 .35

12827.45

12825.07

12321.79

12818.80

1.2814 .99

12810.49

12803.94

$\mathrm{L} 2752.90$

$1 ? 71,5.147$

12742.04

12737.72

12733.50

12728.79

12724.05

12718.83

1271.2 .68

12704.65

61

$69 \quad 63$

12811.56

$12800.0 \%$

12802.93

12799.37

12796.15

12792.46

12789.05

12784.81

12782.58

12712.01

$12705.5 \%$

12700.63

12695.44

12690.65

12685.36

12680.61

12675.58

12670.68

blank

XBL $707-1378$ 
6. TELL 2 calculates and plots. T/4J vs J (see Eq. .4). The same data deck setup used for TELL 1 can be used here. Sample plots are shown in Figs. 8-13. 
PROGRAM TELL2 (INPUT, OUTPUT, TAPE98,PLOT,TAPE99:PLOT)

DIMENSION $R(150), P(150), X(150), T(150)$

$$
\text { GO TO } 157
$$

156

CONTINUE

PRINT $378, V H, V L$

378 FORMAT $(1 H 2 * V H, V L=* 2 F 5.1)$

100 READ $1, J R L, J R H, J P L, J P H$

1 FORMAT (4I5)

$D=J R L-J R H$

IF $(D . E Q .0 .0) \cdot G O$ TO 155

DO $3 I=1,150$

$R(I)=0.0$

$P(I)=0.0$

3 CONTINUE

READ 2, (RII I), I = JRL, JRH )

READ $2,(P(I), I=J P L, J P H)$

2 FORMAT $\left(12 X_{0} F 10.2\right)$

$J T E S T=J R H+1$

4 IF(J.GT.JTEST) GO TO 100

IF $(P(J+1) \cdot E Q \cdot 0 \cdot 0 \cdot O R \cdot P(J) \cdot E Q \cdot 0 \cdot 0 \cdot O R \cdot R(J-1) \cdot E Q \cdot 0 \cdot 0 \cdot O R \cdot R(J-2) \cdot E Q \cdot 0 \cdot)$

1. GO TO 5

$A=J$

$I T=I T+1$

$T(I T)=(R(J-2)-R(J-1)+P(J)-P(J+1)) /(4 \cdot 0 * A)$

$X(I T)=A$

PRINT $6, X(I T), T(I T)$

6 FORMAT $(1 X, 2 \mathrm{~F} 10.5)$

$I F(T(I T) \cdot G T \cdot 0 \cdot 1 \cdot O R \cdot T(I T) \cdot L T \cdot 0.02) \quad I T=I T-1$

$5 \quad J=J+1$

GO TO 4

155 CONTINUE

CALL GRAPHIX,T,ITI

157 READ $25, \mathrm{VH}, \mathrm{VL}$

25 FORMAT $(2 F 10.2)$

IF (VH.LT.99.0) GO TO 156

CALL CCENO

END

SUBROUTINE GRAPH $(X, Y, N T)$

COMMON/CCPOOL/XL,XH,YL,YH, CXL,CXH,CYL,CYH

DIMENSION $X(150), Y(150)$

$X M I N=F M I N(N T, X)$ \& XMAX $=F M A X(N T, X)$

IF (XMAX.LT.100.)GO TO 9

$J A=X M A X / 4 \cdot 0+1.0$

$A=J A$

$N \times L=J A$

$X H=J A * 4$

$\mathrm{CXH}=100 \cdot+100 * * A$

GO TO IU

$9 \quad \mathrm{CXH}=2600$.

$X H=100$.

$N X L=25$

$10 \quad X L=U .0$

NYL $=8$

$\dot{Y} L=.02$

$Y H=.1$ 


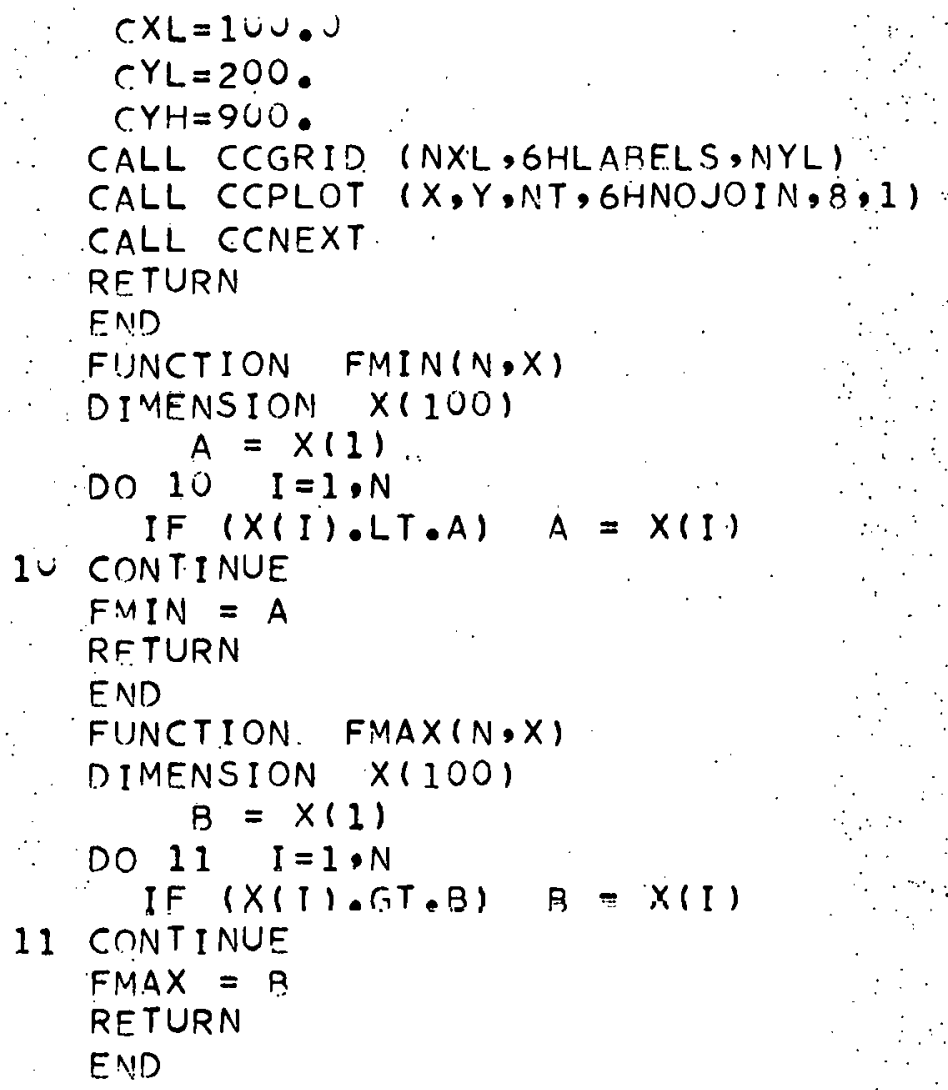


7. ORIGIN calculates and plots $[(R(J-I)+P(J)) / 2]$ vs $J^{2}$ (see Eq. 6) and the left-hand side of Eq. 7 vs $\mathrm{J}$. It uses the same data decks as TELL $I$ only the second data card for each band has $B_{v} "$ (format $10 X, F 10.2$ ). Sample plots are given in Figs. B-6 and B-7. 


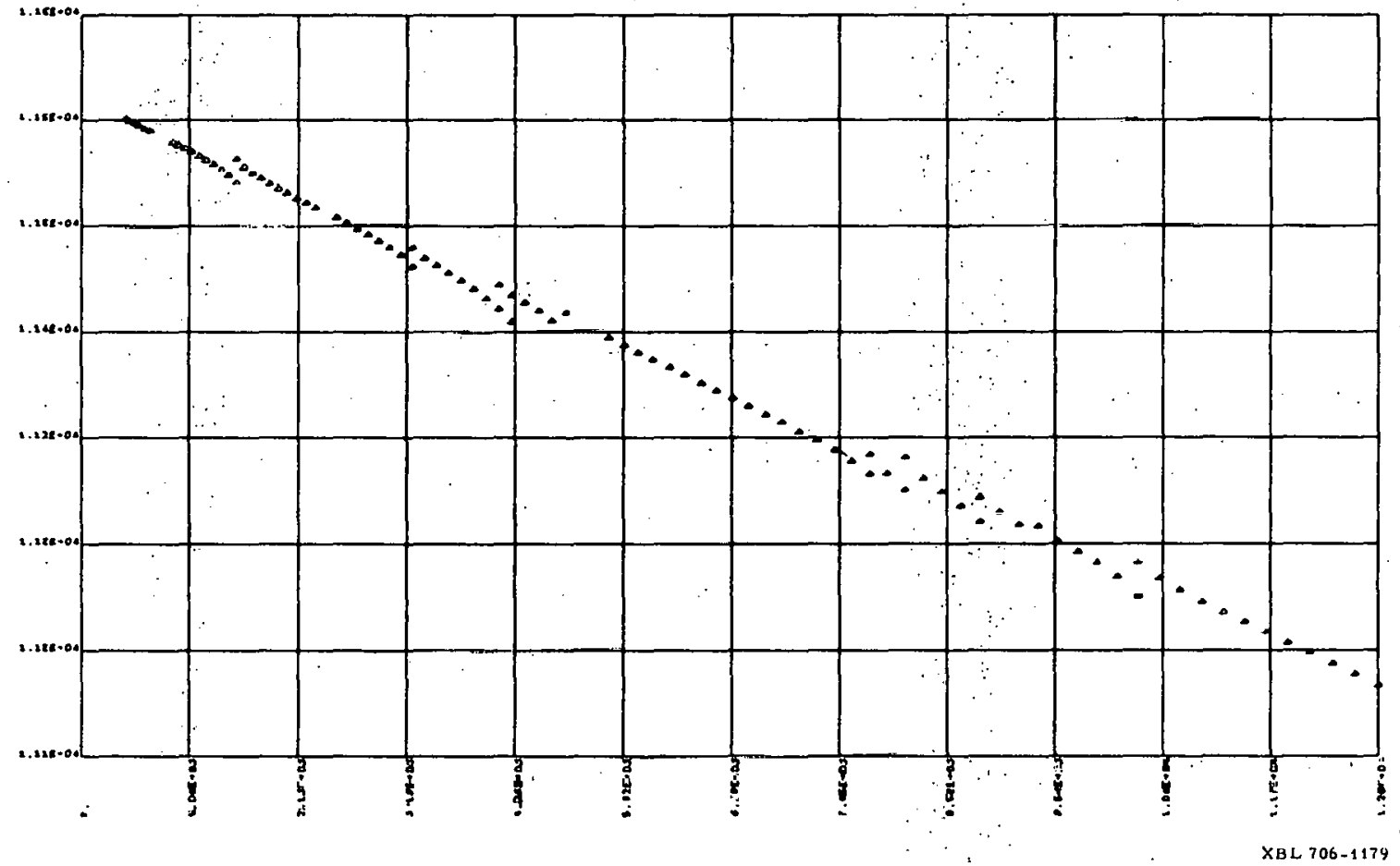

Fig. B-6. Plot of $[(R(J-1)+P(J)) / 2]$ vs $J^{2}$ for the $(0,0)$ band from program ORIGIN. See Eq. 6 . 


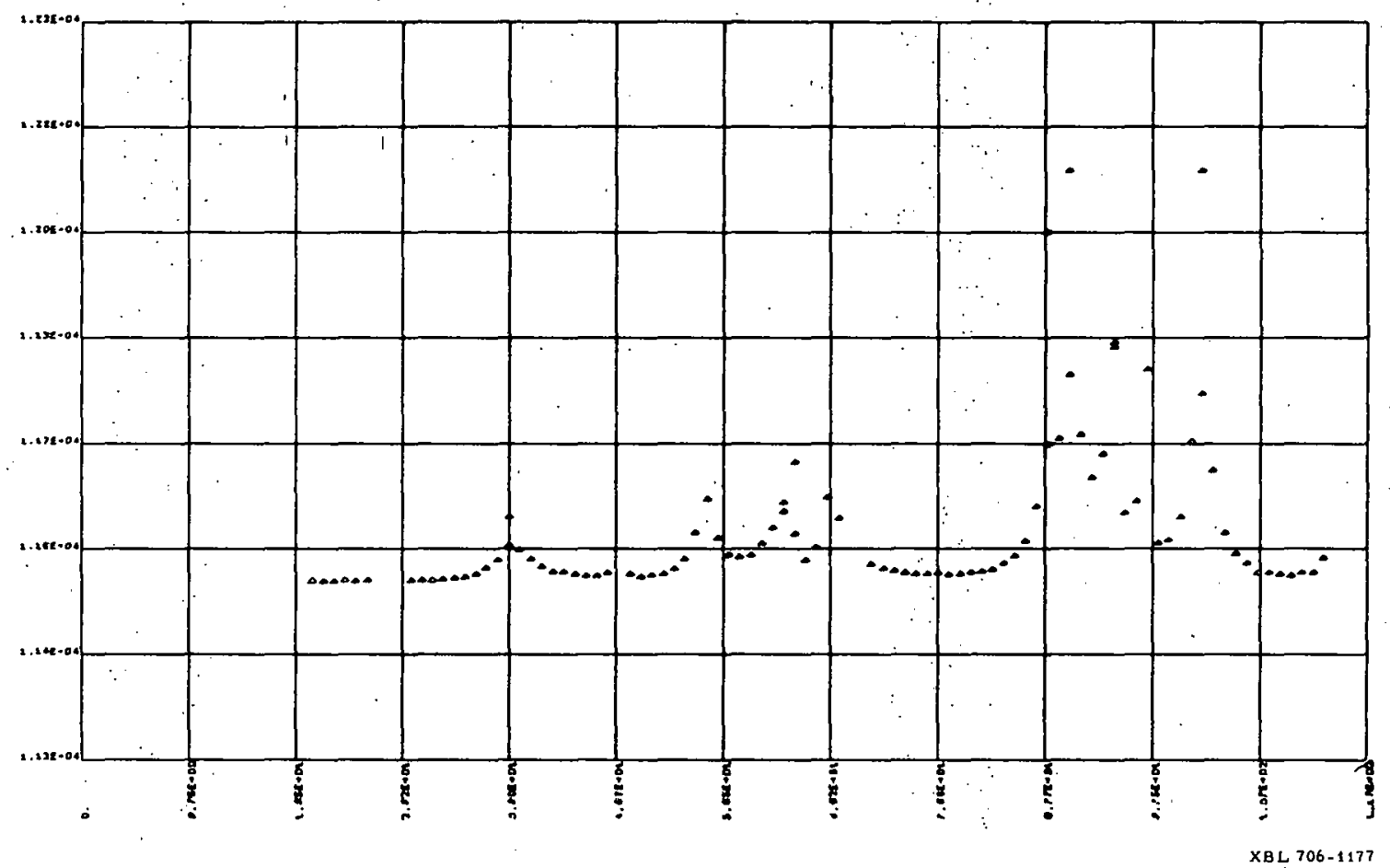

Fig.: B-7. Plot of $\left[B_{V} "-\frac{1}{4}[J(J+I)[P(J)+R(J-2)]-(J-I)[P(J+1)+R(J-I)]\}\right.$ vs $J$ for the $(0,0)$ band from program ORIGIN. See Eq. 7 . 
PROGRAM ORIGIN(INPUT, OUTPUT, TAPE98, PLOT, TAPE99=PLOT) DIMENSION R(150),P(15)),X(150),T(150)

DIMENSION VI $(150), V 2(150)$

DIMENSION $\times 1(250)$

GO TO 157

156 CONTINUE PRINT $378, V H, V L$

378 FORMAT $(1 H 1 * V H, V L=* 2 F 5.1)$

READ $7,9 \vee 1, Q V 2$

7 FORMAT ( $F 10.5)$

$I T=0$

IUU READ 1,JRL,JRH,JPL,JPH

1 FORMAT (4I5)

$D=J R L-J R H$

IF $(D . E Q .0 .0) \quad G O$ TO 155

DO $3 I=1.150$

$R(I)=0.0$

$P(I)=0.0$

3 CONTINUE

READ 2, (R(I),I = JRL, JRH )

READ $2,(P(I), I=J P L, J P H)$

2 FORMAT $(12 X, F 10.2)$

ITEST $=J R H+1$

$J=J R L+2$

4 IF(J.GT.JTEST) GO TO 100

$I F(P(J+i) \cdot E Q \cdot 0,0 \cdot O R \cdot P(J) \cdot E Q \cdot 0 \cdot 0 \cdot O R \cdot R(J-1) \cdot E Q \cdot 0 \cdot 0 \cdot O R \cdot R(J-2) \cdot E \cdot 0 \cdot 0 \cdot)$

1 $A=J$ GO TO 5

$I . T=I T+I$

VI $(I T)=B V 2+.25 *((P(J)+R(J-2)) *(A+1.0)-(P(J+1)+R(J-1)) *(A-1.0))$

$V 2(I T)=(R(J-1)+P(J)) / 2 \cdot 0$

$X(I T)=A * A$

$X I(I T) \cap A$

PRINT $8, A, V I(I T), V 2(I T), X(I T)$

8 FORMAT $(1 X, 4(3 X, F 10.2))$

IF (V2 IT ).GT $115000 \cdot 0 \cdot 0 R \cdot V 2(\mathrm{IT}) \cdot \mathrm{LT} \cdot 10000 \cdot 0) \cdot I T=I T-1$

IF (VIIIT).GT.15000.0.OR.VIIIT).LT.10000.0) IT =IT-I

$5 \quad J=J+1$

GO TO 4

155 CONTINUE

CALL LINE $(X, V 2, I T)$

CALL GRAPH $(X, V 2, I T)$

CALL GRAPH $\left(X_{1}, V_{1}, I T\right)$

157 READ $25, V H, V L$

25 FORMAT (2F10.2)

IF (VH.LT.99.0) GO TO 156

CALL CCEND

END

SUBROUTINE GRAPH $(X, Y, N T)$

COMMON/CCPOOL/XL,XH,YL,YH,CXL,CXH,CYL,CYH

DIMENSION ROUND (4)

DIMENSION $X(150), Y(150)$

$X M I N=F M I N(N T, X)$ \& XMAX $=F M A X(N T, X)$

$I A=X \dot{M} I N-4.0$

$I B=X M A X+4.0$

$X H=I B$

$X L=0.0$ 
$C X L=100 . \quad \$ C X H=1300$.

$N X L=12$

$N Y L=7$

$C Y L=200$. क $\quad C Y H=900$.

$N O=N T+1$

$Y(N O)=F M A X(N T, Y)+25$.

NROUND $=4$

ROUND $(1)=1.0$

ROUND $(2)=2.0$

ROUND $(3)=2.5$

ROUND $(4)=5 . \dot{ }$

CALL LINEUP (Y,NO,ROUND, NROUND, NYL, YL, YH)

PRINT $1, Y L ; Y H$

1. FORMAT $(20 X * Y L, Y H=* 2 F 15.5)$

$Y W H Y=(Y H-Y L) \cdot 17.0$

PRINT $2, Y$, WHY

FORMAT (2OX*DIVI ION=* F15.5)

CALL CCGRID (NXL, GHLARELS,NYL)

CALL CCPLOT $(X, Y, N T, 6 H N O J O I N, 8,1)$

CALL CCNEXT

RETURN

END

FIJNCTION F:IIN $(N, X)$

DIMENSION $X(100)$

$A=x(1)$

DO $10 \quad I=1, N$

10 CONTINUE

F $(X i$
$N T I N U E$
$N=A$

RETURN

END

FUNCTION FMAX $(N, X)$

DIMENSION $X(1 \cup 0)$

DO $11=X(1)$

IF $(X(I), G T \cdot B) \quad B=X(I)$

11 CONTINUE

FMAX = B

RETURN

END

SUBROUTINE LINE $(X, Y, M)$

DIMENSION $X(150), Y(150)$

$I A=0$

3

CONTINUE

$5 X=0 . U$

$S Y=0.0$

$S X Y=0.0$

$5 \times 2=0.0$

DO $1 J=1 \cdot M$

$S X=S X+X(j)$

$S Y=S Y+Y(J)$

$S X Y=S X Y+X(J) * Y(D)$

$S X 2=S \times 2+X(J) * 2$

CONT I NUE.

$R=M$

$D=R * S \times 2-S X * 2$

$C I=(R * S X Y-S X * S Y) / D$

XBL 707-1379 
$C 2=(S X 2 * S Y-S X * S X Y) / D$

PRINT $2, C I, C 2$

2 FORMAT $(1 X *$ LEAST SQUARES FIT.OF LINE $C 1 \quad X+C 2=Y * / 10 X * C 1=*$

$1 \quad 1: F 10.5 / 10 X *(2=* F 15.5)$

IF.(I.A.GT.O) GO TO 7

TEST $=25$.

$J=U$

$I A=1+I A$

DO. $4 I=1 \cdot M$

$Y T=C 1 * X(I)+C 2$

$D I=A B S(Y T-Y(I))$

IF:(DI.GT.TEST) GO TO 5

$j=j+1$

$X(J)=X(I)$

$Y(j)=Y(I)$

GO TO 4

5 PR.INT $6, X(I), Y(I), D I$

6. FORMAT $(/ / / 40 X, 3 F 15.5)$

4 CONTINUE

$M=\mathcal{J}$

GO TO 3

7 CONTINUE

RETURN

END

XBL $707-1381$

$\|$ 
8. VIBDIF calculates and plots. A/2 vs $J^{2}$ (see Eq. 10). The input data is two TELL 1-data decks of two bands having the same upper vibrational level. 
PROGRAM VIBDIF (HNPUT, OUTPUT, TAPE98,PLOT,TAPE99=PLOT) DIMENSION R(150),P(150),V(2,2),X(150), T(2,150),A(150) PRINT 1 


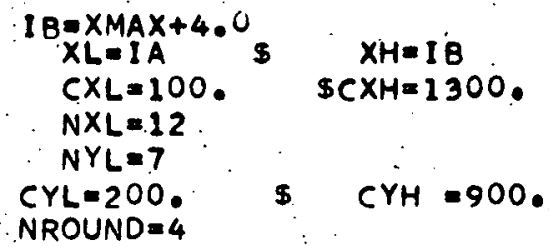




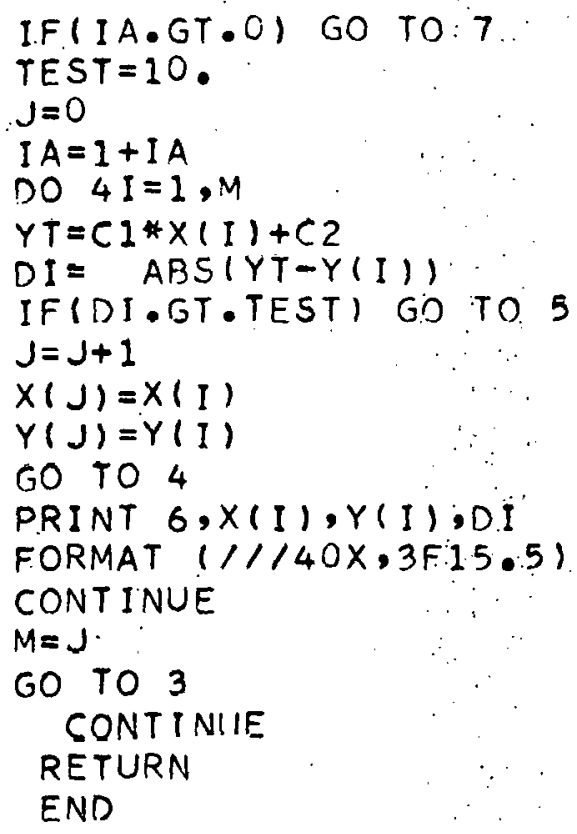

XBL $707-1387$ 


\section{ACKONOWLEDGMENTS}

I would like to thank. Dr. Brewer for his patience, help, and friendship. His weekly group seminars were very profitable and he was never too busy to answer our questions. I would also like to thank Dr. S. Davis of the Physics Department and Dr. J. Phillips of the Astronomy Department for their generous contributions of both time and equipment.

The staff and shops of Lawrence Radiation Laboratory have spoiled me with their consistent friendly help.

It has been very pleasant to be part of Dr. Brewer's research group. 1 appreciated their help in the lab and enjoyed our minature golf games and coffee breaks. In particular, I would like to mention. Dr. Joel Tellinghuisen.

I would also like to thank my friends in Berkeley and my parents for their support and encouragement.

This work was done under the auspices of the U. S. Atomic Energy Commission. 
Ballik and Ramsey, Astrophs. J., 137, 61 (1963).

Brewer, L., Proceedings of the Robert A. Welch Foundation Conferences on Chemical Research, 1962.

Brewer and Hauge, J. of Mol. Spect., 25 No. 3, 330 (1968).

Carlson, Kaiser, Moser, Wahl, J. of Chem. Phys., 52 No. 9, 1678 (1970).

Gaydon, Proc. Roy. Soc., 231, 437 (1955).

Gerö, L., Z. Physik, 93, 669 (1935).

Hauge, Ph. D. Thesis, University of California, Berkeley, UCRL-16338 (1965).

Herzberg, G., Spectra of Diatomic Molecules, D. Van Nostrand, Ind. Ed., N. Y. (1950).

Kasai, P., J. of Chem. Phys. 49 , 4979 (1968).

Kovacs, Z. Physik., 106, 431 (1937).

Kovacs, Rotational Structure in the Bpectra of Diatomic Molecules, Adam-Hilger, London (1969).

Hultin and Lagerqvist, Arkiv Fysik, Vol. 1-2, 471 (1950).

Kopp, I., Aslund, N., Edvenssion, G., Lindgren, B., Arkiv for Fysik, Band $30 \cdot \mathrm{nr}$ 23, 321 (1965).

Lagerqvist, Arkị for Fysik, Band 8, nr 6, 83 (1954).

Wang, J. L. F., Ph. D. Thesis, University of California, Berkeley, UCRL-19093 (1969).

Wharton, L., and Klemperer, W., J. of Chem. Phys., 38, No. 1, 2705 (1963). 
This report was prepared as an account of Government sponsored work. Neither the United States, nor the Commission, nor any person acting on behalf of the Commission:

A. Makes any warranty or representation, expressed or implied, with respect to the accuracy, completeness, or usefulness of the information contained in this report, or that the use of any information, apparatus, method, or process disclosed in this report may not infringe privately owned rights; or

B. Assumes any liabilities with respect to the use of, or for damages resulting from the use of any information, apparatus, method, or process disclosed in this report.

As used in the above, "person acting on behalf of the Commission" includes any employee or contractor of the Commission, or employee of such contractor, to the extent that such employee or contractor of the Commission, or employee of such contractor prepares, disseminates, or provides access to, any information pursuant to his employment or contract with the Commission, or his employment with such contractor. 
TECHNICAL INFORMATION DIVISION

LAWRENCE RADIATION LABORATORY

UNIVERSITY OF CALIFORNIA

BERKELEY, CALIFORNIA 94720 